\title{
Does Higher Education Reduce Mortality? Evidence from a Natural Experiment*
}

\author{
Felipe González \\ Insituto de Economía, Pontificia Universidad Católica de Chile \\ Av. Vicuña Mackenna 4860, Macul, Santiago, Chile \\ fagonza4@uc.cl \\ Luis R. Martínez \\ Harris School of Public Policy, University of Chicago \\ 1307 E 60th St, Chicago, IL 60637, USA \\ luismartinez@uchicago.edu \\ Pablo Muñoz \\ FGV EPGE Brazilian School of Economics and Finance \\ Praia de Botafogo, 190 11th floor, Rio de Janeiro - RJ 22250-040, Brazil. \\ pablo.munoz@fgv.br \\ Mounu Prem \\ Facultad de Economía, Universidad del Rosario \\ Calle 12C No. 4-59, Bogotá, Colombia \\ francisco.munoz@urosario.edu.co
}

${ }^{*}$ This version: February 2022. María Angélica Bautista was a co-author in a previous version of this paper and provided valuable comments and suggestions. We thank Pablo Celhay, José Ignacio Cuesta, Robert Kaestner, Adriana Lleras-Muney, Felipe Menares, Emily Oster, Maria Perdomo-Meza, Paul Rodríguez and seminar participants at INSPER, the Essen Health Conference, and the LACEA Ridge Health Economics Workshop for their comments and suggestions. We also thank Fondecyt (project 1210239), Coordenação de Aperfeiçoamento de Pessoal de Nível Superior - Brasil (CAPES) - Finance Code 001 and the Pearson Institute for the Study and Resolution of Global Conflicts at the University of Chicago for financial support. Prem acknowledges IAST funding from the French National Research Agency (ANR) under the grant ANR-17-EURE-0010 (Investissements d'Avenir program). Maria Ballesteros, Leonor Castro, and Anita Zaldivar provided outstanding research assistance. 


\begin{abstract}
We provide new evidence on the causal effect of education on health. Our empirical strategy exploits the reduction in access to college experienced by individuals reaching college age shortly after the 1973 military coup in Chile, which led to a sharp downward kink in enrollment for the affected cohorts. Using data from the vital statistics for the period 1994-2017, we document an upward kink in the age-adjusted yearly mortality rate for these cohorts, a pattern that we also observe in matched individual-level records for hospitalized patients. Leveraging the downward kink in college enrollment, we estimate a negative effect of college on mortality, which is larger for men, but also sizable for women. Affected individuals have worse labor market outcomes, lower income, and are more likely to be enrolled in the public health system. They also report lower consumption of health services, which suggests that economic disadvantage and limited access to care plausibly contribute to the effect of education on health.
\end{abstract}

February 2022 


\section{Introduction}

The relationship between education and health ranks among the most widely studied in economics. Observational evidence suggests that more educated people live longer lives, but existing research on the causal effect of education on mortality has provided largely null findings (Galama et al., 2018; Xue et al., 2021). Previous work, however, has mostly studied changes to compulsory schooling laws affecting education at the primary or secondary level; and little is known about the impact of higher education on mortality (Buckles et al., 2016). Insofar as primary, secondary, and tertiary education each have their own unique effects on preferences, knowledge, income or other health inputs (Cutler and Lleras-Muney, 2008; Montez et al., 2012), the effect of education on mortality is likely to vary across different levels of educational attainment.

In this paper, we provide new evidence on the causal effect of higher education on mortality. We exploit plausibly exogenous variation in university enrollment among cohorts that reached college age in a narrow window around the 1973 military coup that brought General Augusto Pinochet to power in Chile. Following the coup, the Pinochet regime quickly assumed control of all universities in the country and, over the following years, steadily reduced public subsidies to higher education (Bautista et al., 2020b). This fiscal austerity was part of the regime's technocratic reforms, aimed at improving the efficiency of public spending and fostering universities' financial independence. The result, however, was a large contraction of the higher education system and a steady reduction in the number of openings offered by universities for incoming students, which led to a sharp downward kink in the college enrollment rate for men and women reaching college age at this time. This kink was entirely supply-driven, with no change in the secondary completion rate and with more college applicants than openings throughout this period.

Our empirical strategy exploits this kink in college enrollment to study the effect of higher education on mortality. Combining census records with vital statistics, we uncover an upward kink in the age-adjusted mortality rate among the affected cohorts. Matched individual-level records for hospitalized patients display a similar kink in mortality, which is partly explained by differences in observable characteristics such as diagnostic and type of health insurance. Moreover, using several waves of a large and nationally representative household survey, we show that individuals in the affected cohorts have worse labor market outcomes and lower income. They are also more likely to be enrolled in the public health system and report lower consumption of health services. These last results suggest that socio-economic conditions and access to care play an important mediating role in the link between college and mortality.

Our main empirical analysis leverages individual-level records from the 1992 population census and the vital statistics for the 1994-2017 period to calculate yearly mortality rates by cohort, gender and region of residence. To ensure a relevant counterfactual for college enrollment, we use 
information on educational attainment available in both sources and restrict the sample to individuals with complete secondary education. We also restrict the sample to individuals reaching age 21 between 1964 and 1981, leaving us with an 18-cohort window centered around 1973. We begin by showing that college enrollment was rising before 1973 at a rate of 2 percentage points (pp) per cohort for women and $1.4 \mathrm{pp}$ for men. This trend breaks after the coup, with enrollment for those reaching college-entry age after 1973 decreasing at a rate of approximately -2 pp per cohort for both men and female. This is equivalent to a $7 \%$ per-cohort decrease relative to the sample mean for women, and to a $6 \%$ fall for men. We then provide reduced-form estimates of changes in the mortality trend for the cohorts reaching college age after the military coup. Our preferred specification includes year by region fixed effects and age fixed effects, which allow mortality to vary flexibly at each point in the life cycle. We find that each additional post-coup female cohort experiences a 0.11 unit increase in the age-adjusted yearly mortality rate, equivalent to $2.8 \%$ of the sample mean of 3.9 deaths per 1,000. Likewise, for men, we find that each younger post-coup cohort has a 0.32 -unit higher mortality rate, equivalent to a $4.4 \%$ increase over the sample mean of 7.1 deaths per 1,000 .

Since estimating the effect of college enrollment on mortality is fraught with many of the same difficulties that plague estimations of the average return to schooling (Card, 2001), we implement an instrumental variables (IV) approach. Our IV strategy - based on a purely supply-side shock - allows us to overcome the potential bias in OLS estimates arising from the correlation between educational attainment and unobserved individual characteristics that may affect health, including genes and parental inputs. In the spirit of a regression kink design (Card et al., 2015), we use the kink in college enrollment as an excluded instrument. Reassuringly, the large decline in enrollment experienced by the affected cohorts provides a very strong first stage. The exclusion restriction for our IV estimates requires that any change in the mortality of the affected cohorts is purely driven by the reduction in college enrollment. Underlying this assumption is the idea that any other changes brought about by the military regime should have affected contiguous cohorts of young adults with complete secondary education in a roughly similar fashion. To the best of our knowledge, there were no other events that could have differentially affected the health of the study cohorts. Furthermore, the uniqueness of our setting, in which younger cohorts experience a reduction in educational attainment, means that secular improvements in health conditions, information or technology should - if anything - attenuate our results.

As further evidence in support of the exclusion restriction, we show that our results are unaffected if we use tighter bandwidths (as little as four cohorts on each side) or if we control for fluctuations in macroeconomic factors around the time of the military coup. Results are also similar if we split the sample based on county-level military presence in 1970, which is an important predictor of exposure to repression after the coup (Bautista et al., 2020a). We also fail to detect evidence of kinks in the share of people per cohort that completed secondary education. This 
suggests the absence of other factors that differentially affected the cohorts reaching college age after the coup (e.g., changes to economic conditions), to the extent that these would have also affected educational attainment at the secondary level (which is mandatory in Chile only since 2003). Furthermore, we show that there is no kink in the mortality rate among individuals that have no secondary education. This is reassuring as these individuals were equally exposed to other aspects of the military regime, but they can be thought of as never-takers of the "treatment" that changed the number of college openings. Finally, a more agnostic approach based on Conley et al. (2012) indicates that violations of the exclusion restriction would have to be quite large $(70 \%$ or more of the reduced-form effects) to undo our results.

The IV estimates from our preferred specification with age fixed effects indicate that college enrollment decreases the yearly probability of death by $0.26 \mathrm{pp}$ for women and by $0.92 \mathrm{pp}$ for men. These are large but precisely-estimated effects, and are significantly different from each other at the $0.1 \%$ level. ${ }^{1}$ Fewer deaths from cancer, diseases of the circulatory system and diseases of the digestive system represent $85 \%$ of the effect of college on female mortality and $74 \%$ of the effect on male mortality. Our IV results are only slightly larger and not statistically different from their OLS counterparts, which is consistent with limited positive selection into college or with the effect of college on health being larger than average for the compliers (Card, 1999). The latter seems plausible as compliers in our setting were marginal applicants with lower test scores, and coming from less affluent family backgrounds, who were mechanically rejected by a centralized matching algorithm as the number of openings fell. Alternatively, the cohort-level variation we exploit could also be capturing spillover effects that OLS fails to incorporate (Grossman, 2006).

We then shed light on some of the mechanisms underlying the reduction in mortality caused by higher education. First, we use data from 13 waves of a large and representative household survey between 1990-2017 to study labor market outcomes and consumption of health services. We show that the cohorts exposed to reduced access to college exhibit sizable downward kinks in labor force participation, quality of occupation and income. The affected cohorts also exhibit an upward kink in enrollment in the public health system, which has fewer resources and is significantly more congested than its private counterpart. ${ }^{2}$ Relatedly, we document downward kinks for the affected cohorts in the probability of having seen a doctor in the past three months and, in the case of women, in the probability of having had a Pap smear in the past three years. These results suggest that reduced access to college leads to worse socio-economic outcomes and limits access to medical care, all of which plausibly contribute to a higher mortality rate.

\footnotetext{
${ }^{1}$ The results are unchanged if we restrict the sample to a common support between ages 46-62. In line with findings by Kaestner et al. (2020) using observational data for the US, our results also suggest that the effect of college is accentuated after age 55 .

${ }^{2}$ In 2014 , there were 5.3 physicians per 1,000 beneficiaries in the private sector, compared to 1.2 in the public sector. See section 2.2 for details.
} 
Secondly, we perform complementary exercises using the universe of hospital discharge summaries in Chile between 2002 and 2018. We find no robust evidence of a kink in the hospitalization rate for the affected cohorts, which is consistent with the presence of offsetting effects from worse health and reduced access to care. In line with this interpretation, we provide suggestive evidence of a compositional effect, as reflected by an upward - albeit somewhat imprecise - kink in hospitalizations using public health insurance. We also combine the discharge summaries with the vital statistics at the individual level to study the mortality of hospitalized patients. Ex-ante, it is unclear whether education affects mortality in this population. Nonetheless, we find evidence of an upward kink in the probability of dying for hospitalized patients in the affected cohorts over multiple time horizons, ranging from 30 days to five years. This kink is present even after conditioning on observable characteristics such as diagnostic, hospital, or type of insurance. This arguably reflects other channels through which education affects mortality, including unobservable differences in comorbidities and health behaviors (e.g.,adherence to physician instructions).

Our paper complements previous research on the effects of education on health (Galama et al., 2018). ${ }^{3}$ An extensive body of work dating back to Kitagawa and Hauser (1968) has documented an educational gradient in health status, but causal evidence remains limited, as plausibly exogenous sources of variation in educational attainment are scarce. Previous research on mortality has mostly exploited changes to compulsory schooling laws affecting lower levels of education and has found largely null results. ${ }^{4}$ However, the findings from these studies have limited external validity to higher education, insofar as the latter could plausibly have a differential effect on health behaviors and mediating socioeconomic outcomes (Cutler and Lleras-Muney, 2008, 2010).

The existing literature has also largely focused on European countries with relatively equitable access to high-quality medical care, which could attenuate the impact of education. To the best of our knowledge, only Buckles et al. (2016) have studied the causal effect of college on mortality, exploiting the avoidance of the military draft by young males in the US during the Vietnam war (Card and Lemieux, 2001). They find that college reduces mortality in that setting, but face the complication that men in cohorts exposed to the draft were also more likely to participate in the war. Moreover, women and non-white men are excluded from their sample. We contribute to the literature by exploiting a unique setting that allows us to credibly estimate the causal effect of college enrollment on mortality for men and women, both in the population at large and among hospitalized patients. Our setting further enables us to directly combine data from multiple sources to gain insights on the mediating role of labor market outcomes and consumption of health services.

\footnotetext{
${ }^{3}$ This is part of a broader literature on the non-pecuniary effects of education (Grossman, 2006; Oreopoulos and Salvanes, 2011).

${ }^{4}$ See Lleras-Muney (2005); Mazumder (2008); Albouy and Lequien (2009); Van Kippersluis et al. (2011); Clark and Royer (2013); Black et al. (2015); Meghir et al. (2018). Papers studying other health outcomes are similarly inconclusive (Arendt, 2005; Oreopoulos, 2006; Braakmann, 2011; Kemptner et al., 2011).
} 


\section{Institutional Background}

\subsection{Regime Change and Higher Education}

President Salvador Allende was overthrown by a military coup on September 11, 1973. At the time, there were eight universities in Chile, with presence throughout the country. Only two universities were public, but the entire system depended almost exclusively on government funding, which represented $77 \%$ of total revenue in 1972 . Differentiated tuition based on family income was charged, but fees were generally low. Starting in 1967, admissions were determined by a deferred acceptance algorithm based on applicants' preferences, their score in a centralized admissions exam and the yearly number of openings that universities made available for each of their programs.

A military junta presided by General Augusto Pinochet assumed control of the government after the coup and would remain in power until 1990. The junta quickly appointed members of the armed forces as rectors to all universities and endowed them with full discretion over university administration. However, policy quickly began to be dictated by a group of technocratic economists leading the regime's efforts at economic stabilization and modernization. These economists would come to be known as the "Chicago Boys", as most had studied at the University of Chicago and were strong supporters of the free-market views associated with the Chicago school (Valdés, 1995). The Chicago boys advocated for a reduction in public subsidies to universities, arguing that these were inefficient and failed to promote effort and thrift. Following their advice, the military government drastically cut back on its contributions to universities over the following years. Panel (a) in Figure 1 shows that the share of the government's education budget allocated to universities fell from a high of $47 \%$ in 1974 to $29 \%$ by 1980 (38\% decrease).

The reduction in government transfers was not compensated by increases in tuition (which faced strong internal resistance) or in revenue from other sources. Universities were thus forced to scale down and steadily reduce the number of openings for incoming students, as panel (b) in Figure 1 shows. This led to a dramatic reduction in the college enrollment rate, as a growing number of graduates from secondary education competed over a decreasing number of spots. Panel (a) shows that college enrollment had risen in the decade before the coup, reaching a gross rate of 9\% (77,000 students) by the end of the Christian-Democrat government of Eduardo Frei in 1970. The enrollment rate grew even more during the Socialist Allende government and peaked at 17\% (146,000 students) in 1973. It steadily declined after the coup and was back down to around $10 \%$ by $1980 . .^{5}$ Panel (b) also shows that the number of college applicants exceeded the number of openings in all years, which implies that the supply of openings was always the binding constraint

\footnotetext{
${ }^{5}$ The unexpected nature of the drop in enrollment is supported by the fact that UNESCO projected 200,000 university students for 1975, highly overestimating the real figure of 150,000 (Levy, 1986).
} 
determining the total number of incoming college students.

Naturally, the initial period following the military take-over brought about other changes to universities. In particular, the first months after the coup were characterized by targeted repression against supporters of the deposed Allende, though "most previously enrolled students remained enrolled" (Levy, 1986, p. 101). ${ }^{6}$ Several research centers and academic units deemed politically undesirable were shut down and extracurricular activities were banned or tightly controlled (Brunner, 1984). However, the vast majority of academic units continued functioning and the distribution of students across fields of study hardly changed (Bautista et al., 2020b). Moreover, several important features of the system were also left unchanged. For instance, the regime preserved the centralized admissions process, which remains largely the same until the present day. Hence, even though the initial wave of expulsions was highly targeted, the ensuing reduction in openings (which provides the bulk of the variation in college enrollment that we use in the empirical analysis below), was not. ${ }^{7}$ Students with lower test scores (i.e., just below the increased admissions cut-off), who predominantly came from less affluent socio-economic backgrounds, were the ones that mechanically failed to gain admission (Bautista et al., 2020b). The number of universities and campuses would also remain unchanged until a large reform in 1981.

\subsection{Socioeconomic Characterization and Health System}

Chile has experienced rapid economic growth since the mid-1980s, with GDP per capita (in constant 2010 USD) rising from $\$ 4,700$ in 1985 to $\$ 14,700$ in 2015 . These numbers correspond to 0.7 and 1.5 times the average income per person in Latin America in the respective year, giving rise to the notion of the Chilean 'economic miracle'. Chile has been a member of the OECD since 2010. However, the benefits of economic growth have not accrued to everyone equally and Chile's Gini index of 0.46 in 2014 was the highest among OECD countries, where it averaged 0.32.

Chile's sustained economic growth over the past decades has been reflected in improved health outcomes. Life expectancy in 1970 was 62.3 years, only slightly higher than the Latin American average of 60.4 , but rapidly increased over the following decades, catching up with the OECD average of 75 years by the early 1990s. The infant mortality rate plummeted over the same period, from 67 deaths per 1,000 live births in 1970 to 16 in 1990, slightly lower than the OECD average of 17.5. Chile is also near the OECD average in terms of avoidable mortality and self-rated health (OECD , 2019). ${ }^{8}$ According to records from the National Institute of Statistics (INE), people aged

\footnotetext{
${ }^{6}$ Repression during the Pinochet dictatorship led to the death or forced disappearance of about 3,200 people (Bautista et al., 2020a). Bautista et al. (2020b) estimate death rates of $0.2 \%$ for university faculty and students.

${ }^{7}$ Bautista et al. (2020b) show that the negative kink in college enrollment after the military coup is present among siblings, as well as within quintiles of housing wealth in 1992.

${ }^{8}$ However, the country has higher-than-average rates of smoking (25\% of adults), obesity ( $74 \%$ of adults) and chronic disease morbidity ( $9 \%$ of adults with diabetes).
} 
60-64 had very similar death probabilities in Chile (0.015) and the U.S. (0.014) in the early 2000s (Kaestner et al., 2020).

Health insurance in Chile operates under a dual system that includes several private providers and a public alternative via the National Health Fund (Fondo Nacional de Salud - FONASA). This system dates back to the period 1979-1981, and was created as part of the Chicago Boys' technocratic reforms. ${ }^{9}$ FONASA is a pay-as-you-go system financed with government funds and a $7 \%$ payroll tax. It has no exclusions and offers three levels of copay (0, 10 or $20 \%)$ based on income and number of dependents. The main private providers, known as ISAPREs (Instituciones de Salud Previsional), are insurance companies that compete by offering contracts at different prices in a regulated market. ${ }^{10}$ ISAPREs receive the payroll tax contributions made by their members and usually require additional payment. In 2011, payments to ISAPREs averaged $10.3 \%$ of wages, while the average copay was close to $33 \%$ (Galetovic and Sanhueza, 2013).

The share of the population covered by FONASA has risen over time, from around $66 \%$ in the 1990 s to almost $80 \%$ in more recent years, while the share affiliated to an ISAPRE is now close to $14 \%$, falling from a maximum of almost $25 \%$ in the mid-1990s (MDS, 2018). The share without insurance has steadily fallen is now at around $3 \%$. The small remaining share $(<4 \%)$ either gets separate insurance through the Armed Forces or is affiliated to some other private insurer. These changes are partly explained by the rising cost of private insurance, which increased in real terms by a factor of 2.2 between 1991 and 2011, while real wages only increased by a factor of 1.8 over the same time period (Galetovic and Sanhueza, 2013). Cream skimming in this market is well documented: FONASA serves lower-income and riskier people, while ISAPREs serve a richer, healthier, and younger segment of the population (Pardo and Schott, 2012). Switching between ISAPREs and FONASA is relatively uncommon, though FONASA often acts as a safety net and absorbs people that lose their job (Duarte, 2011).

Health service provision also involves private and public providers: laboratories, clinics, hospitals. In general, public providers tend to be more crowded and have longer wait times. In 2016, only $24 \%$ of the 348 hospitals in the country were private, but $55 \%$ of doctors worked in the private sector (Clínicas de Chile, 2016). Relatedly, there were 5.3 physicians per 1,000 beneficiaries in the private sector in 2014, compared to 1.2 in the public sector (Appendix Figure A1). Spending per capita in 2014 amounted to almost $\$ 3,000$ in the private sector, while it was less than $\$ 1,000$ in the public option. ${ }^{11}$ ISAPREs tend to offer full flexibility over providers and reduced copay for in-network or preferred providers. In 2012, 97\% of payments made by ISAPREs went to private

\footnotetext{
${ }^{9}$ Before then, public health insurance was comprised of separate white-collar and blue-collar health funds (SERMENA and SNS), which were created in 1942 and 1952, respectively.

${ }^{10}$ These firms can implement risk pricing or risk selection based on gender and age. In 2012, ISAPREs made available more than 52,000 different health insurance plans (Galetovic and Sanhueza, 2013).

${ }^{11} \mathrm{~A}$ thorough comparison of the quality of services provided by public and private providers is beyond the scope of this paper and is made difficult by underlying differences in the populations served.
} 
providers (Galetovic and Sanhueza, 2013). FONASA, on the other hand, mostly covers services by public providers and additional payment is required to access private providers.

Health spending as a percentage of GDP has risen over time, from around 5\% in the 1990s to $9 \%$ in 2017, near the OECD average. Still, Chile ranks highly in terms of the efficiency of health expenditure. For example, the Bloomberg Health-Care Efficiency Index ranks the country 8th out 55 considered (Clínicas de Chile, 2016). Private spending represented 56\% of the total in 2015, $85 \%$ of which corresponded to out-of-pocket expenses.

\section{Data}

We rely on four main data sources for the analysis. First, individual death records from the vital statistics for the period 1994-2017. Secondly, individual records from the 1992 and 2002 population censuses. Third, the universe of hospital discharge summaries between 2002 and 2018. Lastly, individual responses from the CASEN household survey between 1990 and 2017. In the rest of this section, we introduce our criteria for inclusion in the sample, provide an overview of each of these sources and describe the construction of our main variables of interest.

We restrict the sample to individuals born between 1943 and 1960. These individuals reached age 21 between 1964 and 1981, creating an 18-cohort window centered around 1973, the year of the military coup. Bautista et al. (2020b) show that the average age of first-year college students in 1970 was 20.5 years. We end the sample with the 1981 cohort to mitigate the confounding effect of the large reform of the Chilean university system that was implemented by the military regime after that year. Starting with the 1964 cohort creates a balanced sample centered around 1973. The discrete nature of the running variable prevents us from applying a non-parametric approach to select an optimal bandwidth, but we verify that our results are robust to other bandwidths. To ensure a relevant counterfactual for college enrollment, we further restrict the sample to individuals reporting four (or more) years of secondary education (educación media), which corresponds to the statutory length of secondary education. Unfortunately, information on secondary completion is mostly unavailable in these sources. Our results are also robust to removing this constraint, though the interpretation changes somewhat, as we discuss below.

The Department of Health Statistics and Information (Departamento de Estadísticas e Información de Salud - DEIS) provides rich individual-level data from the death certificates. Basic information on each deceased individual includes year of birth, gender, educational attainment, county of residence, and cause of death. ${ }^{12}$ In order to calculate mortality rates, we use information from the 1992 census provided by the National Institute of Statistics (Instituto Nacional

\footnotetext{
${ }^{12}$ The mortality files for 1990-1993 lack information on several relevant variables, including educational attainment, so we exclude these years from the sample.
} 
de Estadística - INE). The census provides basic demographic characteristics and information on educational attainment analogous to the death certificates.

To construct our main outcome of interest, we proceed as follows. For each year between 1994 and 2017, we calculate the risk-adjusted yearly mortality rate at the cohort-gender-region level. ${ }^{13}$ In doing so, we follow Clark and Royer (2013) and iteratively adjust the initial population count in the 1992 census for the number of deaths per cell in the previous year. We initially observe 997,484 individuals that meet our sample criteria in the census, with ages between 32 and 49 . We observe 124,729 deaths among these individuals during the sample period, yielding an aggregate mortality rate of $12.5 \%$. Male mortality is almost twice as high as female mortality (16\% vs $9 \%$ ), similarly to other settings (Beltrán-Sánchez et al., 2015).

Using the information on the cause of death reported in the mortality files, we replicate the previous procedure to obtain cause-specific mortality rates. ${ }^{14}$ We also calculate the share of people in each cohort-gender-region cell that report any college education in the census and iteratively adjust this share based on the educational attainment of the people that passed away from that cell in the previous year. Since the youngest cohort in the panel has age 32 in 1992, we can confidently assume that people in the sample have completed their education. We verify below that our results are robust to using the unadjusted mortality rates and/or college shares.

The third piece of data comes from the universe of hospital discharge summaries between 2002 and 2018. This dataset has almost five million observations and reports basic demographic information of the patient as well as the hospital of admission, diagnostic and type of insurance, among other characteristics. Unfortunately, it does not include information on educational attainment, so when using this data we cannot restrict the sample to individuals with full secondary and can only provide reduced-form results. We combine this data with the 2002 census to construct yearly hospitalization rates at the cohort-gender-region level for the period 2002-2018, which we can disaggregate by type of insurance or hospital (i.e., public vs private). Importantly, the discharge summaries have a unique individual identifier that allows us to merge this data with the mortality files in the vital statistics. This enables us to track the mortality of hospitalized patients over multiple time horizons. Naturally, we must omit from this analysis those patients with a missing identifier ( $8 \%$ of total). To ensure that we observe outcomes for all hospitalized patients for at least five years, we end the sample for this part of the analysis in 2012.

Finally, we use 13 waves of Chile's National Socioeconomic Survey (CASEN), conducted between 1990 and 2017, to analyze other health outcomes that we are unable to study using the

\footnotetext{
${ }^{13}$ In this calculation, we rely on reported region of residence in the 1992 census and exclude Chileans living abroad and foreign nationals. Chile is administratively divided into 346 counties located in 16 different regions.

${ }^{14}$ Cause of death is reported using the International Statistical Classification of Diseases and Related Health Problems (ICD), versions 9 and 10.
} 
administrative sources above. ${ }^{15}$ CASEN is collected biennially and records information on education, health, income and labor market outcomes. We study two families of outcomes. First, mediating socio-economic outcomes, including labor force participation, occupation, income and type of insurance. Second, measures of consumption of health services, including consultations with primary care physicians or specialists, ER visits, and procedures such as the Pap smear in the case of women. CASEN is a very large survey including more than 260,000 individuals from over 80,000 households in its most recent wave. This allows us to have a relatively large sample even after restricting to individuals with 4+ years of secondary that reached age 21 between 1964 and 1981. Not every question is asked in every wave, which leads to varying sample sizes.

\section{Empirical Strategy}

If we could connect the individuals in the 1992 census to the mortality files in the vital statistics, a natural model to estimate the relationship between college and mortality would be as follows:

$$
D_{i, t}=\beta C_{i}+\delta X_{i, t}+\varepsilon_{i, t},
$$

where $D_{i, t}$ is a dummy indicating whether individual $i$ is deceased by time $t . X_{i, t}$ is a vector of controls that potentially vary across individuals or over time (and a constant), while $C_{i}$ is a dummy equal to one for individuals with any college education. ${ }^{16}$ This is a fixed individual characteristic assuming we only observe people with completed education. The parameter of interest is $\beta$, which captures the average difference in the mortality rate for people with college. By restricting the sample to individuals with complete secondary education, we can interpret $\beta$ as the average difference in mortality for people with college relative to those that stop their schooling after finishing the level immediately below, which is arguably the relevant counterfactual.

The model in equation (1) poses two problems. First, we must overcome the fact that we cannot individually link people in the census and the mortality files. Secondly, even if we could, concerns about omitted variable bias (OVB) prevent us from interpreting the OLS estimate of $\beta$ as capturing the causal effect of college enrollment (Card, 1999). In our setting, OVB may arise because of unobservable differences in genetic characteristics, parental inputs or individual preferences (e.g.,discount rates) that affect both the decision to go to college and health later in life (Fuchs, 1982). Previous work has shown, for instance, that low birth weight is associated with worse health during childhood and with reduced educational attainment (Behrman and Rosenzweig, 2004; Black

\footnotetext{
${ }^{15}$ Survey years are 1990, 1992, 1994, 1996, 1998, 2000, 2003, 2006, 2009, 2011, 2013, 2015 and 2017.

${ }^{16}$ We focus on college enrollment, rather than completion, because this is the margin that was directly affected by the dictatorship's policies. Bautista et al. (2020b) show that, in all of the study cohorts, at least $68 \%$ of people with any college report four or more years of study (a proxy for completion), a figure comparable to those from other settings (e.g., Zimmerman, 2014).
} 
et al., 2007). Case et al. (2002) further show that household income is positively correlated both with children's health and educational attainment.

To tackle the first problem, we aggregate the data into larger units that we observe in both data sources. As discussed in the previous section, we can collapse the data into cells at the cohortgender-region level. Here, region refers to the region of residence, as the mortality files do not include information on place of birth. ${ }^{17}$ Similarly to Lleras-Muney (2005), we can then derive the aggregate model by averaging the previous model over individuals in a given cell:

$$
\bar{D}_{k, r, t}=\beta \bar{C}_{k, r, t}+\delta \bar{X}_{k, r, t}+\bar{\varepsilon}_{k, r, t}
$$

$\bar{D}_{k, r, t}$ represents the share of people in a given cohort-region cell, denoted by $k$ and $r$, that die in year $t$, while $\bar{C}_{k, r}$ represents the share of people per cell with any college. ${ }^{18}$ By weighting each observation by the number of people in that cell, we obtain an estimate of $\beta$ that is identical to the one provided by the individual microdata (Angrist and Pischke, 2009). Since people that are already deceased are no longer at risk of dying, we follow Clark and Royer (2013) and adjust the denominator in $\bar{D}_{k, r, t}$ and $\bar{C}_{k, r, t}$ based on the cumulative number of previous deaths per cell.

Still, OVB in the individual-level estimate of $\beta$ will carry over to the cohort-level estimate. To tackle the second problem (i.e., identification), we leverage plausibly exogenous variation provided by the kink in college enrollment experienced by cohorts reaching college age in the years immediately after the 1973 military coup. In the spirit of a regression kink design (Card et al., 2015), our baseline reduced-form specification looks for a change in the cohort-level trend of the mortality rate among those affected:

$$
\bar{D}_{k, r, t}=\alpha_{r, t}+\pi_{0} k+\pi_{1} \mathbb{1}(k>0) \times k+\eta_{k, r, t}
$$

Here, we have normalized the indicator $k$ to denote the year in which the cohort reaches age 21 , as this is the average age of first-year college students in our setting (Bautista et al., 2020b). We have also re-scaled $k$ to equal zero in 1972 , so $\pi_{0}$ captures the cohort-level trend in the mortality rate, while $\pi_{1}$ captures any change in this trend (i.e., a kink) for cohorts reaching age 21 in 1973 or later $(k>0)$. As control, we include a region by year fixed effect, denoted by $\alpha_{r, t}$, which accounts for geographic differences in mortality and allows these differences to vary flexibly over time. It also accounts for common shocks or secular changes in health and allows their impact to vary flexibly

\footnotetext{
${ }^{17}$ Collapsing by region allows us to account for spatial differences in mortality, while minimizing the measurement error caused by migration or misreporting. This error could be quite large in sparsely populated cells, which is why we do not use the more granular county (comuna) level. Reassuringly, we verify below that our main results are almost identical if we do the analysis at the national level, where the threat posed by measurement error is even smaller.

${ }^{18}$ For simplicity, we are omitting the gender subindex in equation (2), but the collapsed cells are gender-specific. We estimate all of our models separately for men and women, but results are identical to running pooled regressions and allowing the region-year fixed effect included in all our estimations to be gender-specific.
} 
across regions. We allow for spatial correlation in mortality by clustering the error term $\eta_{k, r, t}$ at the region-year level. To account for within-cohort correlation in the error term, we also report the p-values from the wild cluster bootstrap procedure suggested by Cameron et al. (2008) and formalized by Canay et al. (2021). ${ }^{19}$

The identifying assumption in this reduced-form model is that in the absence of the military coup there should not be a kink in the cohort trend of the mortality rate for those reaching age 21 after 1973. The parsimonious specification focuses on a linear trend to avoid over-fitting and we provide visual evidence that it fits the data relatively well. In Appendix B, we also derive a quadratic score test statistic (Lindsay and Qu, 2003) to check whether a linear kink model is reasonable. Reassuringly, we cannot reject the null hypothesis that linearity can perfectly explain the evolution of cohort means.

Moreover, while in a purely cross-sectional analysis a linear specification might cause concern regarding confounding non-linearities in the effect of age, in our setting this threat is minimized by the fact that we observe the study cohorts repeatedly over 23 years. Indeed, we can further exploit the longitudinal nature of the data to estimate a more demanding specification that replaces the baseline cohort trend with an age fixed effect, $\gamma_{a} \cdot{ }^{20}$ In this way, we allow the mortality rate to vary flexibly throughout the life cycle and we restrict the comparison to people from different cohorts observed at the same age:

$$
\bar{D}_{k, r, t}=\alpha_{r, t}+\gamma_{a}+\phi \mathbb{1}(k>0) \times k+v_{k, r, t}
$$

Based on the reduced-form models in equations 3 and 4, we can now return to equation 2 and use the kink in college enrollment after 1973 as an excluded instrument. For the specification with age fixed effects, we estimate the following system of equations:

$$
\begin{aligned}
& \bar{C}_{k, r, t}=\omega_{r, t}+\psi_{a}+\theta \mathbb{1}(k>0) \times k+\mu_{k, r, t}, \\
& \bar{D}_{k, r, t}=\alpha_{r, t}+\gamma_{a}+\tilde{\beta} \bar{C}_{k, r}+\bar{\varepsilon}_{k, r, t}
\end{aligned}
$$

where $\theta$ is the first-stage estimate of the kink in college enrollment for the affected cohorts and $\tilde{\beta}$ is the instrumental variables (IV) estimate of the causal effect of college enrollment on the mortality rate. Under standard assumptions, $\tilde{\beta}$ can be interpreted as a local average treatment effect (LATE) (Angrist et al., 1996). This is the average causal effect of college entry for the set of compliers whose college enrollment was negatively affected by the military coup. In our setting, this is a

\footnotetext{
${ }^{19}$ Insofar as the asymptotics are based on the number of observations within a cluster, and since we have more than 300 observations per cluster, these standard errors are a reasonable choice.

${ }^{20}$ We cannot simultaneously include year fixed effects, age fixed effects and the baseline cohort trend as this would induce perfect multicollinearity.
} 
population of particular interest as these are the marginal college applicants that failed to gain admission as the supply of college openings tightened in the years after the coup.

Our IV strategy requires the exclusion restriction to be satisfied, namely, that the kink in the mortality rate for the affected cohorts is exclusively driven by the reduction in college enrollment. We find this assumption to be plausible insofar as any other changes brought about by the military regime should have affected contiguous cohorts of young adults in a roughly similar fashion. In this regard, our baseline sample focuses on a narrow bandwidth including only nine cohorts on each side of the kink, but as part of our robustness tests we show that our results are unaffected if we use tighter bandwidths (as little as four cohorts on each side), which increases the likelihood of homogenous exposure to other factors. The fact that the drop in enrollment is entirely driven by the fall in openings (as shown above) and that there is no kink in secondary completion (as shown below), further suggests that the effect we are capturing corresponds to the change in higher education policy implemented by the military regime. Moreover, the uniqueness of our setting, in which younger cohorts experience a reduction in educational attainment, means that secular improvements in health conditions, information or technology should - if anything - attenuate our results. We verify below that our findings are not driven by changes in macroeconomic conditions around the coup, including GDP growth, food production, and the contemporary mortality rate.

Moreover, we fail to detect evidence of kinks in the share of people per cohort that completed secondary education. This suggests the absence of other factors that differentially affected the cohorts reaching college age after the coup to the extent that these would have also affected educational attainment at the secondary level (non-mandatory in Chile until 2003). We also show that there is no kink in the mortality rate among individuals that have no secondary education. This is reassuring as these individuals were equally exposed to other aspects of the military regime, but they can be thought of as "never-takers" of our treatment of reduction in college attainment. Finally, we also verify that the effects are not concentrated in areas near military bases, which experienced more repression in the aftermath of the coup (Bautista et al., 2020a). To further assuage concerns about violations of the exclusion restriction, we carry out tests following Conley et al. (2012), which reveal that such violations would have to be quite large (70\% or more of the reduced-form effects) to undo our results.

\section{Results: College Enrollment and Mortality}

This section presents our main results on the causal effect of college enrollment on mortality. We begin by documenting a sharp kink in the college enrollment rate for cohorts that reached college age shortly after the 1973 military coup (i.e., our first stage). We then provide reduced-form estimates of analogous kinks in the yearly mortality rate between 1994 and 2017 for these cohorts, 
as well as IV estimates using the post-1973 kink as an excluded instrument for college enrollment.

\subsection{Educational attainment}

Figure 2 plots raw data from the 1992 population census. Panel (a) shows the shares of men and women per cohort that report four or more years of secondary education (our proxy for secondary completion). These shares rise smoothly over time, starting at around $25 \%$ for the cohort reaching age 21 in 1960 (born in 1939) and peaking at around 47\% for the cohort reaching age 21 in 1990 (born in 1969). Panel (b) shows the respective shares that report any college education, among those with 4+ years of secondary. Cohorts reaching age 21 before 1973 experienced a rising college enrollment rate, especially during the Allende government that began in 1970. However, cohorts reaching the same age after the military coup (denoted by the red vertical line), experienced a sharp kink and a steady decline in the enrollment rate. While men and women reaching age 21 in 1972 (with full secondary) had enrollment rates of around 38\%, those reaching the same age in 1980 had enrollment rates closer to $22 \%$, which corresponds to a $42 \%$ decrease. The fact that secondary completion is increasing smoothly for these cohorts indicates that the drop in the enrollment rate is driven by fewer people entering higher education (i.e., the numerator). The dashed lines in both panels correspond to the start and end points for the study cohorts that we include in the analysis to follow, but the figure shows that the trends are unchanged in adjacent cohorts.

Table 1 presents estimates of equation 3 using different measures of educational attainment as dependent variable. Columns 1-3 show results for women, while columns 4-6 show the corresponding estimates for men. In columns 1 and 4, we use the estimating sample for the mortality analysis below (i.e., cohort-region-year panel). The dependent variable is the mortality-adjusted share of people per cell that report any college education. We express this rate per ten people to facilitate the interpretation of the reduced-form and IV results on mortality below. The coefficients can be interpreted as percentage point changes if multiplied by ten. Consistent with the visual evidence, the results in the top row show that college enrollment was rising before 1973 at a rate of 2 percentage points ( $\mathrm{pp}$ ) per cohort for women and $1.4 \mathrm{pp}$ for men. The results in the bottom row quantify the kink in enrollment for the cohorts reaching the same age in the post-coup years. By adding the coefficients, we see that the net trend for both men and women in the affected cohorts is approximately -2 pp per cohort. This is equivalent to a $7 \%$ per-cohort decrease relative to the sample mean for women, and to a $6 \%$ fall for men. Columns 2 and 5 show that the estimates hardly change if we ignore the variation in the share with college caused by mortality during the sample period and estimate equation 3 using the cross-section from the 1992 census. ${ }^{21}$ In columns 3 and 6 , we use average years of college as dependent variable instead. Again, we find a sharp reversal and net negative trends among the affected cohorts. Relative to the respective sample means, affected

\footnotetext{
${ }^{21}$ Appendix Table A1 shows analogous results for the 2002 census.
} 
women experience a $7 \%$ per-cohort decline in years of college, while men see a $5 \%$ drop.

Panels (a) and (b) in Figure 3 provide a visualization of our first stage results for women and men in our study cohorts. In these figures, the markers show average college enrollment per cohort. The solid lines indicate the estimated trends before and after the coup, while the dashed line denotes the counterfactual trend for the post-coup cohorts. The parsimonious linear model accurately describes the evolution of the college enrollment rate across cohorts and captures the sharp negative kink for those reaching college age after 1973.

\subsection{Impact on Mortality}

Panels (c) and (d) in Figure 3 illustrate our main result. The markers show the risk-adjusted mortality rate by cohort, averaged across years and weighted by cell size. As above, the solid lines correspond to the estimated trends before and after the coup, while the dashed line shows the counterfactual post-coup trend. The plots show that younger cohorts are less likely to die over the fixed sample period. ${ }^{22}$ Moreover, as for college enrollment, the simple linear model yields an accurate representation of the cohort-level trend in mortality before the coup and provides clear indication of an upward kink in mortality for the cohorts reaching age 21 after 1973.

Panel A in Table 2 provides reduced-form estimates of the magnitude of the kink in the riskadjusted mortality rate for the affected cohorts. Columns 1-2 show results for women and columns 3-4 for men. Odd-numbered columns correspond to the specification that controls for the baseline cohort trend (equation 3), while even-numbered ones correspond to the more flexible specification with age fixed effects instead (equation 4). All regressions include region-year fixed effects. We report in parenthesis standard errors clustered at the region-year level, while the number in brackets corresponds to the p-value for the null of a zero coefficient when we cluster by cohort and implement the wild bootstrap procedure following Cameron et al. (2008).

Column 1 shows that the yearly number of deaths per 1,000 decreases at a rate of -0.61 per cohort among women that reached college age before 1973. For the affected cohorts, however, the mortality rate kinks upwards and decreases at the much smaller rate of -0.25 per cohort ($0.61+0.36$ ). We observe a similar pattern for men in column 3. A baseline trend of -1.2 fewer deaths per 1,000 for each additional cohort before the coup, that flattens for the post-coup cohorts and becomes -0.44 . Expressed as a percentage of the baseline trends, the measured mortality kinks for women and men in the affected cohorts equal $59 \%$ and $64 \%$ respectively.

Columns 2 and 4 show that the upward kink in mortality is present even if we replace the baseline trend with the much more flexible age fixed effects. In doing so, we restrict the comparison to cohorts at the same point in the life cycle (i.e, one-year age group) and effectively discard informa-

\footnotetext{
${ }^{22}$ Appendix Figure A2 shows mortality profiles by age and year.
} 
tion from observations for which such a comparison is not possible (very old or very young). This is a much more demanding specification that expectedly absorbs a large share of the identifying variation. As a result, the estimates of the post-1973 kink become smaller, though they remain economically meaningful. The coefficient in column 2 indicates that each additional post-coup female cohort experiences a 0.11 unit increase in the age-adjusted yearly mortality rate, equivalent to $2.8 \%$ of the sample mean of 3.9 deaths per 1,000. The corresponding estimate for men in column 4 similarly shows that each younger post-coup cohort has a 0.32 -unit higher mortality rate $(4.4 \%$ increase over sample mean of 7.1 deaths per 1,000). While the estimates for men remain extremely precise in this specification (statistically significant at $0.1 \%$ level), those for women are somewhat noisy once we account for clustering by cohort ( $p$-value of 0.076$)$.

Panel B shows the IV estimates of the effect of college enrollment. We report at the bottom the Kleibergen-Paap F-statistics, which are in the several thousands and indicate a very strong first stage relationship. Since we express the endogenous variable as the share with college per every ten individuals, we can interpret the estimated effects on deaths per 1,000 as percentage point effects on the probability of dying. The estimate from the baseline specification in column 1 indicates that college enrollment reduces the yearly probability of dying during the sample period by 0.88 percentage points ( $\mathrm{pp}$ ) for women, while the age-adjusted estimate in column 2 places this effect at $-0.26 \mathrm{pp}$. In the case of men, the estimates in columns 3 and 4 point to reductions in the probability of dying of $-2.4 \mathrm{pp}$ and $-0.9 \mathrm{pp}$ for the specifications without and with age fixed effects. Focusing on the estimates with age fixed effects, our more conservative and preferred specification, we find that the reduction in mortality caused by college enrollment is equivalent to $68 \%$ and $130 \%$ of the respective female and male sample means. ${ }^{23}$ As with the reduced-form estimates, the results for women are somewhat imprecise once we account for clustering by cohort (p-value of 0.091), while those for men are very precise throughout. Using the baseline clustering at the region-year level, we can reject at the $0.1 \%$ level that college has the same effect on female and male mortality.

Panel C reports the corresponding OLS estimates of the correlation between college enrollment and mortality. ${ }^{24}$ Our IV estimates are slightly larger than their OLS counterparts, but remain very much comparable. For our preferred specification with age fixed effects, we cannot reject at conventional levels that the IV and OLS estimates are equal. Larger IV estimates are common in the returns-to-education literature (Card, 2001), even in very well identified studies (e.g., Oreopoulos, 2006). This pattern is also common in studies on the effects of education on health (Galama et al.,

\footnotetext{
${ }^{23}$ Appendix Table A2 shows that one year of college reduces female mortality by 0.7 deaths per 1,000 and male mortality by 2.4 deaths (specifications with age fixed effects). These effects correspond to $18 \%$ and $34 \%$ of the respective sample means. Buckles et al. (2016) estimate for the US that one year of college reduces aggregate male mortality between 1981 and 2007 by 26 deaths per 1,000, equivalent to $19 \%$ of their sample mean. Hence, our estimated effect size on male mortality is somewhat larger. This comparison should be interpreted with caution, though, as it could be affected by differences in the setting, the composition of the sample and the methodology.

${ }^{24}$ Appendix Figure A3 shows a positive mortality gradient across all education levels for our cohorts and years.
} 
2018). One explanation is that the returns to college are particularly high for the compliers affected by the instrument (Card, 1999). In our case, it seems plausible that the marginal applicants that failed to enroll in university after 1973 had particularly high health returns to college, as they disproportionately came from less affluent backgrounds (Bautista et al., 2020b). Additionally, people in the affected cohorts could have been affected not only by their individual reduction in the probability of college enrollment, but also by the fact that their peers experienced similar reductions in educational attainment. Our cohort-level instrument captures these spillover effects, which OLS fails to incorporate (Grossman, 2006). ${ }^{25}$

\subsection{The exclusion restriction and robustness checks}

We provide several pieces of evidence that suggest that violations of the exclusion restriction are unlikely to inflate our IV estimates. To start, the strong first stage means that such violations would have to be quite substantial to generate meaningful bias. Nonetheless, we use the methodology developed by Conley et al. (2012) to provide a more specific assessment of the robustness of our results to such violations. As reported at the bottom of Table 2, we find that the vast majority of the observed kink in mortality would have to be driven by factors other than reduced college enrollment ( $70 \%$ for women, $85 \%$ for men) in order for the $90 \%$ confidence interval of our IV estimates to include zero.

In light of the evidence presented in Schwandt and Von Wachter (2019, 2020), one might particularly worry about the confounding effect of entering the labor market amid a recession. To address potential confounding effects related to changes in macroeconomic conditions as the study cohorts enter the labor market, Appendix Table A4 shows that the results are robust to controlling for prevailing macroeconomic conditions, such as growth in GPD per capita, in the year in which the cohort reaches age 21 . Interestingly, we observe that the results become smaller (though remain negative and significant), when we control for government spending as a share of GDP. This is in line with the fact that the reduction in college enrollment was caused by the regime's cuts to subsidies for higher education.

To further address concerns related to changes in economic conditions, we carry out additional analyses based on yearly microdata from a large employment survey (EOD), which is representative for the Santiago region and covers the period 1964-1981. Appendix Figure A4 shows that

\footnotetext{
${ }^{25}$ Appendix Table A3 replicates the reduced-form analysis for modified samples imposing different educational constraints. We find evidence of much smaller upward kinks in mortality for the population lacking any higher education, but no effect on the population without any secondary education. These results are consistent with the presence of spillovers across adjacent education levels (e.g., people with full secondary that fail to go to college compete for clerical jobs with people with incomplete secondary, who are thus pushed down the socio-economic ladder and have worse health as a result). The absence of a change in mortality for the population without secondary education (who had no chance of attending college) lends further support to our exclusion restriction, as we discuss below.
} 
youth unemployment (ages 20-30) increased sharply between 1973 and 1976, but also decreased rapidly between 1977 and 1981. Hence, the unemployment rate does not exhibit a sharp linear kink like the one observed in the cohort-level series for college enrollment and mortality. Indeed, column 2 of Table A4 shows that the results are robust to controlling for the unemployment rate.

Relatedly, in Table A5 we present estimates using unemployment from EOD as our first-stage outcome. The results show that there is no kink in the unemployment rate faced by the study cohorts in the year in which they reached age 21 . This result is robust to measuring yearly unemployment for all individuals aged $20+$ (column 3), restricting the sample to young individuals (ages 20-30, column 4), or even further imposing that the individuals must have at least some secondary education (column 5). Reassuringly, the EOD also includes a question on whether each person is currently studying, which does have a sizable downward kink in the years after the military coup among those with ages 20-25 (column 2). Also reassuring is that we observe a downward kink in college enrollment (column 1) and an upward kink in mortality (column 6) when we restrict our baseline sample to the Santiago region.

As the previous discussion on labor market conditions highlights, the question regarding the exclusion restriction in our setting is not whether some factor other than college enrollment changed after the military coup (i.e., across years), but whether such a factor differentially affected the cohorts reaching college age after the coup and, particularly, whether it more strongly affected the younger affected cohorts. In other words, an alternative mechanism must generate a linear kink across cohorts like the one we observe for college enrollment and for mortality. In this regard, to ensure that we are not simply picking up a discontinuity between cohorts reaching college age before and after the coup, Table A6 replicates our main analysis including an additional dummy for post-coup cohorts (i.e., allowing for a discontinuity). The results hardly change. This table also examines the robustness of our main results to the inclusion of a second-order polynomial in the running variable (i.e., the cohort-level trend). The point of this exercise is to verify whether we can rule out that our estimated kink is simply picking up a non-linearity in the cohort-level trend. If anything, the size of the estimated kink and the corresponding IV estimate increases.

We add four additional pieces of evidence in support of the exclusion restriction. First, as shown by panel (a) of Figure 2 there is no evidence of kinks in the share of people per cohort that completed secondary education. This suggests the absence of other confounding changes in socioeconomic factors, to the extent that socioeconomic factors differentially affecting cohorts reaching college age shortly after the coup would have also affected educational attainment at the secondary level. Importantly, secondary education was not mandatory in Chile until 2003. Second, in Appendix Table A3, we replicate the reduced-form analysis but for different samples based on their educational attainment. Reassuringly, columns 3 and 6 show a null effect of the coup on mortality for the population without secondary education. The absence of a change in mortality 
for this population lends further support to our exclusion restriction since these individuals were equally exposed to other aspects of the military regime, but they can be thought of as never-takers with no chance of attending college, even if exposed to the "treatment." Third, Appendix Table A7 shows that the results are highly comparable in separate subsamples corresponding to counties that had and did not have a military base in 1970. This suggests that the results are not driven by varying exposure to repression at the hands of the Pinochet regime (Bautista et al., 2020a).

Finally, Appendix Figure A5 shows results from regressions imposing different changes on the composition of the sample. We focus here on the IV results from our preferred specification with age fixed effects (equation 6). Panel (a) plots the estimated effect of college enrollment on mortality as we change the set of cohorts in the sample. The rightmost set of estimates correspond to our baseline bandwidth of cohorts reaching age 21 between 1964 and 1981. Each set of estimates to the left corresponds to a one-cohort reduction on each side of the bandwidth. We find that the results are largely stable and remain negative and statistically significant. The estimates with the tightest bandwidth (age 21 between 1969-1976: four cohorts on either side) are essentially identical to our baseline results, though slightly less precise. Insofar as this exercise homogenizes the overall economic and social environment faced by the study cohorts on both sides of the cut-off, it further alleviates concerns about a differential impact of the military coup across cohorts along margins other than educational attainment. Panels (b) and (c) further show that our estimates are also robust to changes in the years included in the sample or to the ages at which we observe the study cohorts.

As an additional battery of robustness checks, we also verify that our results are unaffected if we do not adjust the mortality rate, the share with college, or both, based on the cumulative number of previous deaths in each cell. These results are presented in Appendix Tables A8-A10. The results are likewise unaffected if we estimate our models at the cohort-year level, ignoring the geographic variation across regions (Appendix Table A11). This addresses potential concerns about measurement error caused by changes in location after 1992. Our results are also similar if we use the population counts in the 2002 census as starting point and study mortality between 2003 and 2017 (Appendix Table A12).

\subsection{Heterogeneous effects by age}

The effect of education on health is likely to vary over the life cycle (Kaestner et al., 2020). To shed light on potential heterogeneous effects of college on mortality by age, we begin by replicating the analysis for a restricted sample that ensures that we observe all cohorts over the same ages. We then iteratively modify the sample by excluding one age at a time and we examine the impact of these changes on our estimates. For this analysis, we focus on the IV estimates from our preferred specification with age fixed effects (equation 6). Our baseline sample only allows us to observe all 
the study cohorts between ages 51 and 57 (Appendix Figure A6). But, as mentioned above, our main results are almost identical for the smaller bandwidth of cohorts that reached age 21 between 1969 and 1976 (four on each side of the 1973 threshold). Using this bandwidth enables us to observe all cohorts for a larger range of ages: 46-62.

Appendix Figure A7 plots the results using this more conservative bandwidth. We find that the estimated effect of college on mortality is smaller for samples that do not include individuals with ages 58 and above, especially for women. This suggests that the reduction in mortality caused by college enrollment largely materializes when people reach their late fifties or early sixties. This result is in line with findings by Kaestner et al. (2020), who use observational data for the US to show that education only affects mortality after age sixty, arguably because the overall risk of death is fairly low before that age.

\subsection{Cause of death}

Appendix Table A13 provides estimates of the effect of college enrollment on mortality disaggregated by cause, based on our preferred specification with age fixed effects (equation 6). The causes of death in the table are not exhaustive, but include the main drivers of mortality in the sample: tumors, diseases of the circulatory, respiratory or digestive systems, and external causes. Panel A provides results for women, while panel B replicates the analysis for men.

The reduction in female mortality caused by college enrollment is largely driven by fewer deaths from cancer, diseases of the circulatory system and diseases of the digestive system. The effects on mortality from these three broad causes amounts to $85 \%$ of the aggregate effect of college. We find no impact on deaths from external causes or from diseases of the respiratory system. Appendix Table A14 further disaggregates cancer deaths into the most common types of tumor. College enrollment reduces female mortality from tumors of the digestive organs (39\% of aggregate effect on cancer deaths), breast (28\%), female genital organs (21\%) and lymphoid tissue $(25 \%)$. We find no effect on tumors of the respiratory organs.

For men, the largest effects of college enrollment are also on deaths from tumors and diseases of the circulatory or digestive systems (74\% of the aggregate effect between them). There are also significant reductions in deaths from external causes or from diseases of the respiratory system. ${ }^{26}$ The disaggregate results for cancer show that the effect is concentrated in tumors of the digestive organs, respiratory organs or lymphoid tissue (82\% of the aggregate effect on cancer mortality). Appendix Table A15 further shows that the effect on male mortality from external causes is driven by non-traffic accidents (i.e., occupational), medical complications and other (unknown) causes.

\footnotetext{
${ }^{26}$ Buckles et al. (2016) similarly find that the effect of college on male mortality in the US is largely concentrated in deaths from cancer and heart disease. They provide no estimates for women.
} 
Expressed as a percentage of the sample mean, we find that the reduction in cancer mortality caused by college enrollment amounts to $5.5 \%$ for women and $9.6 \%$ for men. These effect sizes are substantially smaller than the ones found for diseases of the circulatory system $(11.6 \%$ for women and $15.3 \%$ for men) or from diseases of the digestive system (12.5\% and $22 \%)$. This is consistent with the idea that idiosyncratic or hereditary factors beyond a person's control play a larger role in cancer incidence and mortality, while deaths from diseases of the respiratory or

digestive system are more strongly affected by individual behaviors (e.g., diet, exercise, alcohol consumption). These cause-specific effect sizes are systematically larger for men, especially for diseases of the respiratory system (17.8\% for men vs an insignificant $3.7 \%$ effect for women). This could reflect a differential impact of higher education on occupational choice, whereby men without college are more likely to work in occupations with high risk for respiratory disease, such as mining or manufacturing.

\section{Mechanisms}

In this section, we present evidence on some of the mechanisms underlying the causal link between college enrollment and reduced mortality. The existing literature has identified many potential channels (Cutler and Lleras-Muney, 2008, 2010). Borrowing the notation from Grossman (2006), we can classify these mechanisms as 'market' or 'nonmarket'. Market mechanisms relate to the well-documented fact that higher education leads to better jobs and higher income (Card, 1999). Higher income enables people to access better health care, whether of the preventive or curative type, while occupational choice can lead to differences in health hazards or access to health insurance. Nonmarket mechanisms include multiple factors related to preferences, beliefs, and skills that influence health-relevant behaviors and are potentially affected by education. For instance, education may affect health through changes in important characteristics of individual preferences, such as risk aversion or discount rates (e.g., Becker and Mulligan, 1997), or through exposure to different peers. Education could also increase knowledge on health-related matters or improve decision-making ability, thereby making the production of health more efficient (Grossman, 1972).

Without meaning to be exhaustive, we provide results from four sets of exercises (involving two additional data sources) that shed light on the relevance of some of these mechanisms in our setting. First, we use data from a large household survey (CASEN) to document large negative kinks for the affected cohorts in labor market outcomes and income, in line with previous findings by Bautista et al. (2020b). These negative effects could themselves directly contribute to higher mortality through occupational hazards and reduced purchasing power. Relatedly, we show that people in these cohorts are substantially more likely to be enrolled in the - more congested public health system. Second, we also use information from CASEN to show negative kinks in the 
consumption of health services by individuals in the cohorts reaching college age after the coup, which could naturally contribute to increased mortality. Lower consumption of health services, including consultations with a primary care physician or specialist and preventive procedures such as the Pap smear for women, could be a reflection of reduced access to care associated with the type of health insurance, but could also reflect differences in preferences or information. Third, we use administrative records from hospital discharge summaries to study the hospitalization rate as an additional intermediate health outcome. We fail to find evidence of kinks in hospitalizations for the affected cohorts, which suggests potential offsetting effects of worse health and limited access to care. Finally, we combine the discharge summaries with the vital statistics at the individual level to study the mortality of hospitalized patients. Confirming our findings for the broader population, we find an upward kink in the mortality rate of hospitalized patients over multiple time horizons. This kink is present even after conditioning on observable characteristics such as diagnostic, hospital and type of insurance. This could reflect other channels through which education affects mortality, including unobservable differences in comorbidities and health behaviors, such as adherence to post-hospitalization treatment.

\subsection{Labor market outcomes}

In this section, we present results on labor market outcomes based on individual responses to the CASEN household survey between 1990 and 2017. Though the information in CASEN is all selfreported, we have no reason to expect differential misreporting across our study cohorts. It also remains unclear whether misreporting varies with education (Cutler and Lleras-Muney, 2010). Importantly, CASEN records information on educational attainment, which enables us to restrict the sample to individuals with four or more years of secondary education - as in our main sample above - and to provide both reduced-form and IV estimates.

Our outcomes of interest are respective indicators for labor force participation, white-collar high-skill occupation and enrollment in the public health insurance. We also study total individual income. These outcomes allow us to establish the extent to which the cohorts affected by reduced access to higher education experience economic disadvantage, which may plausibly contribute to their worse health status. Figure 4 plots the raw data for these outcomes, averaged across survey years by cohort. We observe sizable downward kinks in labor force participation, white-collar high-skill occupation and income for both men and women in the cohorts reaching age 21 after 1973. These kinks - which are indicative of worse economic conditions for the affected cohorts are matched by an upward kink in enrollment in the public health insurance.

Table 3 quantifies these kinks and provides IV estimates of the effect of college enrollment from our preferred specification with age fixed effects (equation 6). We estimate our models at 
the individual level and include county by year fixed effects in all regressions, which account for a host of spatial and temporal factors. We cluster standard errors two-way by county and regionyear following Cameron et al. (2011), but also provide in brackets p-values from the Wild cluster bootstrap at the cohort level. Panel A corresponds to women, while panel B shows results for men.

Focusing on the IV results, column 1 shows that college enrollment increases labor force participation for women by 14 percentage points (pp) and for men by $21 \mathrm{pp}$. These effects correspond to respective increases of $27 \%$ and $24 \%$ relative to the sample mean. Column 2 shows that college enrollment increases the probability of a white-collar, high-skill occupation for women by $50 \mathrm{pp}$ and for men by $35 \mathrm{pp}$. These very large effects (equivalent to $110 \%$ and $94 \%$ of the respective sample means) are unsurprising as the occupations in question are mostly professional ones (e.g., doctor, lawyer), which are largely unattainable without a college degree. The dependent variable in column 3 is total individual income, which we express in thousands of 2010 Chilean pesos. College enrollment increases average income by 173,000 pesos for women and by 234,000 for men, corresponding to increases of $57 \%$ and $36 \%$ over the sample means. Finally, column 4 shows that going to college reduces enrollment in the public health insurance by $20 \mathrm{pp}$ for women and by $41 \mathrm{pp}$ for men, which corresponds to decreases of $32 \%$ and $74 \%$ relative to the mean. This result is consistent with the findings in the previous columns, as the public health system mostly caters to the underprivileged. The much larger effect for men plausibly reflects that women can more easily access private health insurance through their partner or spouse during this time period. This difference could partly explain the larger effect of college on male mortality documented above.

\subsection{Consumption of health services}

The CASEN survey also allows us to gain insight on the consumption of medical services. We analyze individual responses to questions asking individuals whether they have seen a primary care physician or a specialist in the past three months, as well as whether they have visited an emergency room (ER) during the same period. The expected effect of college enrollment on these outcomes is theoretically ambiguous. On the one hand, the cohorts exposed to reduced access to college could consume health services at higher rates due to their worse health status, as reflected by their higher mortality. On the other hand, the results in the previous section indicate substantial economic disadvantage and high reliance on the public health system, which may limit their access to care. In the case of women, we can further study the use of preventive care based on a question asking whether they have had a Pap smear in the past three years.

Figure 5 plots the raw data for these outcomes, averaged across survey years by cohort. Women in the affected cohorts exhibit downward kinks in the probability of having seen a specialist in the past three months (panel b), as well as in the probability of having had a Pap smear in the past 
three years (panel d). In the case of men, panel (e) shows a downward kink in the probability of having seen a primary care physician in the past three months. There is no evidence of changes in the cohort trends for ER visits (panels $\mathrm{c}$ and $\mathrm{g}$ ), which is consistent with fewer barriers to access for this service, relative to outpatient consultations. It is also consistent with lower heterogeneity in the demand, insofar as a visit to the ER is often unavoidable given a large negative health shock.

Table 4 has a similar structure to Table 3 and provides reduced-form estimates of the kink in the consumption of health services for the affected cohorts, as well as IV estimates of the effect of college enrollment. Focusing on the latter, column 1 shows that college enrollment increases the probability of having seen a primary care physician in the past three months by $12.8 \mathrm{pp}$ for men. This is a large and precisely-estimated effect, equivalent to $97 \%$ of the sample mean. For women, the estimated effect of college on primary care visits is much smaller (4.1 pp) and is not statistically significant. Column 2 shows, however, that college enrollment increases the probability of having recently seen a specialist by $10.1 \mathrm{pp}$ for women (70\% increase over sample mean), while the effect for men is only $5.2 \mathrm{pp}$ and is not significant. In line with the visual evidence, we find no effect on ER visits. Taken together, these results are consistent with more educated individuals making larger investments in health capital in order to increase their time available for market and nonmarket activities (Grossman, 1972). They are also consistent with previous research documenting a positive correlation between education and the use of preventive care services (e.g., Fletcher and Frisvold, 2009; Cutler and Lleras-Muney, 2010; Lange, 2011).

Column 4 in Table 4 examines the probability that women have had a Pap smear done in the past three years. This is the main procedure to test for cervical cancer and the Chilean Health Ministry recommends it for all women over the age of 25. As mentioned above, panel (d) in Figure 5 provides clear evidence of a downward kink for the affected cohorts, which the regression estimates help to quantify. We estimate that college enrollment increases the probability of having had this procedure done in a timely fashion by $16.8 \mathrm{pp}$, equivalent to $23 \%$ of the sample mean. This arguably contributes to the negative impact of college on deaths from female genital cancer documented in Appendix Table A14. Importantly, CASEN asks women that report not having had a Pap smear the reason for not doing so, which we use as additional dependent variables in Appendix Table A16. We find that negligence or forgetfulness explains $45 \%$ of the college effect, while lack of knowledge or lack of interest explain a further 18\%. These results are imprecise and should be interpreted with caution. They suggest, however, that college affects health through non-market channels, including changes in knowledge and preferences. 


\subsection{Hospitalizations}

In this section, we present results from two exercises based on administrative data from hospital discharge summaries. Unfortunately, this source does not contain information on educational attainment, so the analysis is exclusively reduced form. First, we study the hospitalization rate, at the cohort-year level, as an intermediate health outcome that allows us to further explore the role of health services consumption in the link between college enrollment and mortality. Given their worse health status - as reflected by their higher mortality - we would expect to find evidence of a higher hospitalization rate for the cohorts exposed to reduced access to college. Failing to find such evidence could indicate the presence of barriers in access to care. Second, we combine the discharge summaries with the vital statistics to compare, at the individual level, the mortality of hospitalized patients across cohorts. Ex-ante, it is unclear whether cohorts with reduced access to college have higher mortality in this selected sub-population.

\subsubsection{Hospitalization rates}

We study hospitalization rates at the cohort-gender-region-year level, similarly to our main analysis. Since the hospital discharge summaries are only available since 2002, we source the initial population count per cell from that year's census, which we adjust for mortality over time.

Figure 6 shows the hospitalization rate (per 1,000) by cohort, averaged across years. The raw data suggests the presence of upward kinks in the male and female hospitalization rates, though these are small and the cross-cohort variation is noisy. Column 1 in Table 5 provides estimates of equation 4 - our preferred reduced-form specification with age fixed effects - for this outcome. Once we flexibly account for age effects, we find no evidence of kinks for women (panel A) or men (panel B). The previous outcome corresponds to the number of hospitalizations per 1,000 individuals, irrespective of whether these represent different hospitalized patients or multiple hospital stays by the same person. Using the individual identifier in the discharge summaries, we can distinguish between a patient's first admission per year and subsequent readmissions during the same year. Column 2 in Table 5 shows results using the yearly number of hospitalized individuals per 1,000 as dependent variable. We find a similar pattern to the one observed for total hospitalizations. There is no evidence of a kink in the hospital admission rate. ${ }^{27}$

This null result for hospitalizations is striking given the upward kink in mortality observed for the affected cohorts. ${ }^{28}$ It suggests that lower educational attainment leads these cohorts to be in

\footnotetext{
${ }^{27}$ First admissions per patient-year represent $67 \%$ of total admissions, while within-year readmissions correspond to $25 \%$ of the total. The remaining $8 \%$ are admissions without an individual ID. Appendix Table A17 shows a negative kink for the readmission rate, which is largely matched by an upward kink in the rate of unidentified admissions. We interpret the latter as further evidence of economic disadvantage and limited access to care in the affected cohorts.

${ }^{28}$ Appendix Table A18 replicates the main analysis for this sample (i.e., 2002 census as baseline, no restriction on
} 
worse health while simultaneously limiting their access to medical care. These two effects push the hospitalization rate in opposite directions and arguably cancel out. The fact that the affected cohorts are increasingly reliant on the public health system lends support to this interpretation. To further explore this possibility, columns 3 and 4 provide disaggregate estimates on hospitalizations by type of insurance. Results are very similar if we use type of hospital instead (not reported). For both women and men, we find evidence of an upward kink in the hospitalization rate using public insurance and of a comparable downward kink in the hospitalization rate using private insurance. ${ }^{29}$ These results are consistent with the notion that increased reliance on the public health system is a contributing factor in the limited access to care faced by the affected cohorts. They must be interpreted with caution, though, as their statistical significance is sensitive to the type of clustering.

\subsubsection{Mortality of Hospitalized patients}

We turn next to the mortality of hospitalized patients. We study this topic at the individual level, which allows us to exploit the availability of individual-level covariates in the hospital discharge summaries. We drop hospitalizations lacking a patient ID (8\% of total) and restrict the sample to the first observation per patient, though we do take readmissions into account below. We merge these records with the mortality files and establish for each individual whether death occurs over various time horizons, ranging from time of discharge to five years. Some variables in the discharge summaries are unavailable before 2004, so we start the sample on this year. To ensure that we properly measure survival for all patients for up to five years, we only consider hospitalizations up to 2012 and track the mortality of these patients until 2017, the last year with mortality data. By looking at different time horizons, we can study whether any observed changes in mortality for the affected cohorts correspond to temporary effects that disappear over longer time periods (i.e., dying within six months rather than within a year). Our final estimating sample includes roughly 1.1 million individuals that were admitted to hospital between 2004 and 2012.

Table 6 presents the results for deaths within one year of hospitalization. We estimate a modified version of our reduced-form models that replaces the region-year fixed effects with more conservative county-year fixed effects and sequentially adds additional controls. We cluster standard errors two-way by county and region-year following Cameron et al. (2011), but also provide p-values from the Wild cluster bootstrap at the cohort level following Cameron et al. (2008). We focus here on the one-year horizon to maximize comparability with our estimates of yearly mor-

education). The slight difference in sample size relative to Table 5 is caused by the absence of mortality data for 2018 . Appendix Table A19 provides results on hospitalizations disaggregated by main diagnostic. Focusing on the leading causes of death, we find negative kinks in cancer-related hospitalizations for both genders and no difference in the hospitalization rate for diseases of the circulatory system for men.

${ }^{29}$ Appendix Table A17 shows that there is also a negative kink in hospitalizations with missing insurance information for women. There are no kinks in hospitalizations by the uninsured. 
tality in the main analysis, but Appendix Tables A20-A24 show equivalent estimations for other time horizons. The average one-year female mortality rate in this sample is 46 deaths per 1,000 patients, while for men it is 78 deaths per 1,000 patients. These rates are one order of magnitude larger than the averages from our main sample in Table 2 and indicate that hospitalized patients are at a much higher risk of death than the population at large. ${ }^{30}$

Column 1 shows estimates of equation 3 and provides evidence of an upward kink in mortality for women (panel A) and men (panel B) in the affected cohorts. These kinks are quite sizable, at $49 \%$ and $45 \%$ of the respective female and male baseline trends. Figure 7 plots the one-year mortality rate across cohorts and provides compelling visual evidence of the upward shift in the mortality trend. Appendix Figure A9 shows similar plots for other time horizons. Column 2 corresponds to equation 4, our preferred specification with age fixed effects. The estimated kinks decrease slightly once we account for age effects, but remain largely comparable to the baseline results. We take these estimates as the benchmark as we proceed to include additional controls in the following columns. Some of these controls are arguably 'bad controls' as defined by Angrist and Pischke (2009), so we expect the estimated kink to decrease once we control for them. ${ }^{31}$

We first examine whether differences in diagnostic help to explain the kink in mortality. Column 3 includes a full set of diagnostic fixed effects based on the 4-digit ICD code from the discharge summaries. Columns 4-8 then sequentially include additional sets of fixed effects for other observable characteristics. In column 4, we account for the type of insurance (public vs private), while in column 5 we control for the specific hospital of admission (381 different establishments) and in column 6 for the type of admission (emergency room, transfer from other hospital, etc.). Column 7 further controls for whether surgery was performed, while column 8 accounts for whether the patient was previously admitted in 2002-2003, before the start of the sample period. To maximize explanatory power, we estimate saturated models that interact each additional set of fixed effects with all the previous ones. ${ }^{32}$ For instance, in column 5 we are comparing patients that share the same diagnostic, have the same insurance, and were admitted to the same hospital.

A comparison of columns 2 and 8 reveals that these observable characteristics together explain - in a statistical sense - approximately $40 \%$ of the upward kink in one-year mortality for women and men in the affected cohorts. Among these characteristics, just accounting for differences in diagnostic makes the magnitude of the estimated kink drop by about $24 \%$ for both men and women. This suggests the presence of different morbidity profiles across cohorts with varying levels of educational attainment. The remaining excess mortality that is not explained by observables arguably

\footnotetext{
${ }^{30}$ Appendix Table A25 replicates our main analysis for the period 2004-2012 to further enhance comparability.

${ }^{31}$ Cutler and Lleras-Muney (2008, 2010) employ a similar strategy.

${ }^{32}$ While the sample remains unchanged, the estimation package we employ (reghdfe) drops singleton observations, which become more frequent as we include increasingly stringent combinations of fixed effects (Correia, 2015). Naturally, the point estimates are unaffected by this exclusion.
} 
corresponds to unobservable differences in health behaviors and access to care. ${ }^{33}$ Some of the unexplained variation could also correspond to the inevitable coarseness of some of our controls. For example, diagnostic codes fail to account for comorbidities.

Figure 8 plots the estimated kink from the regressions in Table 6, as well as the corresponding estimates for the other time horizons we consider. Except for the one-month mortality rate for women, most other estimates are statistically significant at the 5\% level (see Appendix Tables A20-A24). For both genders, we find larger kinks over longer time horizons. Hence, it is not the case that the documented effects for the one-year horizon are merely capturing short-term shifts in the probability of death. Instead, the results suggest that the effect of education on the mortality of hospitalized patients persists and grows for at least five years. The explanatory power of the observable characteristics remains largely stable across time horizons. For example, observables explain $42 \%$ of the kink in five-year mortality for women and $47 \%$ of the kink for men. Differences in diagnostic explain $20-25 \%$ of the kink throughout.

\section{Conclusion}

In this paper, we provide novel evidence on the impact of higher education on mortality. For this purpose, we exploit the sharp negative kink in access to college experienced by Chilean cohorts reaching college age shortly after the 1973 military coup. Using data from the vital statistics between 1994-2017, we find that women and men in these cohorts have higher age-adjusted mortality rates, a pattern that we also observe in matched individual-level records for hospitalized patients. Leveraging the kink in college enrollment, we estimate that going to college reduces the agespecific mortality rate by 0.26 percentage points ( $\mathrm{pp}$ ) for women and by $0.9 \mathrm{pp}$ for men. These are large and precisely-estimated effects, equivalent to $68 \%$ and $130 \%$ of the respective sample means.

We further show that the cohorts exposed to reduced access to college experience substantial economic disadvantage throughout the life cycle and are more reliant on the public health system, which has fewer resources and is more congested than its private counterpart. These cohorts also consume health services at lower rates, including consultations with a primary care physician or a specialist, which plausibly contributes to their higher mortality. In the case of women, college enrollment increases the probability of having had a Pap smear in the past three years, which is the main procedure to test for cervical cancer. We fail to find evidence of changes in hospitalization

\footnotetext{
${ }^{33}$ Data limitations prevent us from further studying health behaviors. Questions in CASEN on this topic are limited and infrequent, which leads to small sample sizes. For instance, information on smoking in the past month is only collected in the waves from 1990, 1992 and 1998. Figure A10 plots cohort-level averages of this variable, pooling men and women $(\mathrm{N}=29,613)$. Interestingly, the graph indicates a clear downward kink in smoking for the affected cohorts. This result stands in contrast to previous findings by De Walque (2007) and Grimard and Parent (2007) for the US, and suggests that the liberal environment characteristic of universities may have fostered smoking in our setting.
} 
rates, despite the observed changes in health status, which we interpret as evidence consistent with the presence of barriers in access to care.

Our findings stand in contrast to a previous body of work that has largely struggled to find evidence of a causal effect of education on mortality (Galama et al., 2018; Xue et al., 2021). Existing research has mostly relied on changes to compulsory schooling laws at the primary or secondary level. One limitation of these research designs is that the resulting increase in educational attainment is often small (i.e., one extra year of education) and usually takes place within the same level. In contrast, we document what can truly be described as life-changing socio-economic consequences of entering higher education in our setting. These include respective increases for women and men of 50 percentage points (pp) and $35 \mathrm{pp}$ in the probability of having a professional (i.e., white-collar, high skill) occupation, as well as increases in average income equivalent to $57 \%$ and $36 \%$ of the respective female and male sample means. These large economic impacts of college enrollment set apart our study from most of the previous literature and could plausibly explain the positive impact of education on health that we uncover.

One additional limitation of previous studies is that the compliers affected by compulsory schooling reform are people who otherwise would have chosen not to obtain additional education. ${ }^{34}$ These people arguably have low returns to additional schooling and may exert low effort while in school. As a result, their health may benefit relatively less from further education, especially if the effect partly operates through the acquisition of knowledge. In contrast, the compliers in our setting are people that wanted to attend college -as reflected by the ratio of applications to openings - but failed to do so as a result of the cuts to supply implemented by the military government. Moreover, our compliers are people with relatively lower scores in the college admissions exam, who disproportionately came from less affluent backgrounds. It seems highly plausible that the impact of college on their economic and health outcomes was particularly high.

\footnotetext{
${ }^{34}$ We thank Adriana Lleras-Muney for sharing this insight with us.
} 


\section{References}

Albouy, V. and Lequien, L. (2009). Does Compulsory Education Lower Mortality? Journal of Health Economics, 28(1):155 - 168.

Angrist, J. and Pischke, J.-S. (2009). Mostly Harmless Econometrics. Princeton University Press.

Angrist, J. D., Imbens, G. W., and Rubin, D. B. (1996). Identification of Causal Effects using Instrumental Variables. Journal of the American Statistical Association, 91(434):444-455.

Arendt, J. N. (2005). Does Education Cause Better Health? A Panel Data Analysis Using School Reforms for Identification. Economics of Education Review, 24(2):149-160.

Bautista, M. A., González, F., Martínez, L. R., Muñoz, P., and Prem, M. (2020a). The Geography of Repression and Opposition to Autocracy. Forthcoming at American Journal of Political Science.

Bautista, M. A., González, F., Martínez, L. R., Prem, M., and Muñoz, P. (2020b). Dictatorship, Higher Education and Social Mobility. Working Paper.

Becker, G. S. and Mulligan, C. B. (1997). The Endogenous Determination of Time Preference. Quarterly Journal of Economics, 112(3):729-758.

Behrman, J. R. and Rosenzweig, M. R. (2004). Returns to Birthweight. Review of Economics and Statistics, 86(2):586-601.

Beltrán-Sánchez, H., Finch, C. E., and Crimmins, E. M. (2015). Twentieth Century Surge of Excess Adult Male Mortality. Proceedings of the National Academy of Sciences, 112(29):8993-8998.

Black, D. A., Hsu, Y.-C., and Taylor, L. J. (2015). The Effect of Early-life Education on Later-life Mortality. Journal of Health Economics, 44:1 - 9.

Black, S. E., Devereux, P. J., and Salvanes, K. G. (2007). From the Cradle to the Labor Market? The Effect of Birth Weight on Adult Outcomes. Quarterly Journal of Economics, 122(1):409439.

Braakmann, N. (2011). The Causal Relationship between Education, Health and Health Related Behaviour: Evidence from a Natural Experiment in England. Journal of Health Economics, 30(4):753-763.

Brunner, J. J. (1984). Informe Sobre el Desarrollo y el Estado Actual del Sistema Universitario en Chile. Programa Flacso-Santiago de Chile, Documento de Trabajo.

Buckles, K., Hagemann, A., Malamud, O., Morrill, M., and Wozniak, A. (2016). The Effect of College Education on Mortality. Journal of Health Economics, 50:99 - 114.

Cameron, C., Gelbach, J. B., and Miller, D. L. (2008). Bootstrap-Based Improvements for Inference with Clustered Errors. Review of Economics and Statistics, 90(3):414-427. 
Cameron, C., Gelbach, J. B., and Miller, D. L. (2011). Robust Inference with Multi-way Clustering. Journal of Business and Economic Statistics, 29(2):238-249.

Canay, I. A., Santos, A., and Shaikh, A. M. (2021). The wild bootstrap with a "small" number of "large" clusters. Review of Economics and Statistics, 103(2):346-363.

Card, D. (1999). The Causal Effect of Education on Earnings. In Ashenfelter, O. C. and Card, D., editors, Handbook of Labor Economics, volume 3, pages 1801 - 1863. Elsevier.

Card, D. (2001). Estimating the Return to Schooling: Progress on Some Persistent Econometric Problems. Econometrica, 69(5):1127-1160.

Card, D., Lee, D. S., Pei, Z., and Weber, A. (2015). Inference on Causal Effects in a Generalized Regression Kink Design. Econometrica, 83(6):2453-2483.

Card, D. and Lemieux, T. (2001). Going to College to Avoid the Draft: The Unintended Legacy of the Vietnam War. American Economic Review, 91(2):97-102.

Case, A., Lubotsky, D., and Paxson, C. (2002). Economic Status and Health in Childhood: The Origins of the Gradient. American Economic Review, 92(5):1308-1334.

Clark, D. and Royer, H. (2013). The Effect of Education on Adult Mortality and Health: Evidence from Britain. American Economic Review, 103(6):2087-2120.

Clínicas de Chile (2014). Dimensionamiento del Sector de Salud Privado en Chile. Technical Report.

Clínicas de Chile (2016). Dimensionamiento del Sector de Salud Privado de Chile: Actualización a Cifras 2016. Technical Report.

Conley, T., Hansen, C., and Rossi, P. (2012). Plausibly Exogenous. Review of Economics and Statistics, 94(1):260-272.

Correia, S. (2015). Singletons, Cluster-Robust Standard Errors and Fixed Effects: A Bad Mix. Working Paper.

Cutler, D. M. and Lleras-Muney, A. (2008). Education and Health: Evaluating Theories and Evidence. In Schoeni, R., House, J., Kaplan, G., and Pollack, H., editors, Making Americans Healthier: Social and Economic Policy as Health Policy, pages 29-60. Russell Sage Foundation.

Cutler, D. M. and Lleras-Muney, A. (2010). Understanding Differences in Health Behaviors by Education. Journal of Health Economics, 29(1):1-28.

De Walque, D. (2007). Does Education Affect Smoking Behaviors?: Evidence using the Vietnam Draft as an Instrument for College Education. Journal of Health Economics, 26(5):877-895.

Duarte, F. (2011). Switching Behavior in a Health System with Public Option. Working Paper.

Fletcher, J. M. and Frisvold, D. E. (2009). Higher Education and Health Investments: Does More Schooling Affect Preventive Health Care Use? Journal of Human Capital, 3(2):144-176. 
Fuchs, V. R. (1982). Time Preference and Health: An Exploratory Study. In Fuchs, V. R., editor, Economic Aspects of Health, pages 93-120. University of Chicago Press.

Galama, T., Lleras-Muney, A., and van Kippersluis, H. (2018). The Effect of Education on Health and Mortality: A Review of Experimental and Quasi-experimental Evidence. Oxford Research Encyclopedia of Economics and Finance.

Galetovic, A. and Sanhueza, R. (2013). Un Análisis Económico de la Integración Vertical entre Isapres y Prestadores. Working Paper.

Grimard, F. and Parent, D. (2007). Education and Smoking: Were Vietnam War Draft Avoiders Also More Likely to Avoid Smoking? Journal of Health Economics, 26(5):896-926.

Grossman, M. (1972). On the Concept of Health Capital and the Demand for Health. Journal of Political Economy, 80(2):223-255.

Grossman, M. (2006). Education and Nonmarket Outcomes. In Hanushek, E. A. and Welch, F., editors, Handbook of the Economics of Education, volume 1, pages 577-633. Elsevier.

Kaestner, R., Schiman, C., and Ward, J. (2020). Education and Health Over the Life Cycle. Economics of Education Review, 76:101982.

Kemptner, D., Jürges, H., and Reinhold, S. (2011). Changes in Compulsory Schooling and the Causal Effect of Education on Health: Evidence from Germany. Journal of Health Economics, 30(2):340-354.

Kitagawa, E. M. and Hauser, P. M. (1968). Education Differentials in Mortality by Cause of Death: United States, 1960. Demography, 5(1):318-353.

Lange, F. (2011). The Role of Education in Complex Health Decisions: Evidence from Cancer Screening. Journal of Health Economics, 30(1):43-54.

Levy, D. (1986). Chilean Universities under the Junta: Regime and Policy. Latin American Research Review, 21(3):95-128.

Lindsay, B. G. and Qu, A. (2003). Inference functions and quadratic score tests. Statistical Science, 18(3):394-410.

Lleras-Muney, A. (2005). The Relationship Between Education and Adult Mortality in the United States. Review of Economic Studies, 72(1):189-221.

Mazumder, B. (2008). Does Education Improve Health? A Reexamination of the Evidence from Compulsory Schooling Laws. Economic Perspectives, 32(2).

MDS (2018). Síntesis de resultados Encuesta CASEN 2017: Salud. Ministerio de Desarrollo Social.

Meghir, C., Palme, M., and Simeonova, E. (2018). Education and Mortality: Evidence from a Social Experiment. American Economic Journal: Applied Economics, 10(2):234-56. 
Montez, J. K., Hummer, R. A., and Hayward, M. D. (2012). Educational Attainment and Adult Mortality in the United States: A Systematic Analysis of Functional Form. Demography, 49(1):315-336.

OECD (2019). Health at a Glance 2019: OECD indicators. OECD Publishing.

Oreopoulos, P. (2006). Estimating Average and Local Average Treatment Effects of Education When Compulsory Schooling Laws Really Matter. American Economic Review, 96(1):152175.

Oreopoulos, P. and Salvanes, K. G. (2011). Priceless: The Nonpecuniary Benefits of Schooling. Journal of Economic Perspectives, 25(1):159-84.

Pardo, C. and Schott, W. (2012). Public Versus Private: Evidence on Health Insurance Selection. International Journal of Health Care Finance and Economics, 12:39-61.

PIIE (1984). Las Transformaciones Educacionales Bajo el Régimen Militar, Vols. I y II. Programa Interdisciplinario de Investigaciones en Educación.

Schwandt, H. and Von Wachter, T. (2019). Unlucky cohorts: Estimating the long-term effects of entering the labor market in a recession in large cross-sectional data sets. Journal of Labor Economics, 37(S1):S161-S198.

Schwandt, H. and Von Wachter, T. M. (2020). Socioeconomic decline and death: Midlife impacts of graduating in a recession. Technical report, National Bureau of Economic Research.

Universidad de Chile (1972). La Universidad de Chile: Antecedentes e Informaciones. Editorial Universitaria S.A.

Universidad de Chile (2011). Compendio Estadístico - Proceso de Admisión Año Académico 2011. Vicerectoría de Asuntos Académicos.

Valdés, J. G. (1995). Pinochet's Economists: The Chicago School in Chile. Cambridge University Press.

Van Kippersluis, H., O'Donnell, O., and Van Doorslaer, E. (2011). Long-run Returns to Education: Does Schooling Lead to an Extended Old Age? Journal of Human Resources, 46(4):695-721.

Xue, X., Cheng, M., and Zhang, W. (2021). Does Education Really Improve Health? A MetaAnalysis. Journal of Economic Surveys, 35(1):71-105.

Zimmerman, S. D. (2014). The Returns to College Admission for Academically Marginal Students. Journal of Labor Economics, 32(4):711-754. 


\section{Figure 1: Higher Education Around the Military Coup}

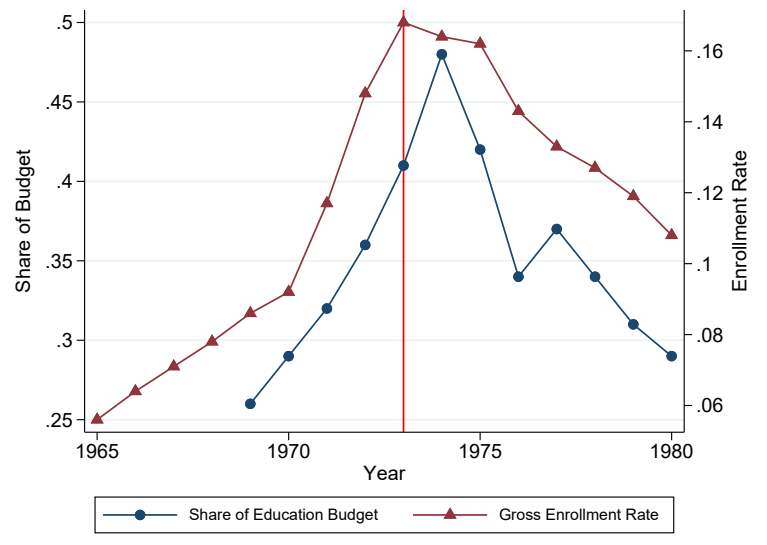

(a) Government subsidies and College Enrollment

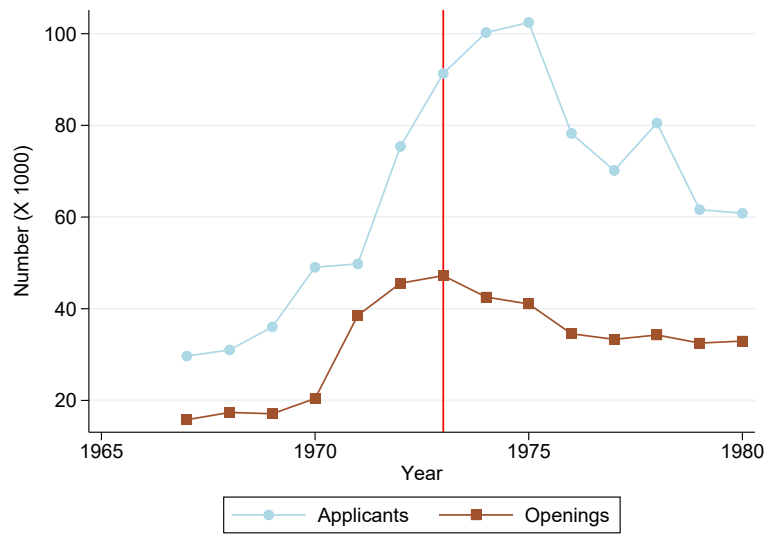

(b) College Applicants and Openings

Notes: Panel (a) shows the share of the government's education budget devoted to higher education (circle markers) and the gross enrollment rate in higher education (triangle markers). Panel (b) shows the yearly number of applicants for college (circle markers) and the number of openings on offer by the universities (square markers). Sources: Universidad de Chile (1972, 2011); PIIE (1984).

Figure 2: Educational Attainment by Cohort

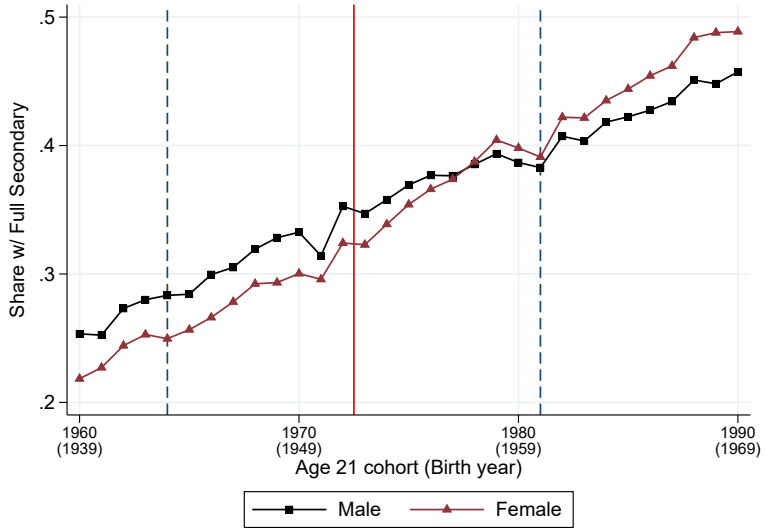

(a) Full Secondary

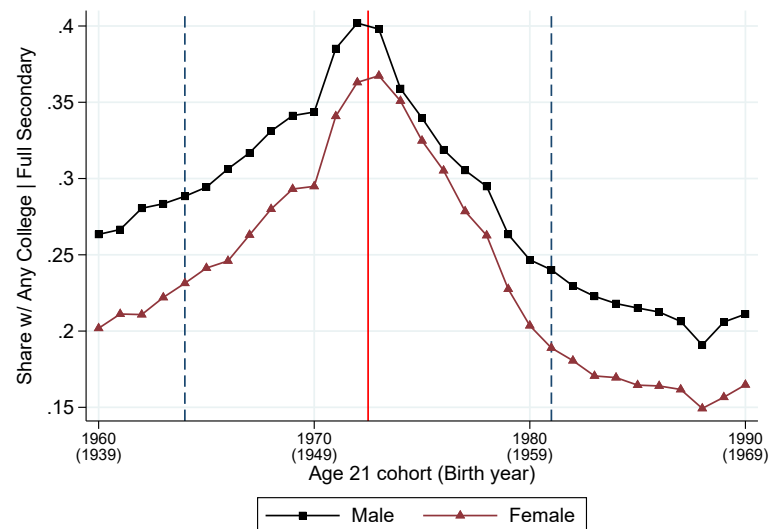

(b) Any College | Full Secondary

Notes: Panel (a) shows the shares of men and women per cohort (normalized to age 21) that report 4+ years of secondary in the 1992 census (our proxy for full secondary). Panel (b) shows the respective shares of people that report having any college education, among those with 4+ years of secondary. Dashed lines show the start (1964) and end date (1981) of the study cohorts included in the analysis. 
Figure 3: Visualization of Kink: College Enrollment and Mortality

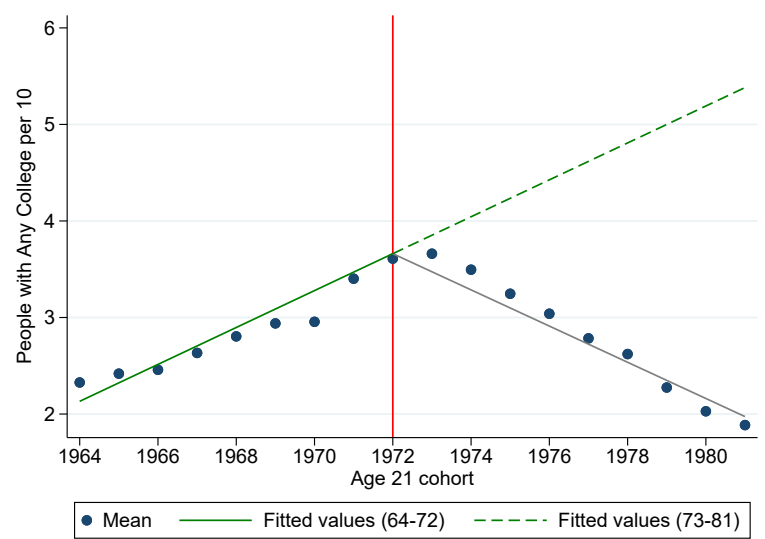

(a) Female: Any College

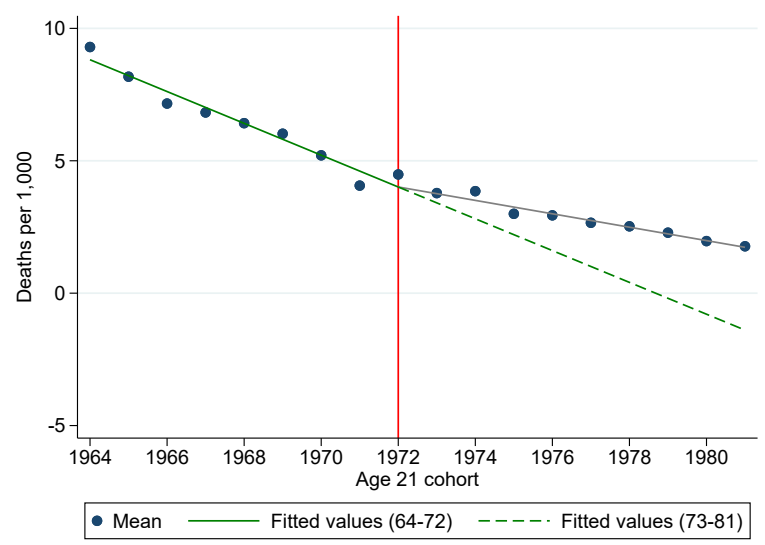

(c) Female: Mortality

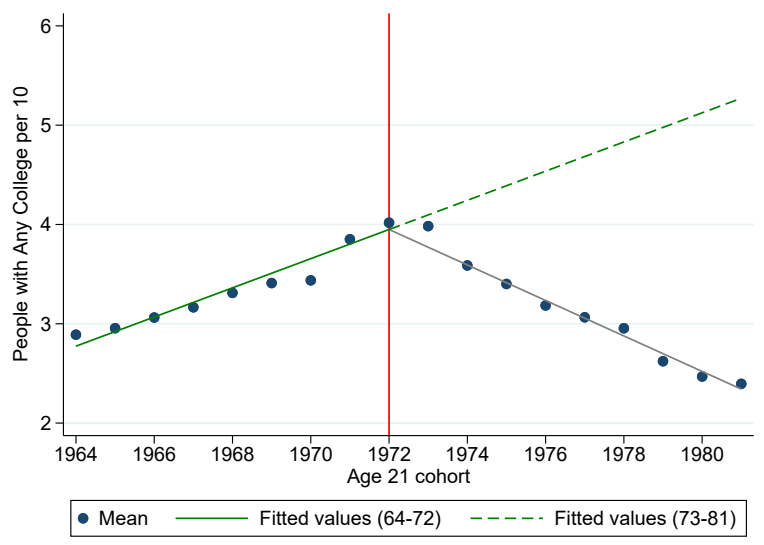

(b) Male: Any College

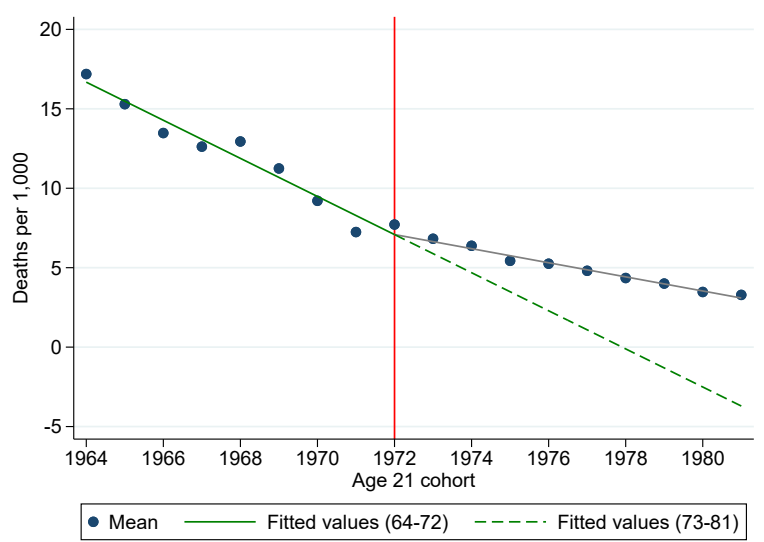

(d) Male: Mortality

Notes: Panels show averages by cohort (across years) for the variable in the caption: Share with college per every 10 individuals in panels (a) and (b); Deaths per 1,000 individuals in panels (c) and (d). Both the mortality rate and the share with college are adjusted for previous mortality before averaging. Average is weighted by cell size (cohort-year). Solid green line corresponds to the line of best fit for cohorts reaching college age before 1973, which we extrapolate for later cohorts (dashed line). Grey line corresponds to line of best fit for cohorts reaching college age in 1973 or afterwards. 
Figure 4: Visualization of Kink: Labor Market Outcomes

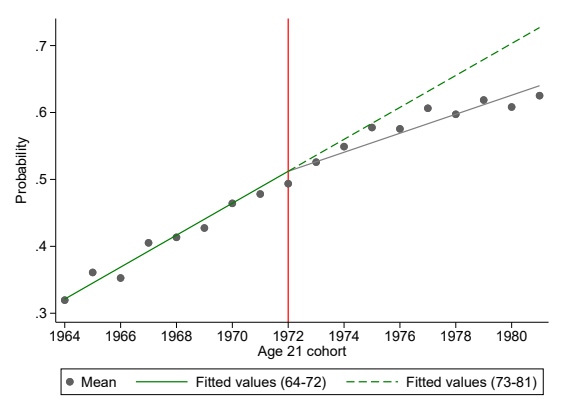

(a) Female: Labor Force Partic.

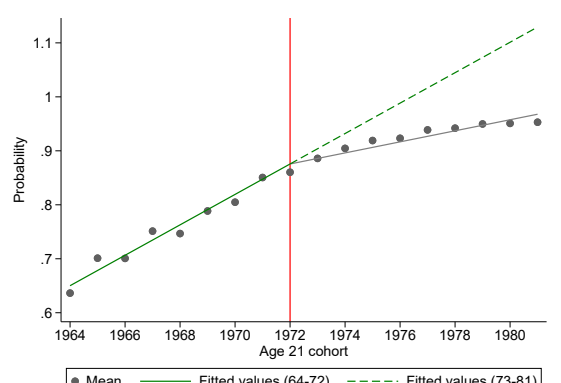

(e) Male: Labor Force Partic.

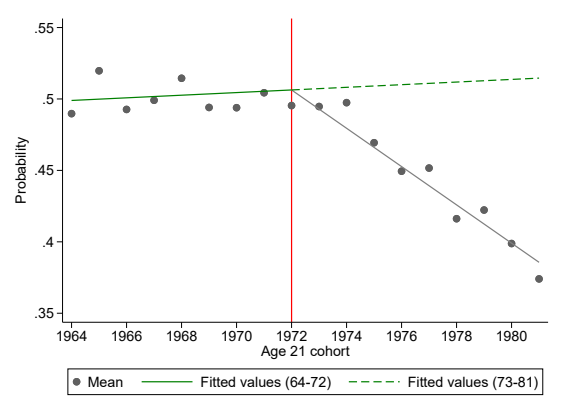

(b) Female: White-collar High-skill

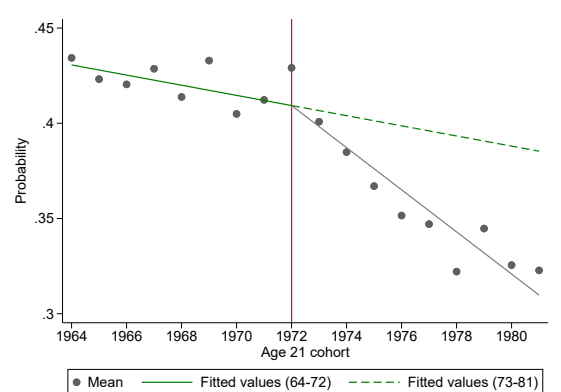

(f) Male: White-collar High-skill

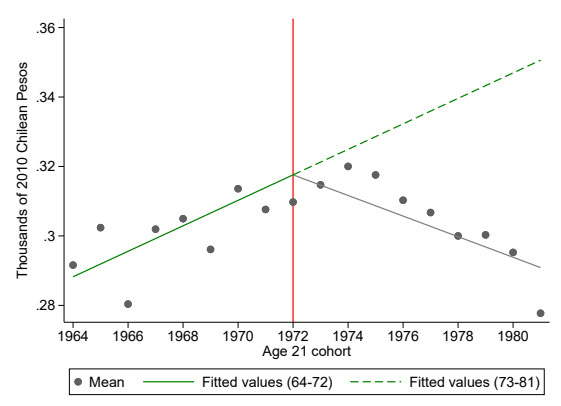

(c) Female: Total Income

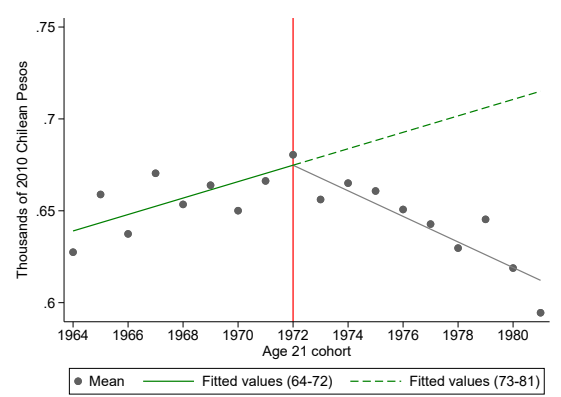

(g) Male: Total Income

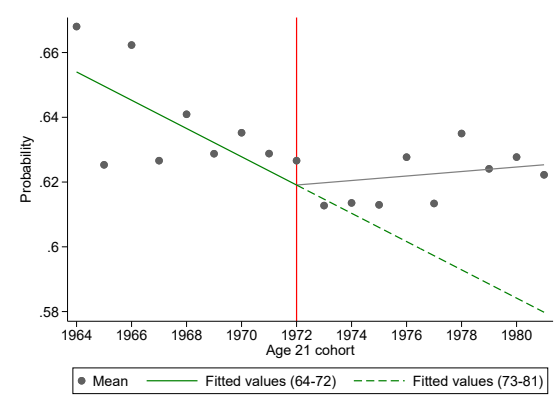

(d) Female: Public health insurance

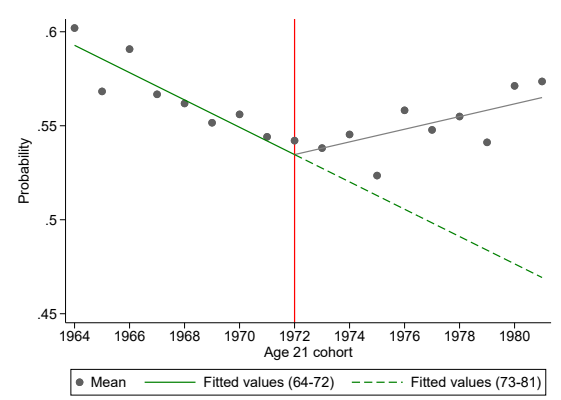

(h) Male: Public health insurance

Notes: Panels show averages by cohort (across years) for the variable in the caption, based on individual responses to the CASEN survey. Panels (a) and (e) show the share per cohort in the labor force. Panels (b) and (f) show the share per cohort with a white-collar high-skill occupation. Panels (c) and (g) show average total income, while panels (d) and (h) show the share per cohort enrolled in the public health insurance (FONASA). Solid green line corresponds to the line of best fit for cohorts reaching college age before 1973, which we extrapolate for later cohorts (dashed line). Grey line corresponds to line of best fit for cohorts reaching college age in 1973 or afterwards. 
Figure 5: Visualization of Kink: Consumption of Health Services

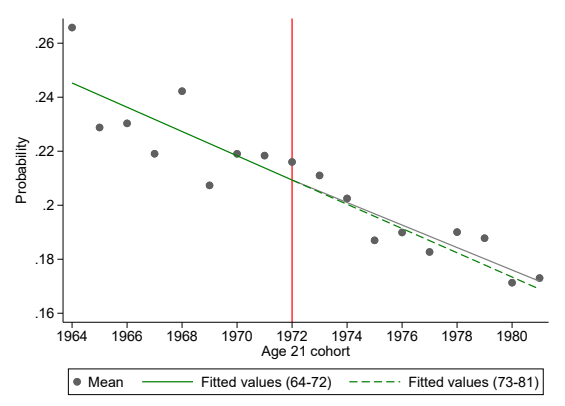

(a) Female: Primary care

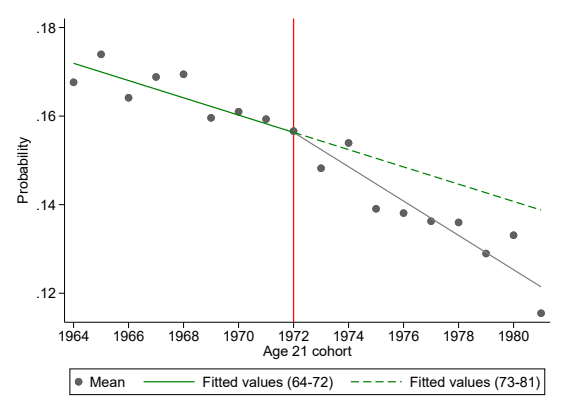

(b) Female: Specialist

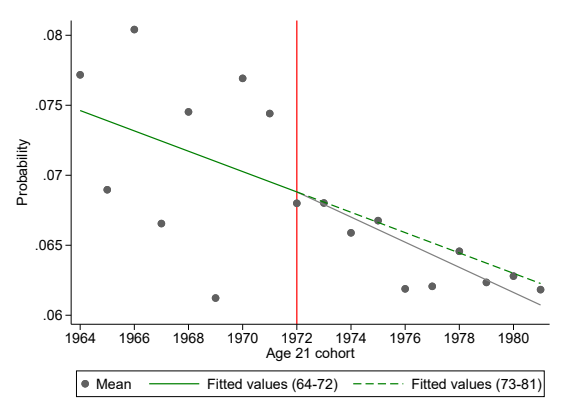

(c) Female: Emergency Room

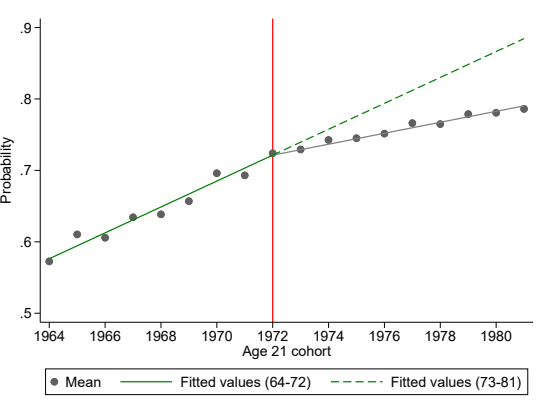

(d) Female: Pap Smear

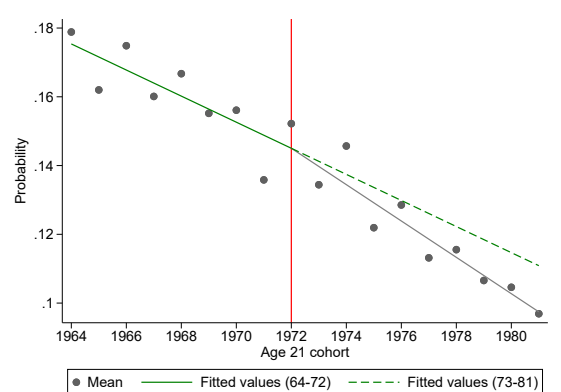

(e) Male: Primary care

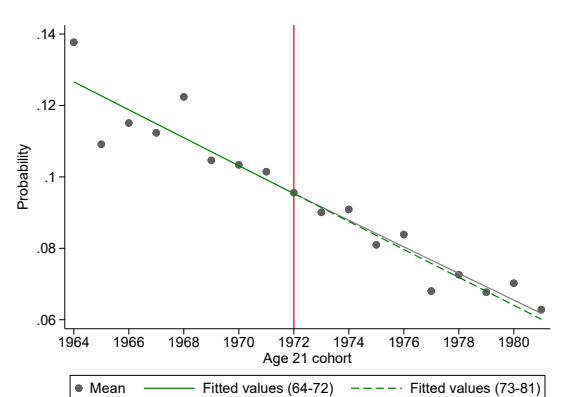

(f) Male: Specialist

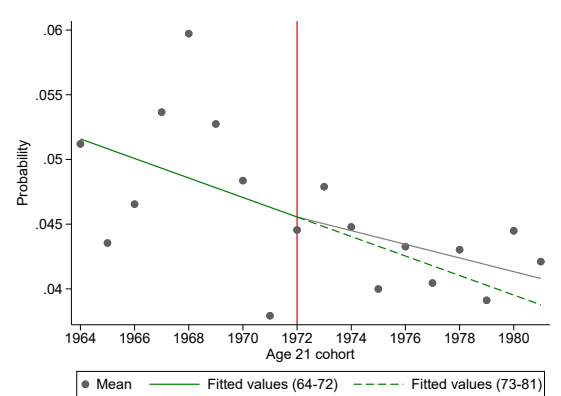

(g) Male: Emergency Room

Notes: Panels show averages by cohort (across years) for the variable in the caption, based on individual responses to the CASEN survey. All questions concern consumption of health services in the past three months, except for panel (d) which shows the share of women per cohort that had a Pap smear in the past three years. Panels (a) and (e) show the share per cohort that visited a primary care practitioner. Panels (b) and (f) show the share per cohort that visited a specialist. Panels (c) and (g) show the share that visited an emergency room. Solid green line corresponds to the line of best fit for cohorts reaching college age before 1973, which we extrapolate for later cohorts (dashed line). Grey line corresponds to line of best fit for cohorts reaching college age in 1973 or afterwards. 
Figure 6: Visualization of Kink: Hospitalization Rates

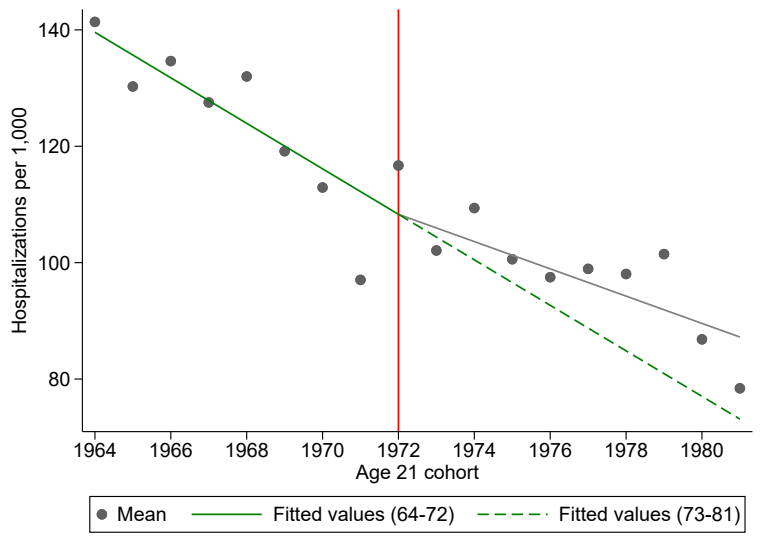

(a) Female

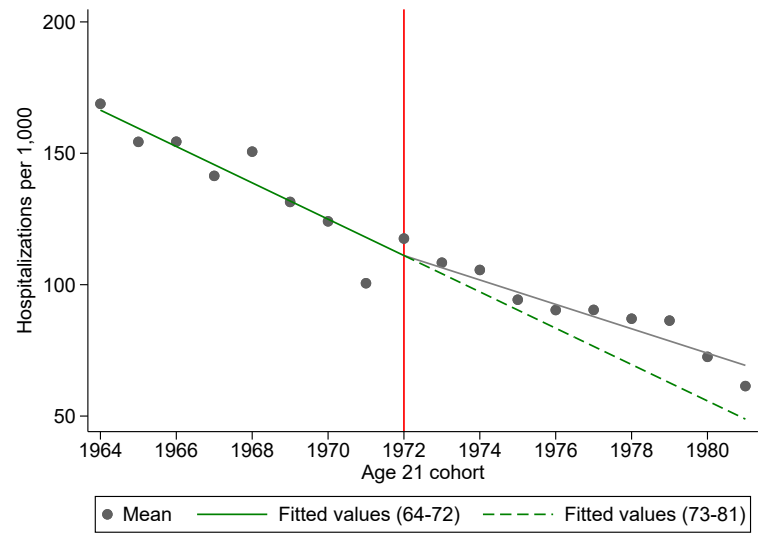

(b) Male

Notes: Panels show the average number of hospitalizations per 1,000 by cohort (across years), disaggregated by gender. Hospitalization rates are adjusted for previous mortality before averaging. Average is weighted by cell size (cohort-year). Solid green line corresponds to the line of best fit for cohorts reaching college age before 1973, which we extrapolate for later cohorts (dashed line). Grey line corresponds to line of best fit for cohorts reaching college age in 1973 or afterwards.

Figure 7: Visualization of Kink: One-year Mortality Rate of Hospitalized Patients

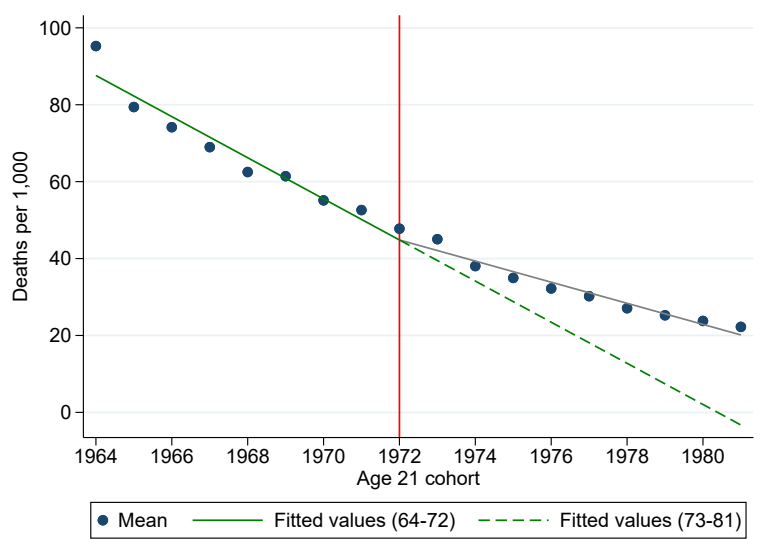

(a) Female

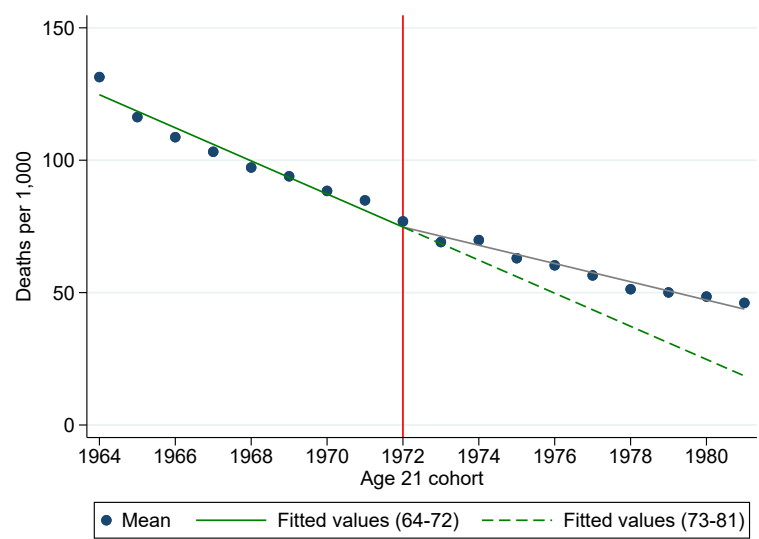

(b) Male

Notes: Panels show the average mortality rate within one year of hospital discharge by cohort (averaged across patients, one observation per patient corresponding to first admission). Sample includes individuals reaching age 21 between 1964 and 1981 (both inclusive). Sample period: 2004-2012. Solid green line corresponds to the line of best fit for cohorts reaching college age before 1973, which we extrapolate for later cohorts (dashed line). Grey line corresponds to line of best fit for cohorts reaching college age in 1973 or afterwards. 
Figure 8: Mortality Rate of hospitalized patients at different time horizons

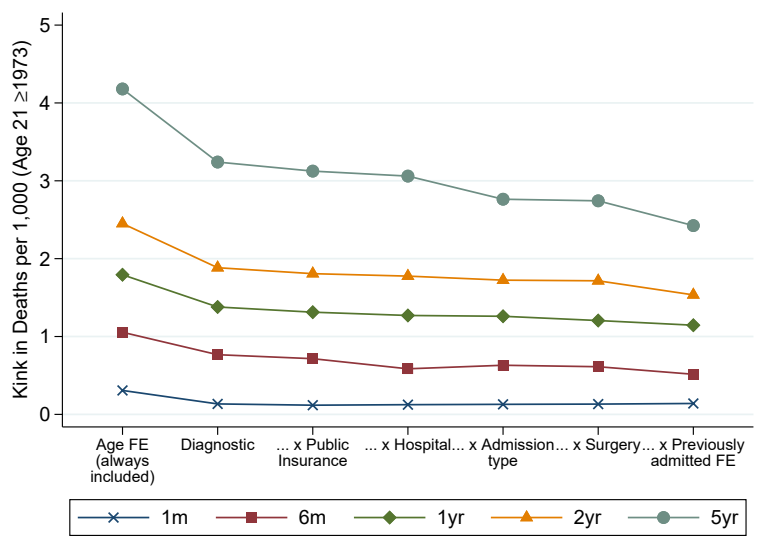

(a) Female

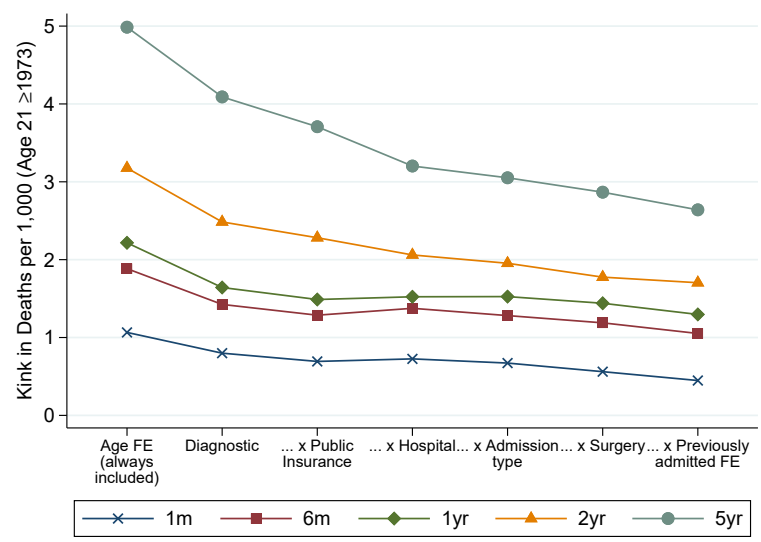

(b) Male

Notes: Figure plots the estimated size of the kink in mortality for hospitalized patients in cohorts reaching age 21 after 1973, i.e., coefficient for Yr Age 21 x $\mathbb{1}$ (Yr Age $21 \geq 1973$ ), where "Yr Age 21" is a continuous variable indicating the year at which the cohort reached age 21, normalized to zero in 1972 and $\mathbb{1}$ (Yr Age $21 \geq 1973$ ) is a dummy for cohorts that reached age 21 on or after 1973. Sample includes patients from cohorts that reached age 21 between 1964 and 1981 (both years inclusive) and is limited to one observation per patient (i.e., first admission). Sample period: 2004-2012. Different lines correspond to different time horizons for mortality relative to time of discharge. Different markers correspond to increasingly stringent sets of fixed effects, similarly to Table 6. Leftmost markers correspond to specification with age and county by year fixed effects, which are always included. 
Table 1: Educational Attainment (1992 Census)




Table 2: Mortality Rate (1994-2017)

\begin{tabular}{|c|c|c|c|c|}
\hline & \multicolumn{4}{|c|}{ Dependent variable: Deaths per 1,000 people } \\
\hline & \multicolumn{2}{|c|}{ Female } & \multicolumn{2}{|c|}{ Male } \\
\hline & Trend & Age FE & Trend & Age FE \\
\hline & (1) & $(2)$ & (3) & (4) \\
\hline & \multicolumn{4}{|c|}{$\underline{\text { Panel A: Reduced Form }}$} \\
\hline Yr Age 21 & $\begin{array}{c}-0.610 * * * \\
(0.031) \\
{[0.000]}\end{array}$ & & $\begin{array}{c}-1.244 * * * \\
(0.064) \\
{[0.000]}\end{array}$ & \\
\hline Yr Age 21 x $\mathbb{1}($ Yr Age $21 \geq 1973)$ & $\begin{array}{c}0.357 * * * \\
(0.024) \\
{[0.000]}\end{array}$ & $\begin{array}{c}0.107 * * * \\
(0.022) \\
{[0.076]}\end{array}$ & $\begin{array}{c}0.800 * * * \\
(0.046) \\
{[0.000]}\end{array}$ & $\begin{array}{c}0.315 * * * \\
(0.042) \\
{[0.000]}\end{array}$ \\
\hline \multirow[b]{2}{*}{ Share with college per 10 people } & \multicolumn{4}{|c|}{$\underline{\text { Panel B: IV }}$} \\
\hline & $\begin{array}{c}-0.880 * * * \\
(0.057) \\
{[0.001]}\end{array}$ & $\begin{array}{c}-0.263 * * * \\
(0.054) \\
{[0.091]}\end{array}$ & $\begin{array}{c}-2.409 * * * \\
(0.137) \\
{[0.001]}\end{array}$ & $\begin{array}{c}-0.922 * * * \\
(0.121) \\
{[0.001]}\end{array}$ \\
\hline & \multicolumn{4}{|c|}{ Panel C: OLS } \\
\hline Share with college per 10 people & $\begin{array}{c}-0.681 * * * \\
(0.045) \\
{[0.000]}\end{array}$ & $\begin{array}{c}-0.189 * * * \\
(0.046) \\
{[0.100]}\end{array}$ & $\begin{array}{c}-1.662 * * * \\
(0.098) \\
{[0.001]}\end{array}$ & $\begin{array}{c}-0.810 * * * \\
(0.102) \\
{[0.001]}\end{array}$ \\
\hline Year x Region FE & Yes & Yes & Yes & Yes \\
\hline Age FE & No & Yes & No & Yes \\
\hline Observations & 6,480 & 6,480 & 6,480 & 6,480 \\
\hline R-squared (panel A) & 0.677 & 0.756 & 0.749 & 0.850 \\
\hline R-squared (panel C) & 0.672 & 0.755 & 0.738 & 0.850 \\
\hline Mean DV & 3.850 & 3.850 & 7.084 & 7.084 \\
\hline Kleibergen-Paap F-statistic (panel B) & 5015 & 4574 & 9875 & 8783 \\
\hline Exclusion restriction test (\% of RF) & $88.2 \%$ & $70.1 \%$ & $88.8 \%$ & $85 \%$ \\
\hline$H_{0}:$ OLS $=$ IV (p-value $)$ & 0.001 & 0.172 & 0.000 & 0.355 \\
\hline
\end{tabular}

Notes: Unit of analysis is cohort-region-year. Observations weighted by cell size. Sample includes all respondents in the 1992 census who (I) reached age 21 between 1964 and 1981 (both years inclusive) and (II) reported full secondary education. Sample period: 1994-2017. "Yr Age 21" is a continuous variable indicating the year at which the cohort reached age 21, normalized to zero in 1972. "Yr Age $21 \times \mathbb{1}$ (Yr Age $21 \geq 1973$ )" is the interaction of this variable with a dummy for cohorts that reached age 21 on or after 1973. In panel B, this variable is used as excluded instrument for the share with college. Mortality rate and share with college adjusted for previous mortality. Standard errors clustered by region-year in parentheses. P-value from Wild cluster bootstrap by cohort reported in brackets. ${ }^{* * *} \mathrm{p}<0.01,{ }^{* *} \mathrm{p}<0.05,{ }^{*} \mathrm{p}<0.1$. 
Table 3: Labor Market Outcomes (1990-2017)

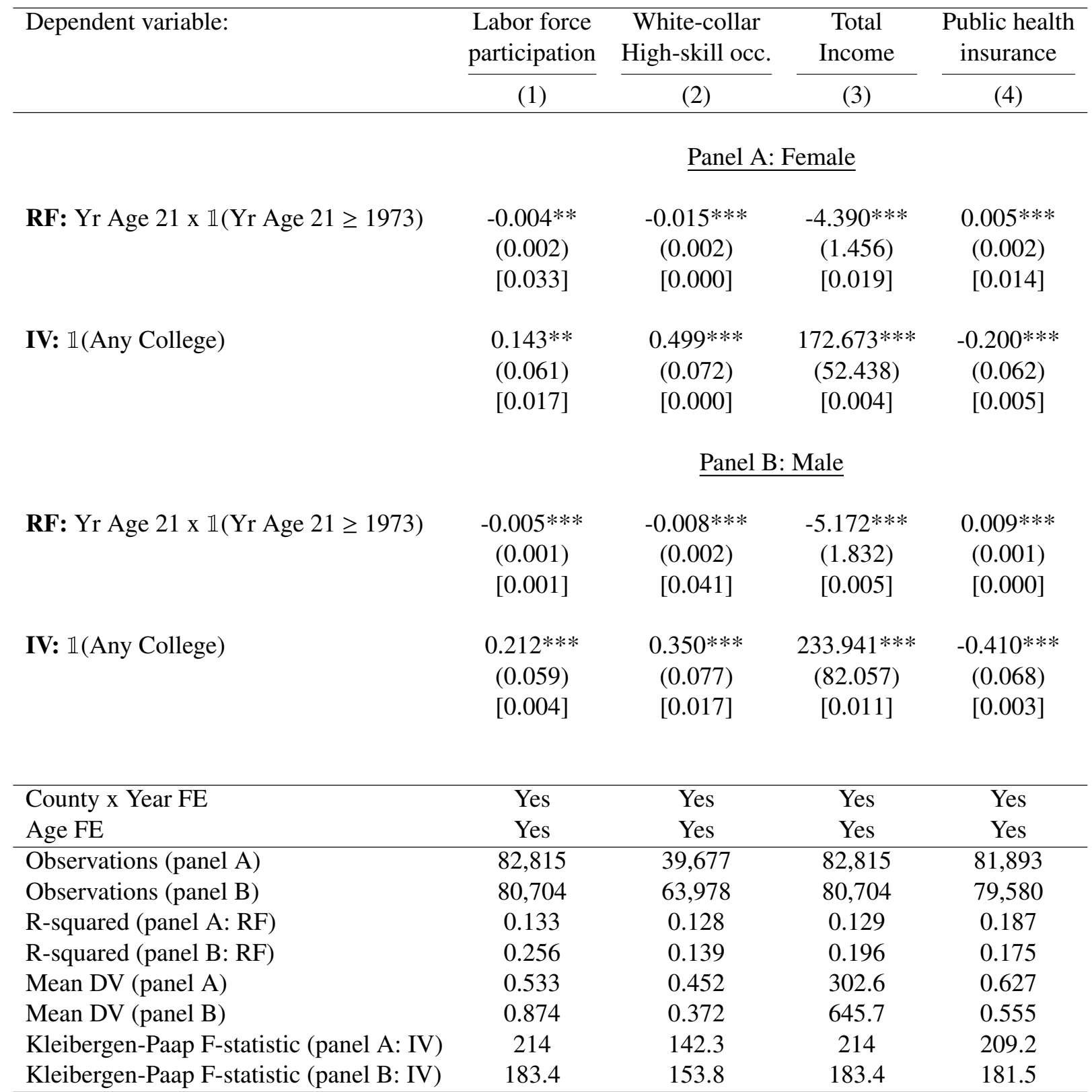

Notes: The unit of analysis is an individual respondent from the CASEN survey. Dependent variable in the header. A dummy for labor force participation in column 1; a dummy for white-collar high-skill occupation in column 2; total income in column 3; a dummy for enrollment in the public health insurance (FONASA) in column 4. Sample period: 1990-2017 (13 waves). Not all questions are asked in all years. Sample includes individuals from cohorts that reached age 21 between 1964 and 1981 (both years inclusive) and report 4+ years of secondary education. "Yr Age 21" is a continuous variable indicating the year at which the cohort reached age 21, normalized to zero in 1972. "Yr Age 21 x 1 (Yr Age 21 $\geq 1973$ )" is the interaction of this variable with a dummy for cohorts that reached age 21 on or after 1973. This variable is used as excluded instrument for the dummy for any college education. All regressions include year by county of residence by gender and age fixed effects. Standard errors clustered two-way by county and region-year reported in parentheses. P-values from Wild cluster bootstrap by cohort reported in brackets. $* * * \mathrm{p}<0.01, * * \mathrm{p}<0.05, * \mathrm{p}<0.1$. 
Table 4: Consumption of Health Services (1990-2017)

\begin{tabular}{|c|c|c|c|c|}
\hline \multirow{3}{*}{ DV: Medical care in the past... } & \multicolumn{3}{|c|}{3 months } & \multirow{2}{*}{$\begin{array}{c}3 \text { years } \\
\text { Pap } \\
\text { smear }\end{array}$} \\
\hline & $\begin{array}{l}\text { Primary } \\
\text { care }\end{array}$ & Specialist & $\begin{array}{c}\text { Emergency } \\
\text { room }\end{array}$ & \\
\hline & (1) & (2) & (3) & (4) \\
\hline & \multicolumn{4}{|c|}{ Panel A: Female } \\
\hline RF: Yr Age $21 \times \mathbb{1}($ Yr Age $21 \geq 1973)$ & $\begin{array}{l}-0.001 \\
(0.001) \\
{[0.405]}\end{array}$ & $\begin{array}{c}-0.003 * * \\
(0.001) \\
{[0.065]}\end{array}$ & $\begin{array}{c}0.001 \\
(0.001) \\
{[0.230]}\end{array}$ & $\begin{array}{c}-0.004 * * \\
(0.002) \\
{[0.008]}\end{array}$ \\
\hline IV: $\mathbb{1}($ Any College $)$ & $\begin{array}{c}0.041 \\
(0.047) \\
{[0.406]}\end{array}$ & $\begin{array}{c}0.101 * * \\
(0.046) \\
{[0.040]}\end{array}$ & $\begin{array}{l}-0.027 \\
(0.029) \\
{[0.236]}\end{array}$ & $\begin{array}{c}0.168 * * \\
(0.084) \\
{[0.004]}\end{array}$ \\
\hline & \multicolumn{3}{|c|}{ Panel B: Male } & \\
\hline RF: Yr Age 21 x $\mathbb{1}($ Yr Age $21 \geq 1973)$ & $\begin{array}{c}-0.003 * * \\
(0.001) \\
{[0.060]}\end{array}$ & $\begin{array}{l}-0.001 \\
(0.001) \\
{[0.260]}\end{array}$ & $\begin{array}{l}-0.000 \\
(0.001) \\
{[0.710]}\end{array}$ & \\
\hline IV: $\mathbb{1}($ Any College $)$ & $\begin{array}{c}0.128 * * \\
(0.053) \\
{[0.055]}\end{array}$ & $\begin{array}{c}0.052 \\
(0.042) \\
{[0.254]}\end{array}$ & $\begin{array}{c}0.013 \\
(0.028) \\
{[0.709]}\end{array}$ & \\
\hline County x Year FE & Yes & Yes & Yes & Yes \\
\hline Age FE & Yes & Yes & Yes & Yes \\
\hline Observations (panel A) & 82,765 & 82,801 & 78,822 & 58,549 \\
\hline Observations (panel B) & 80,671 & 80,693 & 76,682 & - \\
\hline R-squared (panel A: RF) & 0.114 & 0.085 & 0.067 & 0.111 \\
\hline R-squared (panel B: RF) & 0.103 & 0.083 & 0.061 & - \\
\hline Mean DV (panel A) & 0.200 & 0.145 & 0.0665 & 0.726 \\
\hline Mean DV (panel B) & 0.132 & 0.0877 & 0.0447 & - \\
\hline Kleibergen-Paap F-statistic (panel A: IV) & 213.3 & 214 & 197.6 & 131.8 \\
\hline Kleibergen-Paap F-statistic (panel B: IV) & 183.8 & 183.7 & 176.6 & - \\
\hline
\end{tabular}

Notes: The unit of analysis is an individual respondent from the CASEN survey. Dependent variable in the header: Dummy variables for having seen a general practitioner (column 1) or a specialist (column 2), having visited the emergency room (column 3) or having had a Pap smear (column 4) in the past three months (three years in column 4). Sample period: 1990-2017 (13 waves). Not all questions are asked in all years. Sample includes individuals from cohorts that reached age 21 between 1964 and 1981 (both years inclusive) and report 4+ years of secondary education. "Yr Age 21" is a continuous variable indicating the year at which the cohort reached age 21, normalized to zero in 1972. "Yr Age $21 \times \mathbb{1}$ (Yr Age $21 \geq$ 1973)" is the interaction of this variable with a dummy for cohorts that reached age 21 on or after 1973. In the IV regressions, this variable is used as excluded instrument for the share with college. All regressions include year by county of residence and age fixed effects. Standard errors clustered two-way by county and region-year reported in parentheses. P-values from Wild cluster bootstrap by cohort reported in brackets. $* * * \mathrm{p}<0.01, * * \mathrm{p}<0.05, * \mathrm{p}<0.1$ 
Table 5: Hospitalization Rate (2002-2018)

\begin{tabular}{|c|c|c|c|c|}
\hline & \multicolumn{4}{|c|}{ DV: Hospital admissions per 1,000} \\
\hline & \multirow{2}{*}{ All } & \multirow{2}{*}{ Individuals } & \multicolumn{2}{|c|}{ Insurance } \\
\hline & & & Public & Private \\
\hline & (1) & (2) & (3) & (4) \\
\hline \multirow[b]{2}{*}{ Yr Age 21 x $\mathbb{1}($ Yr Age $21 \geq 1973)$} & \multicolumn{4}{|c|}{$\underline{\text { Panel A: Female }}$} \\
\hline & $\begin{array}{l}-0.097 \\
(0.134) \\
{[0.958]}\end{array}$ & $\begin{array}{l}-0.071 \\
(0.090) \\
{[0.947]}\end{array}$ & $\begin{array}{c}0.510 * * * \\
(0.185) \\
{[0.664]}\end{array}$ & $\begin{array}{c}-0.717 * * * \\
(0.088) \\
{[0.135]}\end{array}$ \\
\hline \multirow[b]{2}{*}{ Yr Age $21 \times \mathbb{1}($ Yr Age $21 \geq 1973)$} & \multicolumn{4}{|c|}{$\underline{\text { Panel B: Male }}$} \\
\hline & $\begin{array}{c}0.312 \\
(0.193) \\
{[0.839]}\end{array}$ & $\begin{array}{c}0.036 \\
(0.113) \\
{[0.963]}\end{array}$ & $\begin{array}{c}1.082 * * * \\
(0.261) \\
{[0.434]}\end{array}$ & $\begin{array}{c}-0.818 * * * \\
(0.115) \\
{[0.124]}\end{array}$ \\
\hline Year x Region FE & Yes & Yes & Yes & Yes \\
\hline Age FE & Yes & Yes & Yes & Yes \\
\hline Observations & 4,590 & 4,590 & 4,590 & 4,590 \\
\hline R-squared (panel A) & 0.857 & 0.894 & 0.903 & 0.903 \\
\hline R-squared (panel B) & 0.930 & 0.943 & 0.933 & 0.905 \\
\hline Mean DV (panel A) & 119 & 79.51 & 92.67 & 18.34 \\
\hline Mean DV (panel B) & 123.5 & 80.21 & 92.23 & 21.29 \\
\hline
\end{tabular}

Notes: The unit of analysis is cohort-region-year. Observations weighted by cell size. Dependent variable in the header (all per 1,000). Number of hospitalizations in column 1. Number of hospitalized individuals in column 2. Number of hospitalizations using public insurance (FONASA) in column 3 and hospitalizations using private insurance (ISAPRE, other private, Armed Forces) in column 4. Hospitalizations rates adjusted for previous mortality within cell. Population at risk includes all respondents in the 2002 census that reached age 21 between 1964 and 1981 (both years inclusive). Sample period: 2002-2018. "Yr Age 21" is a continuous variable indicating the year when the cohort reached age 21, normalized to zero in 1972. "Yr Age 21 x $\mathbb{1}$ (Yr Age $21 \geq 1973$ )" is the interaction of this variable with a dummy for cohorts that reached age 21 on or after 1973 All regressions include region by year and age fixed effects. Standard errors clustered by region-year in parentheses. P-values from Wild cluster bootstrap by cohort reported in brackets. $* * * \mathrm{p}<0.01$, $* *$ $\mathrm{p}<0.05, * \mathrm{p}<0.1$. 
Table 6: One-year Mortality Rate of Hospitalized Patients (2004-2012)

\begin{tabular}{|c|c|c|c|c|c|c|c|c|}
\hline & \multicolumn{8}{|c|}{ Dependent variable: Deaths within one year of discharge per 1,000 hospitalized patients } \\
\hline & (1) & (2) & (3) & (4) & (5) & (6) & (7) & (8) \\
\hline & \multicolumn{8}{|c|}{ Panel A: Female } \\
\hline Yr Age 21 & $\begin{array}{c}-5.345^{* * * *} \\
(0.200) \\
{[0.000]}\end{array}$ & & & & & & & \\
\hline Yr Age 21 x $\mathbb{1}($ Yr Age $21 \geq 1973)$ & $\begin{array}{c}2.627 * * * \\
(0.235) \\
{[0.002]}\end{array}$ & $\begin{array}{c}1.794 * * * \\
(0.374) \\
{[0.006]}\end{array}$ & $\begin{array}{c}1.379 * * * \\
(0.296) \\
{[0.014]}\end{array}$ & $\begin{array}{c}1.313 * * * \\
(0.307) \\
{[0.025]}\end{array}$ & $\begin{array}{c}1.271 * * * \\
(0.337) \\
{[0.004]}\end{array}$ & $\begin{array}{c}1.260 * * * \\
(0.338) \\
{[0.004]}\end{array}$ & $\begin{array}{c}1.205^{* * * *} \\
(0.320) \\
{[0.005]}\end{array}$ & $\begin{array}{c}1.145 * * * \\
(0.350) \\
{[0.006]}\end{array}$ \\
\hline
\end{tabular}

Panel B: Male

\begin{tabular}{|c|c|c|c|c|c|c|c|c|}
\hline Yr Age 21 & $\begin{array}{c}-6.255^{* * *} \\
(0.199) \\
{[0.000]}\end{array}$ & & & & & & & \\
\hline Yr Age 21 x $\mathbb{1}($ Yr Age $21 \geq 1973)$ & $\begin{array}{c}2.817 * * * \\
(0.275) \\
{[0.002]}\end{array}$ & $\begin{array}{c}2.217 * * * \\
(0.360) \\
{[0.000]}\end{array}$ & $\begin{array}{c}1.643 * * * \\
(0.354) \\
{[0.000]}\end{array}$ & $\begin{array}{c}1.488 * * * \\
(0.354) \\
{[0.000]}\end{array}$ & $\begin{array}{c}1.524 * * * \\
(0.399) \\
{[0.000]}\end{array}$ & $\begin{array}{c}1.526 * * * \\
(0.403) \\
{[0.000]}\end{array}$ & $\begin{array}{c}1.440 * * * \\
(0.401) \\
{[0.000]}\end{array}$ & $\begin{array}{c}1.297 * * * * \\
(0.400) \\
{[0.002]}\end{array}$ \\
\hline Year x County FE & Yes & Yes & Yes & Yes & Yes & Yes & Yes & Yes \\
\hline Age FE & No & Yes & Yes & Yes & Yes & Yes & Yes & Yes \\
\hline Fixed effects: Diagnostic... & No & No & Yes & No & No & No & No & No \\
\hline$\ldots \times$ Public insurance... & No & No & No & Yes & No & No & No & No \\
\hline ... x Hospital... & No & No & No & No & Yes & No & No & No \\
\hline ... x Type of admission... & No & No & No & No & No & Yes & No & No \\
\hline$\ldots \times$ Surgery... & No & No & No & No & No & No & Yes & No \\
\hline ... x Previously admitted & No & No & No & No & No & No & No & Yes \\
\hline Observations (panel A) & 603,878 & 603,878 & 602,862 & 601,722 & 539,443 & 509,174 & 493,174 & 468,553 \\
\hline Observations (panel B) & 519,615 & 519,615 & 518,681 & 517,564 & 455,207 & 426,039 & 410,436 & 390,574 \\
\hline R-squared (panel A) & 0.019 & 0.019 & 0.237 & 0.247 & 0.344 & 0.374 & 0.387 & 0.401 \\
\hline R-squared (panel B) & 0.019 & 0.019 & 0.254 & 0.266 & 0.363 & 0.389 & 0.401 & 0.412 \\
\hline Mean DV (panel A) & 45.82 & 45.82 & 45.80 & 45.80 & 43.38 & 41.96 & 41.05 & 40.10 \\
\hline Mean DV (panel B) & 77.82 & 77.82 & 77.82 & 77.82 & 76.20 & 74.89 & 74.29 & 73.30 \\
\hline
\end{tabular}




\section{Appendix A}

Table A1: First Stage: Using 2002 Census

\begin{tabular}{|c|c|c|c|c|c|c|}
\hline & \multicolumn{3}{|c|}{ Female } & \multicolumn{3}{|c|}{ Male } \\
\hline & $\begin{array}{l}\text { Adj share w/ } \\
\text { college per } \\
10 \text { people }\end{array}$ & $\begin{array}{l}\text { Share w/ } \\
\text { college per } \\
10 \text { people }\end{array}$ & $\begin{array}{l}\text { Average } \\
\text { years of } \\
\text { college }\end{array}$ & $\begin{array}{l}\text { Adj share w/ } \\
\text { college per } \\
10 \text { people }\end{array}$ & $\begin{array}{l}\text { Share w/ } \\
\text { college per } \\
10 \text { people }\end{array}$ & $\begin{array}{l}\text { Average } \\
\text { years of } \\
\text { college }\end{array}$ \\
\hline & $(1)$ & (2) & (3) & (4) & $(5)$ & (6) \\
\hline Yr Age 21 & $\begin{array}{c}0.140 * * * \\
(0.004)\end{array}$ & $\begin{array}{c}0.142 * * * \\
(0.011)\end{array}$ & $\begin{array}{c}0.048 * * * \\
(0.003)\end{array}$ & $\begin{array}{c}0.010 * * * \\
(0.000)\end{array}$ & $\begin{array}{c}0.100 * * * \\
(0.007)\end{array}$ & $\begin{array}{c}0.030 * * * \\
(0.003)\end{array}$ \\
\hline Yr Age 21 x $\mathbb{1}$ (Yr Age $21 \geq 1973$ ) & $\begin{array}{c}-0.277 * * * \\
(0.007)\end{array}$ & $\begin{array}{c}-0.276 * * * \\
(0.018)\end{array}$ & $\begin{array}{c}-0.093 * * * \\
(0.006)\end{array}$ & $\begin{array}{c}-0.023 * * * \\
(0.000)\end{array}$ & $\begin{array}{c}-0.225 * * * \\
(0.012)\end{array}$ & $\begin{array}{c}-0.071 * * * \\
(0.005)\end{array}$ \\
\hline Year x Region FE & Yes & No & No & Yes & No & No \\
\hline Region FE & No & Yes & Yes & No & Yes & Yes \\
\hline Adjusted for deaths & Yes & No & No & Yes & No & No \\
\hline Observations & 4,050 & 270 & 270 & 4,050 & 270 & 270 \\
\hline R-squared & 0.832 & 0.835 & 0.835 & 0.884 & 0.883 & 0.859 \\
\hline Mean DV & 3.004 & 2.978 & 1.055 & 0.351 & 3.516 & 1.298 \\
\hline
\end{tabular}

Notes: The unit of analysis is cohort-region-year of death in columns 1 and 4, and cohort-region in columns 2, 3, 5, and 6. Dependent variable in the header. "Any College" is the number of people that enrolled in college out of every ten. Original sample includes all respondents of the 2002 census from cohorts born between 1943 and 1960 (both inclusive) that report full secondary education. "Yr Age 21" is a continuous variable indicating the year at which the cohort reached 21 years of age, normalized to zero in 1972. "Yr Age 21 x 1 (Yr Age $21 \geq 1973$ )" is the interaction of this variable with a dummy for cohorts that reached age 21 on or after 1973. All regressions include region fixed effects, columns 1 and 4 include Year of Death $x$ Region fixed effects. Standard errors clustered by region-year in parentheses in columns 1 and 4 , robust standard errors otherwise. $* * * \mathrm{p}<0.01, * * \mathrm{p}<0.05,{ }^{*} \mathrm{p}<0.1$ 
Table A2: Mortality Rate: Years of college

\begin{tabular}{|c|c|c|c|c|}
\hline & \multicolumn{4}{|c|}{ Dependent variable: Deaths per 1,000 people } \\
\hline & \multicolumn{2}{|c|}{ Female } & \multicolumn{2}{|c|}{ Male } \\
\hline & Trend & Age FE & Trend & Age FE \\
\hline & (1) & (2) & (3) & (4) \\
\hline \multirow[b]{2}{*}{ Years of college } & \multicolumn{4}{|c|}{ Panel A: IV } \\
\hline & $\begin{array}{c}-2.282 * * * \\
(0.150)\end{array}$ & $\begin{array}{c}-0.687 * * * \\
(0.142)\end{array}$ & $\begin{array}{c}-6.164 * * * \\
(0.368)\end{array}$ & $\begin{array}{c}-2.415 * * * \\
(0.319)\end{array}$ \\
\hline \multirow[b]{2}{*}{ Years of college } & \multicolumn{4}{|c|}{ Panel B: OLS } \\
\hline & $\begin{array}{c}-1.893 * * * \\
(0.119)\end{array}$ & $\begin{array}{c}-0.508^{* * *} \\
(0.120)\end{array}$ & $\begin{array}{c}-5.176^{* * *} \\
(0.256)\end{array}$ & $\begin{array}{c}-2.176^{* * *} \\
(0.268)\end{array}$ \\
\hline Year x Region FE & Yes & Yes & Yes & Yes \\
\hline Age FE & No & Yes & No & Yes \\
\hline Observations & 6,480 & 6,480 & 6,480 & 6,480 \\
\hline R-squared (panel B) & 0.673 & 0.755 & 0.745 & 0.850 \\
\hline Mean DV & 3.850 & 3.850 & 7.084 & 7.084 \\
\hline Kleibergen-Paap F-statistic (panel A) & 13215 & 10390 & 12299 & 9333 \\
\hline \multicolumn{5}{|c|}{$\begin{array}{l}\text { Notes: Sample includes all respondents in the } 1992 \text { census who (I) reached age } 21 \text { between } 1964 \text { and } 1981 \text { (both } \\
\text { years inclusive) and (II) reported full secondary education. Sample period: } 1994-2017 \text {. In panel A, the interaction } \\
\text { between a continuous variable indicating the year at which the cohort reached age } 21 \text {, normalized to zero in } 1972 \text {, } \\
\text { and a dummy for cohorts that reached age } 21 \text { on or after } 1973 \text { is used as excluded instrument for the average } \\
\text { years of college. Mortality rate is adjusted for previous mortality. Standard errors clustered by region-year in } \\
\text { parentheses. } * * * p<0.01, * * p<0.05, * p<0.1 \text {. }\end{array}$} \\
\hline
\end{tabular}


Table A3: Mortality Rate: Lower Levels of Education

\begin{tabular}{|c|c|c|c|c|c|c|}
\hline & \multicolumn{6}{|c|}{ Dependent variable: Deaths per 1,000 people } \\
\hline & \multicolumn{3}{|c|}{ Female } & \multicolumn{3}{|c|}{ Male } \\
\hline & Baseline & No College & No Secondary & Baseline & No College & No Secondary \\
\hline & (1) & $(2)$ & (3) & (4) & $(5)$ & (6) \\
\hline Yr Age $21 \times \mathbb{1}$ (Yr Age $21 \geq 1973$ ) & $\begin{array}{c}0.107 * * * \\
(0.022)\end{array}$ & $\begin{array}{c}0.052 * * * \\
(0.012)\end{array}$ & $\begin{array}{l}-0.004 \\
(0.021)\end{array}$ & $\begin{array}{c}0.315^{* * *} \\
(0.042)\end{array}$ & $\begin{array}{c}0.129 * * * \\
(0.020)\end{array}$ & $\begin{array}{l}-0.019 \\
(0.030)\end{array}$ \\
\hline Year x Region FE & Yes & Yes & Yes & Yes & Yes & Yes \\
\hline Age FE & Yes & Yes & Yes & Yes & Yes & Yes \\
\hline Observations & 6,480 & 6,480 & 6,480 & 6,480 & 6,480 & 6,480 \\
\hline R-squared & 0.756 & 0.906 & 0.852 & 0.850 & 0.921 & 0.852 \\
\hline Mean DV & 3.850 & 4.597 & 5.531 & 7.084 & 8.383 & 10.03 \\
\hline \multicolumn{7}{|c|}{$\begin{array}{l}\text { Notes: Unit of analysis is cohort-region-year. Observations weighted by cell size. Sample includes all respondents in the } 1992 \text { census who } \\
\text { (I) reached age } 21 \text { between } 1964 \text { and } 1981 \text { (both years inclusive). Sample period: } 1994-2017 \text {. Columns } 1 \text { and } 4 \text { correspond to our baseline } \\
\text { sample that is restricted to individuals reporting full secondary education. The sample in columns } 2 \text { and } 5 \text { is restricted to individuals without } \\
\text { any college (no minimum), while in columns } 3 \text { and } 6 \text { it is restricted to individuals without any secondary education. "Yr Age } 21 \times \mathbb{1} \text { (Yr Age } \\
21 \geq 1973 \text { )" is the interaction of a continuous variable indicating the year at which the cohort reached age } 21 \text { (normalized to zero in } 1972 \text { ) } \\
\text { with a dummy for cohorts that reached age } 21 \text { on or after } 1973 \text {. Mortality rate is adjusted for previous mortality. Standard errors clustered by } \\
\text { region-year in parentheses. *** }<<0.01, * * \mathrm{p}<0.05, * \mathrm{p}<0.1 \text {. }\end{array}$} \\
\hline
\end{tabular}




\section{Table A4: Mortality Rate: Controlling for Macro Characteristics}

\begin{tabular}{|c|c|c|c|c|c|c|}
\hline \multirow{3}{*}{ Control variables: } & \multicolumn{6}{|c|}{ Dependent variable: Deaths per 1,000 people } \\
\hline & $\begin{array}{l}\text { GDP p.c. } \\
\text { growth }\end{array}$ & Unempl. & $\begin{array}{l}\text { Exports } \\
\text { growth }\end{array}$ & $\begin{array}{l}\text { Gov. Spending } \\
\text { (\% GDP) }\end{array}$ & $\begin{array}{c}\text { Food } \\
\text { production }\end{array}$ & $\begin{array}{l}\text { Mortality } \\
\text { rate }\end{array}$ \\
\hline & (1) & $(2)$ & (3) & (4) & $(5)$ & $(6)$ \\
\hline \multirow{4}{*}{$\begin{array}{l}\text { RF: Yr Age } 21 \text { x } \mathbb{1}(\text { Yr Age } 21 \geq 1973) \\
\text { IV: } \mathbb{1} \text { (Any College })\end{array}$} & \multicolumn{6}{|c|}{$\underline{\text { Panel A: Female }}$} \\
\hline & $\begin{array}{c}0.113 * * * \\
(0.025)\end{array}$ & $\begin{array}{c}0.107 * * * \\
(0.022)\end{array}$ & $\begin{array}{c}0.112 * * * \\
(0.022)\end{array}$ & $\begin{array}{c}0.075^{* *} \\
(0.032)\end{array}$ & $\begin{array}{c}0.137 * * * \\
(0.030)\end{array}$ & $\begin{array}{c}0.086 * * * \\
(0.024)\end{array}$ \\
\hline & $\begin{array}{c}-0.290 * * * \\
(0.063)\end{array}$ & $\begin{array}{c}-0.263 * * * \\
(0.054)\end{array}$ & $\begin{array}{c}-0.279^{* * * *} \\
(0.056)\end{array}$ & $\begin{array}{c}-0.209^{* *} \\
(0.089)\end{array}$ & $\begin{array}{c}-0.395^{* * *} \\
(0.087)\end{array}$ & $\begin{array}{c}-0.183 * * * \\
(0.050)\end{array}$ \\
\hline & \multicolumn{6}{|c|}{ Panel B: Male } \\
\hline RF: Yr Age 21 x $\mathbb{1}$ (Yr Age $21 \geq 1973)$ & $\begin{array}{c}0.339 * * * \\
(0.045)\end{array}$ & $\begin{array}{c}0.315 * * * \\
(0.042)\end{array}$ & $\begin{array}{c}0.317 * * * \\
(0.042)\end{array}$ & $\begin{array}{c}0.124 * * \\
(0.055)\end{array}$ & $\begin{array}{c}0.330 * * * \\
(0.050)\end{array}$ & $\begin{array}{c}0.341 * * * \\
(0.041)\end{array}$ \\
\hline IV: $\mathbb{1}$ (Any College) & $\begin{array}{c}-1.010 * * * \\
(0.132)\end{array}$ & $\begin{array}{c}-0.926 * * * \\
(0.121)\end{array}$ & $\begin{array}{c}-0.925^{* * * *} \\
(0.120)\end{array}$ & $\begin{array}{c}-0.368 * * \\
(0.161)\end{array}$ & $\begin{array}{c}-1.077 * * * \\
(0.162)\end{array}$ & $\begin{array}{c}-0.947 * * * \\
(0.115)\end{array}$ \\
\hline Year $\mathrm{x}$ Region FE & Yes & Yes & Yes & Yes & Yes & \\
\hline Age FE & Yes & Yes & Yes & Yes & Yes & \\
\hline Observations & 6,480 & 6,480 & 6,480 & 6,480 & 6,480 & 6,480 \\
\hline R-squared (panel A: RF) & 0.756 & 0.756 & 0.756 & 0.756 & 0.756 & 0.756 \\
\hline R-squared (panel B: RF) & 0.850 & 0.850 & 0.850 & 0.851 & 0.850 & 0.850 \\
\hline Mean DV (panel A) & 3.850 & 3.850 & 3.850 & 3.850 & 3.850 & 3.850 \\
\hline Mean DV (panel B) & 7.084 & 7.084 & 7.084 & 7.084 & 7.084 & 7.084 \\
\hline Kleibergen-Paap F-statistic (panel A: IV) & 3811 & 4698 & 4550 & 2178 & 2130 & 12277 \\
\hline Kleibergen-Paap F-statistic (panel B: IV) & 7476 & 8590 & 8644 & 4419 & 4755 & 7713 \\
\hline
\end{tabular}

Notes: Unit of analysis is cohort-region-year. Observations weighted by cell size. Sample includes all respondents in the 1992 census who (I) reached age 21 between 1964 and 1981 (both years inclusive) and (II) reported full secondary education. Sample period: 1994-2017. "Yr Age 21" is a continuous variable indicating the year at which the cohort reached age 21, normalized to zero in 1972. "Yr Age 21 x $\mathbb{1}$ (Yr Age $21 \geq 1973$ )" is the interaction of this variable with a dummy for cohorts that reached age 21 on or after 1973. In IV specifications, this variable is used as excluded instrument for the share with college. Mortality rate and share with college adjusted for previous mortality. All regressions include region by year and age fixed effects. Each column as additional control the variable in the header, at the yearly level (i.e. value that the variable takes in the year in which the relevant cohort reached age 21 ). In column 1 , the growth rate of GDP per capita. In column 2, the unemployment rate among people with ages 20-30. In column 3 , the yearly growth rate of exports. In column 4, total government spending as a percentage of GDP. In column 5, a food production index. In column 6, the mortality rate. Standard errors clustered by region-year in parentheses. $* * * \mathrm{p}<0.01, * * \mathrm{p}<0.05, * \mathrm{p}<0.1$. 
Table A5: Alternative mechanism: Labor market conditions

\begin{tabular}{|c|c|c|c|c|c|c|}
\hline \multirow{3}{*}{ Dependent variable: } & \multirow{3}{*}{$\begin{array}{l}\text { Share with } \\
\text { college per } \\
10 \text { people } \\
(1)\end{array}$} & \multirow{3}{*}{$\begin{array}{c}\begin{array}{c}\text { Currently } \\
\text { studying } \\
\text { (age 20-30) }\end{array} \\
(2)\end{array}$} & \multicolumn{3}{|c|}{ Unemployed } & \multirow{3}{*}{$\begin{array}{c}\begin{array}{c}\text { Deaths } \\
\text { per } 1,000 \\
\text { people }\end{array} \\
(6)\end{array}$} \\
\hline & & & \multirow{2}{*}{$\frac{\text { age } 20+}{(3)}$} & \multirow{2}{*}{$\frac{\text { age } 20-30}{(4)}$} & \multirow{2}{*}{$\begin{array}{c}\text { age } 20-30+ \\
\text { secondary } \\
(5)\end{array}$} & \\
\hline & & & & & & \\
\hline & & & Panel & Female & & \\
\hline Yr Age 21 & $\begin{array}{c}0.160 * * * \\
(0.019)\end{array}$ & $\begin{array}{c}0.012 * * * \\
(0.002)\end{array}$ & $\begin{array}{c}0.004 \\
(0.003)\end{array}$ & $\begin{array}{c}0.005 \\
(0.004)\end{array}$ & $\begin{array}{c}0.005 \\
(0.004)\end{array}$ & $\begin{array}{c}-0.494 * * * \\
(0.053)\end{array}$ \\
\hline \multirow[t]{2}{*}{ Yr Age 21 x $\mathbb{1}($ Yr Age $21 \geq 1973)$} & $\begin{array}{c}-0.329 * * * \\
(0.032)\end{array}$ & $\begin{array}{c}-0.015^{* * * *} \\
(0.002)\end{array}$ & $\begin{array}{c}0.003 \\
(0.006)\end{array}$ & $\begin{array}{c}0.004 \\
(0.007)\end{array}$ & $\begin{array}{c}0.004 \\
(0.007)\end{array}$ & $\begin{array}{c}0.291 * * * \\
(0.073)\end{array}$ \\
\hline & \multicolumn{6}{|c|}{ Panel B: Male } \\
\hline Yr Age 21 & $\begin{array}{c}0.134 * * * \\
(0.014)\end{array}$ & $\begin{array}{c}0.017 * * * \\
(0.002)\end{array}$ & $\begin{array}{c}0.002 \\
(0.003)\end{array}$ & $\begin{array}{c}0.004 \\
(0.004)\end{array}$ & $\begin{array}{c}0.005 \\
(0.003)\end{array}$ & $\begin{array}{c}-0.979 * * * \\
(0.059)\end{array}$ \\
\hline Yr Age 21 x $\mathbb{1}($ Yr Age $21 \geq 1973)$ & $\begin{array}{c}-0.308 * * * \\
(0.023)\end{array}$ & $\begin{array}{c}-0.023 * * * \\
(0.003)\end{array}$ & $\begin{array}{c}0.004 \\
(0.006)\end{array}$ & $\begin{array}{c}0.003 \\
(0.008)\end{array}$ & $\begin{array}{c}0.003 \\
(0.007)\end{array}$ & $\begin{array}{c}0.608 * * * \\
(0.097)\end{array}$ \\
\hline Observations & 18 & 17 & 18 & 18 & 17 & 18 \\
\hline R-squared (Panel A) & 0.878 & 0.873 & 0.480 & 0.586 & 0.577 & 0.975 \\
\hline R-squared (Panel B) & 0.941 & 0.883 & 0.480 & 0.433 & 0.522 & 0.988 \\
\hline Mean DV (Panel A) & 2.793 & 0.114 & 0.0705 & 0.0982 & 0.109 & 3.670 \\
\hline Mean DV (Panel B) & 3.277 & 0.174 & 0.0831 & 0.107 & 0.0893 & 6.864 \\
\hline \multicolumn{7}{|c|}{$\begin{array}{l}\text { Notes: Unit of analysis is the cohort. Sample is restricted to the Metropolitan region of Santiago. In column 1, the dependent variable is the } \\
\text { share of people per cohort that report any college in the } 1992 \text { census (among those with full secondary). The dependent variables in columns } \\
2-5 \text { are based on survey micro-data from Encuesta de Ocupación y Desocupación (EOD) for the years 1964-1981. In column } 2 \text {, it is a dummy } \\
\text { variable for respondents that report being currently studying, among those with ages } 20-30 \text {. In columns } 3-5 \text { it is a dummy for respondents } \\
\text { that report being currently unemployed. In column } 3 \text {, we include all respondents with ages of } 20 \text { or more. In column } 4 \text {, we restrict the } \\
\text { sample to respondents with ages between } 20 \text { and } 30 \text {, while in column } 5 \text { we further impose that respondents must have at least some secondary } \\
\text { education. The dependent variable in column } 6 \text { is the mortality rate by cohort (averaged across } 1994 \text { and } 2017 \text {, having been adjusted for } \\
\text { previous mortality). "Yr Age } 21 \text { " is a continuous variable indicating the year at which the cohort reached age } 21 \text {, normalized to zero in } 1972 \text {. } \\
\text { "Yr Age } 21 \mathrm{x} \mathbb{1}(\text { Yr Age } 21 \geq 1973) \text { " is the interaction of this variable with a dummy for cohorts that reached age } 21 \text { on or after } 1973 \text {. Robust } \\
\text { standard errors in parentheses. } * * * \mathrm{p}<0.01, * * \mathrm{p}<0.05, * \mathrm{p}<0.1 \text {. }\end{array}$} \\
\hline
\end{tabular}


Table A6: Mortality Rate: Alternative functional forms

\begin{tabular}{|c|c|c|c|c|}
\hline & \multicolumn{4}{|c|}{ Dependent variable: Deaths per 1,000 people } \\
\hline & \multicolumn{2}{|c|}{ Female } & \multicolumn{2}{|c|}{ Male } \\
\hline & Discontinuity & Quadratic & Discontinuity & Quadratic \\
\hline & (1) & (2) & (3) & (4) \\
\hline \multirow{3}{*}{ Yr Age 21 x $\mathbb{1}($ Yr Age $21 \geq 1973)$} & \multicolumn{4}{|c|}{ Panel A: Reduced Form } \\
\hline & $\begin{array}{c}0.108 * * * \\
(0.023)\end{array}$ & $\begin{array}{c}0.107 * * \\
(0.051)\end{array}$ & $\begin{array}{c}0.316^{* * * *} \\
(0.042)\end{array}$ & $\begin{array}{c}0.512 * * * \\
(0.073)\end{array}$ \\
\hline & \multicolumn{4}{|c|}{ Panel B: IV } \\
\hline Share with college per 10 people & $\begin{array}{c}-0.271 * * * \\
(0.056)\end{array}$ & $\begin{array}{c}-0.334 * * \\
(0.157)\end{array}$ & $\begin{array}{c}-0.929 * * * \\
(0.122)\end{array}$ & $\begin{array}{c}-1.168^{* * * *} \\
(0.164)\end{array}$ \\
\hline Year $x$ Region FE & Yes & Yes & Yes & Yes \\
\hline Age FE & Yes & Yes & Yes & Yes \\
\hline Observations & 6,480 & 6,480 & 6,480 & 6,480 \\
\hline R-squared (Panel A) & 0.756 & 0.756 & 0.850 & 0.850 \\
\hline Mean DV & 3.850 & 3.850 & 7.084 & 7.084 \\
\hline Kleibergen-Paap F-statistic (panel B) & 4685 & 894.9 & 8821 & 3455 \\
\hline
\end{tabular}

Notes: Unit of analysis is cohort-region-year. Observations weighted by cell size. Sample includes all respondents in the 1992 census who (I) reached age 21 between 1964 and 1981 (both years inclusive) and (II) reported full secondary education. Sample period: 1994-2017. "Yr Age 21 x $\mathbb{1}$ (Yr Age $21 \geq 1973$ )" is the interaction of a continuous variable indicating the year at which the cohort reached age 21 (normalized to zero in 1972) with a dummy for cohorts that reached age 21 on or after 1973. Columns 1 and 3 include as an additional regressor the dummy variable for cohorts reaching college age after 1972. Columns 2 and 4 include a quadratic term for the running variable Yr Age 21. Mortality rate is adjusted for previous mortality. Standard errors clustered by region-year in parentheses. $* * * \mathrm{p}<0.01, * * \mathrm{p}<0.05, * \mathrm{p}<0.1$. 
Table A7: Mortality Rate: National level splitting by military presence during the dictatorship

\begin{tabular}{|c|c|c|c|c|c|c|c|c|}
\hline & \multicolumn{8}{|c|}{ Dependent variable: Deaths per 1,000 people } \\
\hline & \multicolumn{4}{|c|}{ Military presence } & \multicolumn{4}{|c|}{ No military presence } \\
\hline & \multicolumn{2}{|c|}{ Female } & \multicolumn{2}{|c|}{ Male } & \multicolumn{2}{|c|}{ Female } & \multicolumn{2}{|c|}{ Male } \\
\hline & Trend & Age FE & Trend & Age FE & Trend & Age FE & Trend & Age FE \\
\hline & $(1)$ & $(2)$ & (3) & $(4)$ & $(5)$ & (6) & $(7)$ & $(8)$ \\
\hline & \multicolumn{8}{|c|}{$\underline{\text { Panel A: Reduced Form }}$} \\
\hline Yr Age 21 & $\begin{array}{c}-0.618 * * * \\
(0.069)\end{array}$ & & $\begin{array}{c}-1.298 * * * \\
(0.129)\end{array}$ & & $\begin{array}{c}-0.598 * * * \\
(0.059)\end{array}$ & & $\begin{array}{c}-1.194 * * * \\
(0.130)\end{array}$ & \\
\hline \multirow[t]{2}{*}{ Yr Age 21 x $\mathbb{1}($ Yr Age $21 \geq 1973)$} & $\begin{array}{c}0.356 * * * \\
(0.049)\end{array}$ & $\begin{array}{c}0.074 * * \\
(0.029)\end{array}$ & $\begin{array}{c}0.835 * * * \\
(0.082)\end{array}$ & $\begin{array}{c}0.351 * * * \\
(0.050)\end{array}$ & $\begin{array}{c}0.349 * * * \\
(0.038)\end{array}$ & $\begin{array}{c}0.128 * * * \\
(0.023)\end{array}$ & $\begin{array}{c}0.759 * * * \\
(0.087)\end{array}$ & $\begin{array}{c}0.281 * * * \\
(0.054)\end{array}$ \\
\hline & \multicolumn{8}{|c|}{$\underline{\text { Panel B: IV }}$} \\
\hline Share with college per 10 people & $\begin{array}{c}-0.849 * * * \\
(0.115)\end{array}$ & $\begin{array}{c}-0.176^{* *} \\
(0.068)\end{array}$ & $\begin{array}{c}-2.609 * * * \\
(0.255)\end{array}$ & $\begin{array}{c}-1.067 * * * * \\
(0.148)\end{array}$ & $\begin{array}{c}-0.876^{* * *} \\
(0.094)\end{array}$ & $\begin{array}{c}-0.318^{* * *} \\
(0.056)\end{array}$ & $\begin{array}{c}-2.231 \text { **** } \\
(0.252)\end{array}$ & $\begin{array}{c}-0.804 * * * * \\
(0.154)\end{array}$ \\
\hline Year FE & Yes & Yes & Yes & Yes & Yes & Yes & Yes & Yes \\
\hline Age FE & No & Yes & No & Yes & No & Yes & No & Yes \\
\hline Observations & 432 & 430 & 432 & 430 & 432 & 430 & 432 & 430 \\
\hline Mean DV & 3.968 & 3.966 & 7.403 & 7.397 & 3.765 & 3.765 & 6.852 & 6.842 \\
\hline R-squared (panel A) & 0.845 & 0.956 & 0.856 & 0.966 & 0.861 & 0.961 & 0.844 & 0.971 \\
\hline Kleibergen-Paap F-statistic (panel B) & 80067 & 28319 & 312339 & 90062 & 144220 & 25150 & 377943 & 51042 \\
\hline
\end{tabular}


Table A8: Mortality Rate: Robustness to unadjusted share of college

\begin{tabular}{|c|c|c|c|c|}
\hline & \multicolumn{4}{|c|}{ Dependent variable: Deaths per 1,000 people } \\
\hline & \multicolumn{2}{|c|}{ Female } & \multicolumn{2}{|c|}{ Male } \\
\hline & Trend & Age FE & Trend & Age FE \\
\hline & (1) & (2) & (3) & (4) \\
\hline Share with college per 10 people & $\begin{array}{c}-0.893 * * * \\
(0.059)\end{array}$ & $\begin{array}{c}-0.269 * * * \\
(0.056)\end{array}$ & $\begin{array}{c}-2.416^{* * *} \\
(0.138)\end{array}$ & $\begin{array}{c}-0.948 * * * \\
(0.125)\end{array}$ \\
\hline Year x Region FE & Yes & Yes & Yes & Yes \\
\hline Age FE & No & Yes & No & Yes \\
\hline Observations & 6,480 & 6,480 & 6,480 & 6,480 \\
\hline Mean DV & 3.850 & 3.850 & 7.084 & 7.084 \\
\hline Kleibergen-Paap F-statistic & 5608 & 4990 & 10918 & 9842 \\
\hline
\end{tabular}

Notes: Unit of analysis is cohort-region-year. Observations weighted by cell size. Sample includes all respondents in the 1992 census who (I) reached age 21 between 1964 and 1981 (both years inclusive) and (II) reported full secondary education. Sample period: 1994-2017. The interaction between a continuous variable indicating the year at which the cohort reached age 21, normalized to zero in 1972, and a dummy for cohorts that reached age 21 on or after 1973 is used as excluded instrument for the share with college. Mortality rate is adjusted for previous mortality. Standard errors clustered by region-year in parentheses. $* * * \mathrm{p}<0.01, * * \mathrm{p}<0.05, * \mathrm{p}<0.1$. 
Table A9: Mortality Rate: Robustness to unadjusted mortality

\begin{tabular}{|c|c|c|c|c|}
\hline & \multicolumn{4}{|c|}{ Dependent variable: Deaths per 1,000 people } \\
\hline & \multicolumn{2}{|c|}{ Female } & \multicolumn{2}{|c|}{ Male } \\
\hline & Trend & Age FE & Trend & Age FE \\
\hline & (1) & (2) & (3) & (4) \\
\hline & \multicolumn{4}{|c|}{ Panel A: Reduced Form } \\
\hline Yr Age 21 & $\begin{array}{c}-0.529 * * * \\
(0.024)\end{array}$ & & $\begin{array}{c}-0.961 * * * \\
(0.038)\end{array}$ & \\
\hline \multirow[t]{2}{*}{ Yr Age 21 x $\mathbb{1}($ Yr Age $21 \geq 1973)$} & $\begin{array}{c}0.289 * * * \\
(0.019)\end{array}$ & $\begin{array}{c}0.103 * * * \\
(0.020)\end{array}$ & $\begin{array}{c}0.560 * * * \\
(0.029)\end{array}$ & $\begin{array}{c}0.282 * * * \\
(0.033)\end{array}$ \\
\hline & \multicolumn{4}{|c|}{ Panel B: IV } \\
\hline Share with college per 10 people & $\begin{array}{c}-0.715^{* * *} \\
(0.045)\end{array}$ & $\begin{array}{c}-0.253 * * * \\
(0.049)\end{array}$ & $\begin{array}{c}-1.687 * * * \\
(0.087)\end{array}$ & $\begin{array}{c}-0.825^{* * * *} \\
(0.094)\end{array}$ \\
\hline Year x Region FE & Yes & Yes & Yes & Yes \\
\hline Age FE & No & Yes & No & Yes \\
\hline Observations & 6,480 & 6,480 & 6,480 & 6,480 \\
\hline R-squared (panel A) & 0.679 & 0.737 & 0.770 & 0.831 \\
\hline Mean DV & 3.644 & 3.644 & 6.402 & 6.402 \\
\hline Kleibergen-Paap F-statistic (panel B) & 5015 & 4574 & 9875 & 8783 \\
\hline \multicolumn{5}{|c|}{$\begin{array}{l}\text { Unit of analysis is cohort-region-year. Observations weighted by cell size. Sample includes all respondents } \\
\text { in the } 1992 \text { census who (I) reached age } 21 \text { between } 1964 \text { and } 1981 \text { (both years inclusive) and (II) reported } \\
\text { full secondary education. Sample period: } 1994-2017 \text {. "Yr Age } 21 \text { " is a continuous variable indicating the } \\
\text { year at which the cohort reached age } 21, \text { normalized to zero in } 1972 \text {. "Yr Age } 21 \text { x } \mathbb{1}(\mathrm{Yr} \text { Age } 21 \geq 1973 \text { )" } \\
\text { is the interaction of this variable with a dummy for cohorts that reached age } 21 \text { on or after } 1973 \text {. In panel } \\
\text { B, this variable is used as excluded instrument for the share with college. The share with college is adjusted } \\
\text { for previous mortality. Standard errors clustered by region-year in parentheses. }{ }^{* * *} \mathrm{p}<0.01, * * \mathrm{p}<0.05 \text {, * } \\
\text { p }<0.1 \text {. }\end{array}$} \\
\hline
\end{tabular}


Table A10: Mortality Rate: Robustness to unadjusted mortality rate and share of college

\begin{tabular}{|c|c|c|c|c|}
\hline & \multicolumn{4}{|c|}{ Dependent variable: Deaths per 1,000 people } \\
\hline & \multicolumn{2}{|c|}{ Female } & \multicolumn{2}{|c|}{ Male } \\
\hline & Trend & Age FE & Trend & Age FE \\
\hline & $(1)$ & $(2)$ & (3) & (4) \\
\hline & \multicolumn{4}{|c|}{$\underline{\text { Panel A: Reduced Form }}$} \\
\hline Yr Age 21 & $\begin{array}{c}-0.529 * * * \\
(0.024)\end{array}$ & & $\begin{array}{c}-0.961 * * * \\
(0.038)\end{array}$ & \\
\hline \multirow[t]{2}{*}{ Yr Age 21 x $\mathbb{1}($ Yr Age $21 \geq 1973)$} & $\begin{array}{c}0.289 * * * \\
(0.019)\end{array}$ & $\begin{array}{c}0.103 * * * \\
(0.020)\end{array}$ & $\begin{array}{c}0.560 * * * \\
(0.029)\end{array}$ & $\begin{array}{c}0.282 * * * \\
(0.033)\end{array}$ \\
\hline & \multicolumn{4}{|c|}{$\underline{\text { Panel B: IV }}$} \\
\hline Share with college per 10 people & $\begin{array}{c}-0.725 * * * \\
(0.046)\end{array}$ & $\begin{array}{c}-0.259 * * * \\
(0.050)\end{array}$ & $\begin{array}{c}-1.692 * * * \\
(0.087)\end{array}$ & $\begin{array}{c}-0.848 * * * \\
(0.097)\end{array}$ \\
\hline Year x Region FE & Yes & Yes & Yes & Yes \\
\hline Age FE & No & Yes & No & Yes \\
\hline Observations & 6,480 & 6,480 & 6,480 & 6,480 \\
\hline R-squared (panel A) & 0.679 & 0.737 & 0.770 & 0.831 \\
\hline Mean DV & 3.644 & 3.644 & 6.402 & 6.402 \\
\hline Kleibergen-Paap F-statistic (panel B) & 5608 & 4990 & 10918 & 9842 \\
\hline \multicolumn{5}{|c|}{$\begin{array}{l}\text { Unit of analysis is cohort-region-year. Observations weighted by cell size. Sample includes all respondents } \\
\text { in the } 1992 \text { census who (I) reached age } 21 \text { between } 1964 \text { and } 1981 \text { (both years inclusive) and (II) reported } \\
\text { full secondary education. Sample period: } 1994-2017 \text {. "Yr Age } 21 \text { " is a continuous variable indicating the } \\
\text { year at which the cohort reached age } 21 \text {, normalized to zero in } 1972 \text {. "Yr Age } 21 \times \mathbb{1} \text { (Yr Age } 21 \geq 1973 \text { )" } \\
\text { is the interaction of this variable with a dummy for cohorts that reached age } 21 \text { on or after } 1973 \text {. In panel } \\
\text { B, this variable is used as excluded instrument for the share with college. Standard errors clustered by } \\
\text { region-year in parentheses. } * * * p<0.01, * * p<0.05, * p<0.1 \text {. }\end{array}$} \\
\hline
\end{tabular}


Table A11: Mortality Rate: National level

\begin{tabular}{|c|c|c|c|c|}
\hline & \multicolumn{4}{|c|}{ Dependent variable: Deaths per 1,000 people } \\
\hline & \multicolumn{2}{|c|}{ Female } & \multicolumn{2}{|c|}{ Male } \\
\hline & Trend & Age FE & Trend & Age FE \\
\hline & (1) & (2) & (3) & (4) \\
\hline & \multicolumn{4}{|c|}{ Panel A: Reduced Form } \\
\hline Yr Age 21 & $\begin{array}{c}-0.605^{* * *} \\
(0.062)\end{array}$ & & $\begin{array}{c}-1.232 * * * \\
(0.128)\end{array}$ & \\
\hline \multirow[t]{2}{*}{ Yr Age 21 x $\mathbb{1}($ Yr Age $21 \geq 1973)$} & $\begin{array}{c}0.349 * * * \\
(0.039)\end{array}$ & $\begin{array}{c}0.102^{* * * *} \\
(0.018)\end{array}$ & $\begin{array}{c}0.784 * * * \\
(0.080)\end{array}$ & $\begin{array}{c}0.302^{* * * *} \\
(0.043)\end{array}$ \\
\hline & \multicolumn{4}{|c|}{ Panel B: IV } \\
\hline Share with college per 10 people & $\begin{array}{c}-0.858^{* * *} \\
(0.094)\end{array}$ & $\begin{array}{c}-0.248 * * * \\
(0.044)\end{array}$ & $\begin{array}{c}-2.358 * * * \\
(0.239)\end{array}$ & $\begin{array}{c}-0.883 * * * \\
(0.124)\end{array}$ \\
\hline Year FE & Yes & Yes & Yes & Yes \\
\hline Age FE & No & Yes & No & Yes \\
\hline Observations & 432 & 430 & 432 & 430 \\
\hline R-squared (panel A) & 0.866 & 0.971 & 0.858 & 0.979 \\
\hline Mean DV & 3.849 & 3.847 & 7.077 & 7.069 \\
\hline Kleibergen-Paap F-statistic (panel B) & 110038 & 26971 & 340546 & 61740 \\
\hline
\end{tabular}

Notes: Unit of analysis is cohort-year. Observations weighted by cell size. Sample includes all respondents in the 1992 census who (I) reached age 21 between 1964 and 1981 (both years inclusive) and (II) reported full secondary education. Sample period: 1994-2017. "Yr Age 21" is a continuous variable indicating the year at which the cohort reached age 21, normalized to zero in 1972. "Yr Age 21 x 1 (Yr Age $21 \geq 1973$ )" is the interaction of this variable with a dummy for cohorts that reached age 21 on or after 1973. In panel B, this variable is used as excluded instrument for the share with college. Mortality rate and share with college adjusted for previous mortality. Standard errors clustered by region-year in parentheses. $* * * p<0.01$, ** $\mathrm{p}<0.05, * \mathrm{p}<0.1$. P-value from Wild cluster bootstrap by cohort reported in brackets. 
Table A12: Mortality Rate: Using 2002 Census

\begin{tabular}{|c|c|c|c|c|}
\hline & \multicolumn{4}{|c|}{ Dependent variable: Deaths per 1,000 people } \\
\hline & \multicolumn{2}{|c|}{ Female } & \multicolumn{2}{|c|}{ Male } \\
\hline & Trend & Age FE & Trend & Age FE \\
\hline & $(1)$ & $(2)$ & (3) & (4) \\
\hline & \multicolumn{4}{|c|}{$\underline{\text { Panel A: Reduced Form }}$} \\
\hline Yr Age 21 & $\begin{array}{c}-0.729 * * * \\
(0.034)\end{array}$ & & $\begin{array}{c}-1.285^{* * * *} \\
(0.053)\end{array}$ & \\
\hline \multirow[t]{2}{*}{ Yr Age 21 x $\mathbb{1}($ Yr Age $21 \geq 1973)$} & $\begin{array}{c}0.486 * * * \\
(0.030)\end{array}$ & $\begin{array}{c}0.207 * * * \\
(0.032)\end{array}$ & $\begin{array}{c}0.861 * * * \\
(0.045)\end{array}$ & $\begin{array}{c}0.415^{* * * *} \\
(0.053)\end{array}$ \\
\hline & \multicolumn{4}{|c|}{$\underline{\text { Panel B: IV }}$} \\
\hline Share with college per 10 people & $\begin{array}{c}-1.752 * * * \\
(0.115)\end{array}$ & $\begin{array}{c}-0.744 * * * \\
(0.114)\end{array}$ & $\begin{array}{c}-3.907 * * * \\
(0.220)\end{array}$ & $\begin{array}{c}-1.796 * * * \\
(0.232)\end{array}$ \\
\hline Year x Region FE & Yes & Yes & Yes & Yes \\
\hline Age FE & No & Yes & No & Yes \\
\hline Observations & 4,050 & 4,050 & 4,050 & 4,050 \\
\hline R-squared (panel A) & 0.673 & 0.718 & 0.780 & 0.826 \\
\hline Mean DV & 4.395 & 4.395 & 7.436 & 7.436 \\
\hline Kleibergen-Paap F-statistic (panel B) & 1740 & 1524 & 1915 & 1973 \\
\hline \multicolumn{5}{|c|}{$\begin{array}{l}\text { Notes: Unit of analysis is cohort-region-year. Observations weighted by cell size. Sample includes all } \\
\text { respondents in the } 2002 \text { census who (I) reached age } 21 \text { between } 1964 \text { and } 1981 \text { (both years inclusive) and } \\
\text { (II) reported full secondary education. Sample period: } 2003-2017 \text {. "Yr Age } 21 \text { " is a continuous variable } \\
\text { indicating the year at which the cohort reached age } 21 \text {, normalized to zero in } 1972 \text {. "Yr Age } 21 \times \mathbb{1} \text { (Yr } \\
\text { Age } 21 \geq 1973 \text { )" is the interaction of this variable with a dummy for cohorts that reached age } 21 \text { on or after } \\
1973 \text {. In panel B, this variable is used as excluded instrument for the share with college. Mortality rate and } \\
\text { share with college adjusted for previous mortality. Standard errors clustered by region-year in parentheses. } \\
* * * p<0.01, * * p<0.05, * p<0.1 \text {. }\end{array}$} \\
\hline
\end{tabular}


Table A13: Cause of Death

\begin{tabular}{|c|c|c|c|c|c|}
\hline & \multicolumn{5}{|c|}{ Dependent variable: Deaths per 1,000 people } \\
\hline & Tumors & $\begin{array}{c}\text { Circulatory } \\
\text { system }\end{array}$ & $\begin{array}{c}\text { External } \\
\text { causes }\end{array}$ & $\begin{array}{c}\text { Digestive } \\
\text { system }\end{array}$ & $\begin{array}{l}\text { Respiratory } \\
\text { system }\end{array}$ \\
\hline & (1) & (2) & (3) & (4) & (5) \\
\hline \multirow[b]{2}{*}{ Share with college per 10 people } & \multicolumn{5}{|c|}{ Panel A: Female } \\
\hline & $\begin{array}{c}-0.108 * * * \\
(0.033)\end{array}$ & $\begin{array}{c}-0.083 * * * \\
(0.021)\end{array}$ & $\begin{array}{c}0.001 \\
(0.010)\end{array}$ & $\begin{array}{c}-0.033 * * * \\
(0.011)\end{array}$ & $\begin{array}{l}-0.006 \\
(0.009)\end{array}$ \\
\hline \multirow[b]{2}{*}{ Share with college per 10 people } & \multicolumn{5}{|c|}{ Panel B: Male } \\
\hline & $\begin{array}{c}-0.213 * * * \\
(0.051)\end{array}$ & $\begin{array}{c}-0.293 * * * \\
(0.052)\end{array}$ & $\begin{array}{c}-0.064 * * * \\
(0.024)\end{array}$ & $\begin{array}{c}-0.173 * * * \\
(0.025)\end{array}$ & $\begin{array}{c}-0.059 * * * \\
(0.015)\end{array}$ \\
\hline Year x Region FE & Yes & Yes & Yes & Yes & Yes \\
\hline Age FE & Yes & Yes & Yes & Yes & Yes \\
\hline Observations & 6,480 & 6,480 & 6,480 & 6,480 & 6,480 \\
\hline Mean DV (Panel A) & 1.974 & 0.713 & 0.223 & 0.263 & 0.164 \\
\hline Mean DV (Panel B) & 2.229 & 1.915 & 0.883 & 0.779 & 0.332 \\
\hline Kleibergen-Paap F-statistic (panel A) & 4574 & 4574 & 4574 & 4574 & 4574 \\
\hline Kleibergen-Paap F-statistic (panel B) & 8783 & 8783 & 8783 & 8783 & 8783 \\
\hline
\end{tabular}

Notes: Unit of analysis is cohort-region-year. Observations weighted by cell size. Sample includes all respondents in the 1992 census who (I) reached age 21 between 1964 and 1981 (both years inclusive) and (II) reported full secondary education. Sample period: 1994-2017. Mortality rates and share with college adjusted for previous mortality. "Yr Age 21" is a continuous variable indicating the year at which the cohort reached age 21, normalized to zero in 1972. "Yr Age 21 x $\mathbb{1}$ (Yr Age 21 $\geq 1973$ )" is the interaction of this variable with a dummy for cohorts that reached age 21 on or after 1973. This interaction is used as excluded instrument for the share with college. All regressions include Year $x$ Region and age fixed effects. Standard errors clustered by region-year in parentheses. $* * * \mathrm{p}<0.01, * * \mathrm{p}<0.05, * \mathrm{p}<0.1$. 
Table A14: Cause of Death: Disaggregated Tumors

\begin{tabular}{|c|c|c|c|c|c|}
\hline & \multicolumn{5}{|c|}{ Dependent variable: Deaths per 1,000 people } \\
\hline & (1) & (2) & (3) & (4) & (5) \\
\hline \multirow{5}{*}{ Share with college per 10 people } & \multicolumn{5}{|c|}{$\underline{\text { Panel A: Female }}$} \\
\hline & Digestive & Breast & Genital & Respiratory & Lymphatic \\
\hline & $\begin{array}{c}-0.042 * * \\
(0.019)\end{array}$ & $\begin{array}{c}-0.030 * * \\
(0.012)\end{array}$ & $\begin{array}{c}-0.023^{* *} \\
(0.010)\end{array}$ & $\begin{array}{c}0.015 \\
(0.012)\end{array}$ & $\begin{array}{c}-0.027 * * * \\
(0.008)\end{array}$ \\
\hline & \multicolumn{5}{|c|}{$\underline{\text { Panel B: Male }}$} \\
\hline & Digestive & Respiratory & Lymphatic & Urinary & Genital \\
\hline Share with college per 10 people & $\begin{array}{c}-0.092 * * * \\
(0.031)\end{array}$ & $\begin{array}{c}-0.060^{* * *} \\
(0.019)\end{array}$ & $\begin{array}{c}-0.023 * * \\
(0.011)\end{array}$ & $\begin{array}{l}-0.008 \\
(0.011)\end{array}$ & $\begin{array}{c}0.003 \\
(0.009)\end{array}$ \\
\hline Year x Region FE & Yes & Yes & Yes & Yes & Yes \\
\hline Age FE & Yes & Yes & Yes & Yes & Yes \\
\hline Observations & 6,480 & 6,480 & 6,480 & 6,480 & 6,480 \\
\hline Mean DV (Panel A) & 0.633 & 0.367 & 0.295 & 0.228 & 0.147 \\
\hline Mean DV (Panel B) & 0.906 & 0.437 & 0.208 & 0.169 & 0.137 \\
\hline Kleibergen-Paap F-statistic (panel A) & 4574 & 4574 & 4574 & 4574 & 4574 \\
\hline Kleibergen-Paap F-statistic (panel B) & 8782 & 8782 & 8782 & 8782 & 8782 \\
\hline
\end{tabular}

Notes: Unit of analysis is cohort-region-year. Observations weighted by cell size. Sample includes all respondents in the 1992 census who (I) reached age 21 between 1964 and 1981 (both years inclusive) and (II) reported full secondary education. Sample period: 1994-2017. Mortality rates and share with college adjusted for previous mortality. "Yr Age 21" is a continuous variable indicating the year at which the cohort reached age 21, normalized to zero in 1972. "Yr Age $21 \times 1$ (Yr Age $21 \geq 1973$ )" is the interaction of this variable with a dummy for cohorts that reached age 21 on or after 1973. This interaction is used as excluded instrument for the share with college. All regressions include Year $x$ Region and age FE. Standard errors clustered by region-year in parentheses. $* * * \mathrm{p}<0.01, * * \mathrm{p}<0.05, * \mathrm{p}<0.1$. 
Table A15: Cause of Death: Disaggregated External Causes

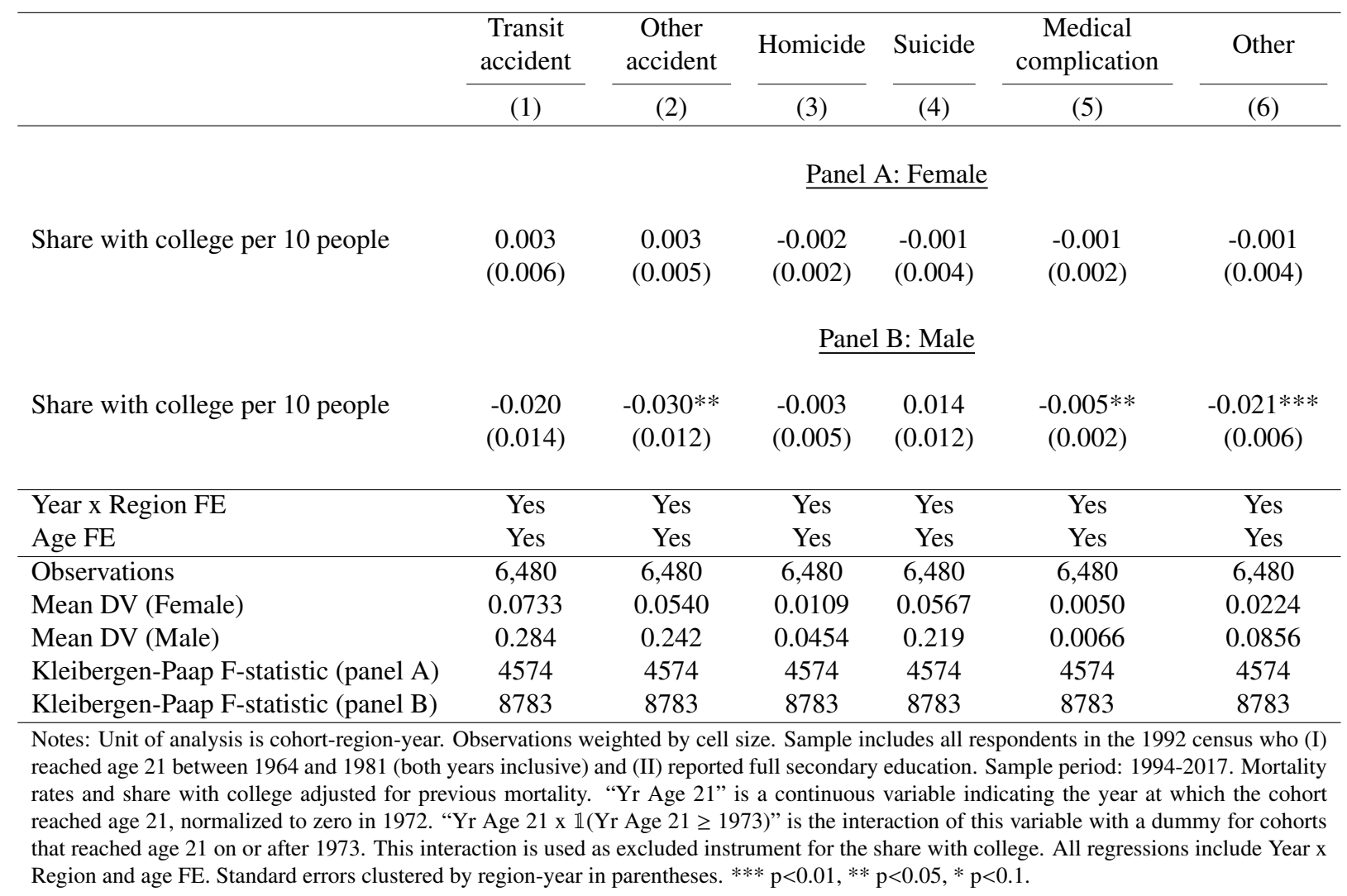


Table A16: Reasons for not Having a Pap Smear

\begin{tabular}{|c|c|c|c|c|c|c|}
\hline & \multicolumn{6}{|c|}{ Pap smear test in last 3 years } \\
\hline & \multirow[b]{2}{*}{ Yes } & \multicolumn{5}{|c|}{ No + stated reason } \\
\hline & & $\begin{array}{c}\text { Doesn't know } \\
\text { about it }\end{array}$ & $\begin{array}{l}\text { Doesn't know } \\
\text { where to do it }\end{array}$ & $\begin{array}{c}\text { Afraid or } \\
\text { doesn't like it }\end{array}$ & $\begin{array}{l}\text { Forgot to } \\
\text { do it }\end{array}$ & $\begin{array}{c}\text { Uninterested } \\
\text { or doesn't need it }\end{array}$ \\
\hline & (1) & (2) & (3) & (4) & (5) & (6) \\
\hline $\mathbb{1}$ (Any College) & $\begin{array}{l}0.168 * * \\
(0.084)\end{array}$ & $\begin{array}{l}-0.016^{*} \\
(0.009)\end{array}$ & $\begin{array}{l}-0.001 \\
(0.007)\end{array}$ & $\begin{array}{l}-0.009 \\
(0.033)\end{array}$ & $\begin{array}{l}-0.075 \\
(0.049)\end{array}$ & $\begin{array}{l}-0.014 \\
(0.048)\end{array}$ \\
\hline County x Year FE & Yes & Yes & Yes & Yes & Yes & Yes \\
\hline Age FE & Yes & Yes & Yes & Yes & Yes & Yes \\
\hline Observations & 58,549 & 58,549 & 58,549 & 58,549 & 58,549 & 58,549 \\
\hline Mean DV & 0.726 & 0.00316 & 0.00162 & 0.0329 & 0.0960 & 0.0958 \\
\hline Kleibergen-Paap F-statistic & 131.8 & 131.8 & 131.8 & 131.8 & 131.8 & 131.8 \\
\hline
\end{tabular}

Notes: The unit of analysis is an individual female respondent from the CASEN survey. Dependent variable in the header. In column 1, a dummy for having had a Pap smear in the past three years. In columns 2-6 respective dummies for stated causes for not having a Pap smear (set to zero if Pap smear in past three years). These causes are not exhaustive. Survey waves: 1992, 1994, 1996, 2000, 2003, 2009, 2011, 2013, 2015, 2017. Sample includes individuals from cohorts that reached age 21 between 1964 and 1981 (both years inclusive) and report 4+ years of secondary education. "Yr Age 21" is a continuous variable indicating the year at which the cohort reached age 21, normalized to zero in 1972. "Yr Age $21 \times \mathbb{1}$ (Yr Age $21 \geq 1973$ )" is the interaction of this variable with a dummy for cohorts that reached age 21 on or after 1973 . We use this variable as excluded instrument for the share with college. All regressions include year by county of residence and age fixed effects. Standard errors clustered two-way by county and region-year reported in parentheses. $* * * \mathrm{p}<0.01, * * \mathrm{p}<0.05, * \mathrm{p}<0.1$. 
Table A17: Hospitalizations: Other Characteristics

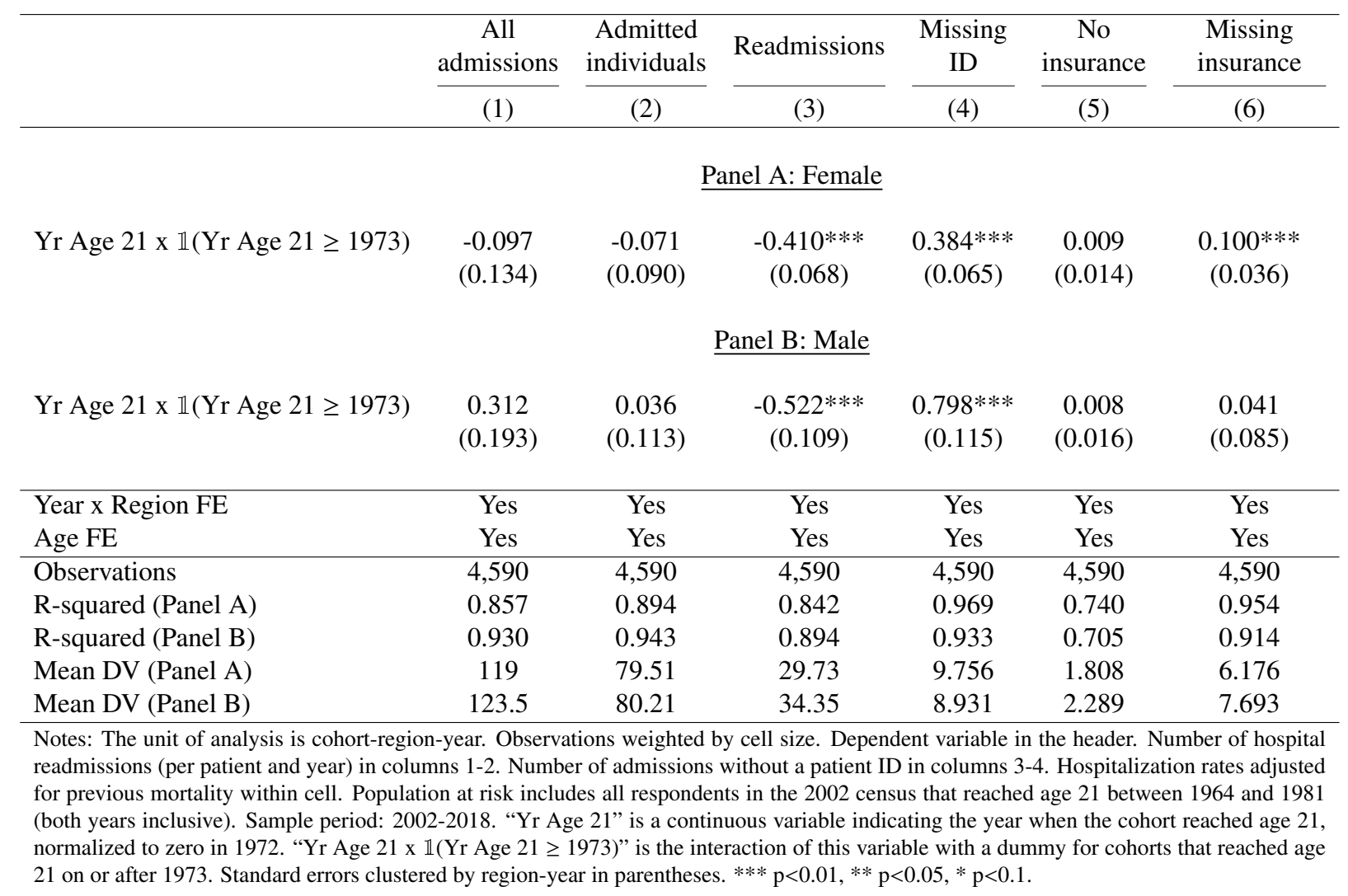


Table A18: Mortality Rate: Unrestricted Sample (2002-2017)

\begin{tabular}{|c|c|c|c|c|}
\hline & \multicolumn{4}{|c|}{ Dependent variable: Deaths per 1,000 people } \\
\hline & \multicolumn{2}{|c|}{ Female } & \multicolumn{2}{|c|}{ Male } \\
\hline & Trend & Age FE & Trend & Age FE \\
\hline & $(1)$ & $(2)$ & (3) & (4) \\
\hline & \multicolumn{4}{|c|}{$\underline{\text { Panel A: Reduced Form }}$} \\
\hline Yr Age 21 & $\begin{array}{c}-0.841 * * * \\
(0.035)\end{array}$ & & $\begin{array}{c}-1.413 * * * \\
(0.050)\end{array}$ & \\
\hline \multirow[t]{2}{*}{ Yr Age 21 x $\mathbb{1}($ Yr Age $21 \geq 1973)$} & $\begin{array}{c}0.509 * * * \\
(0.024)\end{array}$ & $\begin{array}{c}0.124 * * * \\
(0.017)\end{array}$ & $\begin{array}{c}0.871 * * * \\
(0.034)\end{array}$ & $\begin{array}{c}0.286^{* * *} \\
(0.029)\end{array}$ \\
\hline & \multicolumn{4}{|c|}{$\underline{\text { Panel B: IV }}$} \\
\hline Share with college per 10 people & $\begin{array}{c}-3.893 * * * \\
(0.191)\end{array}$ & $\begin{array}{c}-0.950 * * * \\
(0.130)\end{array}$ & $\begin{array}{c}-6.562 * * * \\
(0.278)\end{array}$ & $\begin{array}{c}-2.083 * * * \\
(0.208)\end{array}$ \\
\hline Year x Region FE & Yes & Yes & Yes & Yes \\
\hline Age FE & No & Yes & No & Yes \\
\hline Observations & 4,320 & 4,320 & 4,320 & 4,320 \\
\hline R-squared (panel A) & 0.830 & 0.905 & 0.853 & 0.922 \\
\hline Mean DV & 5.385 & 5.385 & 9.378 & 9.378 \\
\hline Kleibergen-Paap F-statistic (panel B) & 4699 & 3020 & 4946 & 3162 \\
\hline \multicolumn{5}{|c|}{$\begin{array}{l}\text { Notes: Sample includes all respondents in the } 2002 \text { census that reached age } 21 \text { between } 1964 \text { and } 1981 \\
\text { (both years inclusive), but imposes no restriction on educational attainment. Sample period: 2002-2017. } \\
\text { "Yr Age } 21 \text { " is a continuous variable indicating the year at which the cohort reached age } 21 \text {, normalized } \\
\text { to zero in } 1972 \text {. "Yr Age } 21 \mathrm{x} \mathbb{1} \text { (Yr Age } 21 \geq 1973 \text { )" is the interaction of this variable with a dummy for } \\
\text { cohorts that reached age } 21 \text { on or after } 1973 \text {. In panel B, this variable is used as excluded instrument for the } \\
\text { share with college. Mortality rate and share with college adjusted for previous mortality. Standard errors } \\
\text { clustered by region-year in parentheses. } * * * p<0.01, * * p<0.05, * p<0.1\end{array}$} \\
\hline
\end{tabular}


Table A19: Hospitalizations: Main diagnostic

\begin{tabular}{|c|c|c|c|c|c|c|c|}
\hline Tumors & Circulatory & External & Digestive & Respiratory & Musculoskeletal & Genitourinary & Other \\
\hline (1) & (2) & (3) & (4) & (5) & (6) & (7) & (8) \\
\hline
\end{tabular}

\section{$\underline{\text { Panel A: Female }}$}

\begin{tabular}{|c|c|c|c|c|c|c|c|c|}
\hline Yr Age 21 x $\mathbb{1}($ Yr Age $21 \geq 1973)$ & $\begin{array}{c}-0.096 * * \\
(0.042)\end{array}$ & $\begin{array}{c}0.176 * * * \\
(0.042)\end{array}$ & $\begin{array}{c}-0.045^{* *} \\
(0.019)\end{array}$ & $\begin{array}{c}0.003 \\
(0.035)\end{array}$ & $\begin{array}{l}0.076 * \\
(0.041)\end{array}$ & $\begin{array}{c}-0.217 * * * \\
(0.026)\end{array}$ & $\begin{array}{c}-0.108 * * * \\
(0.035)\end{array}$ & $\begin{array}{c}0.116 * * \\
(0.052)\end{array}$ \\
\hline
\end{tabular}

\section{$\underline{\text { Panel B: Male }}$}

\section{$-0.075^{*}$}

0.093

$-0.012$

$0.096 * * *$

$0.177 * * *$

$-0.134 * * *$

$0.053 *$

0.113

(0.043)

(0.061)

$(0.029)$

(0.035)

(0.038)

(0.024)

(0.032)

(0.073)

\begin{tabular}{lcccccccc}
\hline Year x Region FE & Yes & Yes & Yes & Yes & Yes & Yes & Yes & Yes \\
Age FE & Yes & Yes & Yes & Yes & Yes & Yes & Yes & Yes \\
\hline Observations & 4,590 & 4,590 & 4,590 & 4,590 & 4,590 & 4,590 & 4,590 & 4,590 \\
R-squared (panel A) & 0.601 & 0.874 & 0.689 & 0.700 & 0.808 & 0.769 & 0.643 \\
R-squared (panel B) & 0.860 & 0.908 & 0.705 & 0.801 & 0.842 & 0.674 & 0.885 & 0.778 \\
Mean DV (panel A) & 16.33 & 14.48 & 9.262 & 19.91 & 8.287 & 8.155 & 14.67 & 27.90 \\
Mean DV (panel B) & 12.99 & 21.80 & 13.67 & 20.14 & 8.880 & 6.977 & 12.23 & 26.82 \\
\hline
\end{tabular}

Notes: The unit of analysis is cohort-region-year. Observations weighted by cell size. The dependent variable in each column is the number of hospitalizations per 1,000 (including readmissions) with diagnostic corresponding to the chapter from the ICD-10 classification in the header. Hospitalization rates adjusted for previous mortality within cell. Population at risk includes all respondents in the 2002 census that reached age 21 between 1964 and 1981 (both years inclusive). Sample period: 2002-2018. "Yr Age 21" is a continuous variable indicating the year when the cohort reached age 21, normalized to zero in 1972. "Yr Age 21 x $\mathbb{1}$ (Yr Age $21 \geq 1973$ )" is the interaction of this variable with a dummy for cohorts that reached age 21 on or after 1973. All regressions include region by year and age fixed effects. Standard errors clustered by region-year in parentheses. $* * *$ $\mathrm{p}<0.01, * * \mathrm{p}<0.05, * \mathrm{p}<0.1$. 
Table A20: Mortality Rate at time of discharge of Hospitalized Patients (2004-2012)

\begin{tabular}{|c|c|c|c|c|c|c|c|c|}
\hline & \multicolumn{8}{|c|}{ Dependent variable: Deaths at the time of discharge per 1,000 hospitalized patients } \\
\hline & $(1)$ & $(2)$ & (3) & (4) & $(5)$ & (6) & (7) & $(8)$ \\
\hline & \multicolumn{8}{|c|}{ Panel A: Female } \\
\hline Yr Age 21 & $\begin{array}{c}-1.238 * * * \\
(0.092)\end{array}$ & & & & & & & \\
\hline \multirow[t]{2}{*}{ Yr Age $21 \times \mathbb{1}($ Yr Age $21 \geq 1973)$} & $\begin{array}{c}0.496^{* * * *} \\
(0.120)\end{array}$ & $\begin{array}{c}0.141 \\
(0.188)\end{array}$ & $\begin{array}{c}0.029 \\
(0.163)\end{array}$ & $\begin{array}{c}0.024 \\
(0.161)\end{array}$ & $\begin{array}{c}0.060 \\
(0.158)\end{array}$ & $\begin{array}{c}0.093 \\
(0.164)\end{array}$ & $\begin{array}{c}0.079 \\
(0.152)\end{array}$ & $\begin{array}{c}0.104 \\
(0.177)\end{array}$ \\
\hline & \multicolumn{8}{|c|}{$\underline{\text { Panel B: Male }}$} \\
\hline Yr Age 21 & $\begin{array}{c}-1.502 * * * \\
(0.116)\end{array}$ & & & & & & & \\
\hline Yr Age $21 \times \mathbb{1}($ Yr Age $21 \geq 1973)$ & $\begin{array}{c}0.625^{* * * *} \\
(0.176)\end{array}$ & $\begin{array}{c}0.650 * * * \\
(0.212)\end{array}$ & $\begin{array}{c}0.506^{* * *} * \\
(0.183)\end{array}$ & $\begin{array}{c}0.419 * * \\
(0.187)\end{array}$ & $\begin{array}{c}0.505 * * \\
(0.206)\end{array}$ & $\begin{array}{c}0.577 * * \\
(0.253)\end{array}$ & $\begin{array}{c}0.550 * * \\
(0.257)\end{array}$ & $\begin{array}{c}0.436 \\
(0.279)\end{array}$ \\
\hline Year x County FE & Yes & Yes & Yes & Yes & Yes & Yes & Yes & Yes \\
\hline Age FE & No & Yes & Yes & Yes & Yes & Yes & Yes & Yes \\
\hline Fixed effects: Diagnostic... & No & No & Yes & No & No & No & No & No \\
\hline$\ldots \mathrm{x}$ Public insurance... & No & No & No & Yes & No & No & No & No \\
\hline ... x Hospital... & No & No & No & No & Yes & No & No & No \\
\hline$\ldots x$ Type of admission... & No & No & No & No & No & Yes & No & No \\
\hline$\ldots \times$ x Surgery... & No & No & No & No & No & No & Yes & No \\
\hline ... x Previously admitted & No & No & No & No & No & No & No & Yes \\
\hline Observations (panel A) & 603,878 & 603,878 & 602,862 & 601,722 & 539,443 & 509,174 & 493,174 & 468,553 \\
\hline Observations (panel B) & 519,615 & 519,615 & 518,681 & 517,564 & 455,207 & 426,039 & 410,436 & 390,574 \\
\hline R-squared (panel A) & 0.009 & 0.009 & 0.180 & 0.187 & 0.311 & 0.345 & 0.357 & 0.371 \\
\hline R-squared (panel B) & 0.010 & 0.010 & 0.174 & 0.181 & 0.294 & 0.319 & 0.331 & 0.340 \\
\hline Mean DV (panel A) & 11.17 & 11.17 & 11.16 & 11.15 & 10.59 & 10.27 & 10.05 & 9.892 \\
\hline Mean DV (panel B) & 23.56 & 23.56 & 23.55 & 23.55 & 23.62 & 23.54 & 23.28 & 23.17 \\
\hline
\end{tabular}

Notes: The unit of analysis is a hospitalized patient. Dependent variable is an indicator for whether the patient is dead at time of discharge (multiplied by 1,000). Sample includes patients from cohorts that reached age 21 between 1964 and 1981 (both years inclusive) and is limited to one observation per patient (i.e. first admission). Sample period: 2004-2012. "Yr Age 21" is a continuous variable indicating the year at which the cohort reached age 21, normalized to zero in 1972. "Yr Age $21 \times \mathbb{1}$ (Yr Age $21 \geq 1973)$ " is the interaction of this variable with a dummy for cohorts that reached age 21 on or after 1973. All regressions include year by county of residence fixed effects. Columns 2-8 replace the baseline cohort trend with age fixed effects. Columns 3-8 iteratively add interactions of fixed effects for diagnostic (column 3: 4-digit ICD code), public insurance (column 4), hospital (column 5: 381 establishments), type of admission (column 6: ER, other establishment, etc.), surgery (column 7), previously admitted (column 8: 2002-2003). Standard errors clustered two-way by county and region-year reported in parentheses. $* * * \mathrm{p}<0.01, * * \mathrm{p}<0.05, * \mathrm{p}<0.1$. 
Table A21: One-month Mortality Rate of Hospitalized Patients (2004-2012)

\begin{tabular}{|c|c|c|c|c|c|c|c|c|}
\hline & \multicolumn{8}{|c|}{ Dependent variable: Deaths within 30 days of discharge per 1,000 hospitalized patients } \\
\hline & $(1)$ & $(2)$ & (3) & (4) & $(5)$ & $(6)$ & (7) & $(8)$ \\
\hline & \multicolumn{8}{|c|}{$\underline{\text { Panel A: Female }}$} \\
\hline Yr Age 21 & $\begin{array}{c}-2.119 * * * \\
(0.117)\end{array}$ & & & & & & & \\
\hline Yr Age 21 x $\mathbb{1}($ Yr Age $21 \geq 1973)$ & $\begin{array}{c}0.914 * * * \\
(0.165)\end{array}$ & $\begin{array}{c}0.307 \\
(0.230)\end{array}$ & $\begin{array}{c}0.134 \\
(0.189)\end{array}$ & $\begin{array}{c}0.118 \\
(0.187)\end{array}$ & $\begin{array}{c}0.125 \\
(0.200)\end{array}$ & $\begin{array}{c}0.129 \\
(0.214)\end{array}$ & $\begin{array}{c}0.132 \\
(0.207)\end{array}$ & $\begin{array}{c}0.140 \\
(0.210)\end{array}$ \\
\hline
\end{tabular}

\section{Panel B: Male}

\begin{tabular}{|c|c|c|c|c|c|c|c|c|}
\hline Yr Age 21 & $\begin{array}{c}-2.713 * * * \\
(0.138)\end{array}$ & & & & & & & \\
\hline Yr Age $21 \times \mathbb{1}($ Yr Age $21 \geq 1973)$ & $\begin{array}{c}1.244 * * * \\
(0.205)\end{array}$ & $\begin{array}{c}1.066 * * * \\
(0.222)\end{array}$ & $\begin{array}{c}0.799 * * * \\
(0.213)\end{array}$ & $\begin{array}{c}0.693 * * * \\
(0.214)\end{array}$ & $\begin{array}{c}0.726 * * * \\
(0.252)\end{array}$ & $\begin{array}{c}0.672 * * \\
(0.296)\end{array}$ & $\begin{array}{l}0.562 * \\
(0.311)\end{array}$ & $\begin{array}{c}0.448 \\
(0.340)\end{array}$ \\
\hline Year x County FE & Yes & Yes & Yes & Yes & Yes & Yes & Yes & Yes \\
\hline Age FE & No & Yes & Yes & Yes & Yes & Yes & Yes & Yes \\
\hline Fixed effects: Diagnostic... & No & No & Yes & No & No & No & No & No \\
\hline$\ldots \times$ Public insurance... & No & No & No & Yes & No & No & No & No \\
\hline$\ldots$ x Hospital... & No & No & No & No & Yes & No & No & No \\
\hline$\ldots \mathrm{x}$ Type of admission... & No & No & No & No & No & Yes & No & No \\
\hline$\ldots \times$ Surgery... & No & No & No & No & No & No & Yes & No \\
\hline$\ldots \times$ Previously admitted & No & No & No & No & No & No & No & Yes \\
\hline Observations (panel A) & 603,878 & 603,878 & 602,862 & 601,722 & 539,443 & 509,174 & 493,174 & 468,553 \\
\hline Observations (panel B) & 519,615 & 519,615 & 518,681 & 517,564 & 455,207 & 426,039 & 410,436 & 390,574 \\
\hline R-squared (panel A) & 0.011 & 0.011 & 0.180 & 0.189 & 0.305 & 0.340 & 0.355 & 0.370 \\
\hline R-squared (panel B) & 0.012 & 0.012 & 0.188 & 0.197 & 0.304 & 0.331 & 0.344 & 0.352 \\
\hline Mean DV (panel A) & 18.83 & 18.83 & 18.81 & 18.81 & 17.52 & 16.93 & 16.58 & 16.26 \\
\hline Mean DV (panel B) & 37.33 & 37.33 & 37.31 & 37.30 & 36.75 & 36.33 & 36.03 & 35.68 \\
\hline
\end{tabular}

Notes: The unit of analysis is a hospitalized patient. Dependent variable is an indicator for whether the patient dies within 30 days of discharge (multiplied by 1,000). Sample includes patients from cohorts that reached age 21 between 1964 and 1981 (both years inclusive) and is limited to one observation per patient (i.e. first admission). Sample period: 2004-2012. "Yr Age 21" is a continuous variable indicating the year at which the cohort reached age 21, normalized to zero in 1972. "Yr Age $21 \times \mathbb{1}$ (Yr Age $21 \geq 1973)$ " is the interaction of this variable with a dummy for cohorts that reached age 21 on or after 1973. All regressions include year by county of residence fixed effects. Columns 2-8 replace the baseline cohort trend with age fixed effects. Columns 3-8 iteratively add interactions of fixed effects for diagnostic (column 3: 4-digit ICD code), public insurance (column 4), hospital (column 5: 381 establishments), type of admission (column 6: ER, other establishment, etc.), surgery (column 7), previously admitted (column 8: 2002-2003). Standard errors clustered two-way by county and region-year reported in parentheses. $* * * \mathrm{p}<0.01, * * \mathrm{p}<0.05, * \mathrm{p}<0.1$. 
Table A22: Six-month Mortality Rate of Hospitalized Patients (2004-2012)

\begin{tabular}{|c|c|c|c|c|c|c|c|c|}
\hline & \multicolumn{8}{|c|}{ Dependent variable: Deaths within 6 months of discharge per 1,000 hospitalized patients } \\
\hline & (1) & (2) & (3) & (4) & (5) & (6) & (7) & $(8)$ \\
\hline & \multicolumn{8}{|c|}{$\underline{\text { Panel A: Female }}$} \\
\hline Yr Age 21 & $\begin{array}{c}-4.193 * * * \\
(0.188)\end{array}$ & & & & & & & \\
\hline Yr Age $21 \times \mathbb{1}($ Yr Age $21 \geq 1973)$ & $\begin{array}{c}2.054 * * * \\
(0.221)\end{array}$ & $\begin{array}{c}1.055^{* * *} * \\
(0.344)\end{array}$ & $\begin{array}{c}0.767 * * * \\
(0.272)\end{array}$ & $\begin{array}{c}0.715 * * \\
(0.276)\end{array}$ & $\begin{array}{c}0.585^{* *} \\
(0.279)\end{array}$ & $\begin{array}{c}0.631 * * \\
(0.284)\end{array}$ & $\begin{array}{c}0.612 * * \\
(0.279)\end{array}$ & $\begin{array}{l}0.515^{*} \\
(0.300)\end{array}$ \\
\hline
\end{tabular}

\section{Panel B: Male}

\begin{tabular}{|c|c|c|c|c|c|c|c|c|}
\hline Yr Age 21 & $\begin{array}{c}-5.043 * * * \\
(0.186)\end{array}$ & & & & & & & \\
\hline Yr Age 21 x $\mathbb{1}($ Yr Age $21 \geq 1973)$ & $\begin{array}{c}2.402 * * * \\
(0.255)\end{array}$ & $\begin{array}{c}1.884 * * * \\
(0.328)\end{array}$ & $\begin{array}{c}1.425 * * * \\
(0.334)\end{array}$ & $\begin{array}{c}1.287 * * * \\
(0.334)\end{array}$ & $\begin{array}{c}1.375 * * * \\
(0.380)\end{array}$ & $\begin{array}{c}1.282 * * * \\
(0.360)\end{array}$ & $\begin{array}{c}1.189 * * * \\
(0.374)\end{array}$ & $\begin{array}{c}1.052 * * * \\
(0.391)\end{array}$ \\
\hline Year x County FE & Yes & Yes & Yes & Yes & Yes & Yes & Yes & Yes \\
\hline Age FE & No & Yes & Yes & Yes & Yes & Yes & Yes & Yes \\
\hline Fixed effects: Diagnostic... & No & No & Yes & No & No & No & No & No \\
\hline$\ldots \times$ Public insurance... & No & No & No & Yes & No & No & No & No \\
\hline ... x Hospital... & No & No & No & No & Yes & No & No & No \\
\hline$\ldots \mathrm{x}$ Type of admission... & No & No & No & No & No & Yes & No & No \\
\hline$\ldots \times$ Surgery... & No & No & No & No & No & No & Yes & No \\
\hline ... x Previously admitted & No & No & No & No & No & No & No & Yes \\
\hline Observations (panel A) & 603,878 & 603,878 & 602,862 & 601,722 & 539,443 & 509,174 & 493,174 & 468,553 \\
\hline Observations (panel B) & 519,615 & 519,615 & 518,681 & 517,564 & 455,207 & 426,039 & 410,436 & 390,574 \\
\hline R-squared (panel A) & 0.016 & 0.016 & 0.223 & 0.233 & 0.336 & 0.368 & 0.383 & 0.397 \\
\hline R-squared (panel B) & 0.017 & 0.017 & 0.234 & 0.246 & 0.346 & 0.374 & 0.387 & 0.396 \\
\hline Mean DV (panel A) & 35.46 & 35.46 & 35.44 & 35.43 & 33.36 & 32.19 & 31.42 & 30.75 \\
\hline Mean DV (panel B) & 62.09 & 62.09 & 62.09 & 62.10 & 60.74 & 59.72 & 59.16 & 58.47 \\
\hline
\end{tabular}

Notes: The unit of analysis is a hospitalized patient. Dependent variable is an indicator for whether the patient dies within six months of discharge (multiplied by 1,000). Sample includes patients from cohorts that reached age 21 between 1964 and 1981 (both years inclusive) and is limited to one observation per patient (i.e. first admission). Sample period: 2004-2012. "Yr Age 21" is a continuous variable indicating the year at which the cohort reached age 21, normalized to zero in 1972. "Yr Age 21 x $\mathbb{1}$ (Yr Age $21 \geq 1973$ )" is the interaction of this variable with a dummy for cohorts that reached age 21 on or after 1973. All regressions include year by county of residence fixed effects. Columns 2-8 replace the baseline cohort trend with age fixed effects. Columns 3-8 iteratively add interactions of fixed effects for diagnostic (column 3: 4-digit ICD code), public insurance (column 4), hospital (column 5: 381 establishments), type of admission (column 6: ER, other establishment, etc.), surgery (column 7), previously admitted (column 8: 2002-2003). Standard errors clustered two-way by county and region-year reported in parentheses. $* * * \mathrm{p}<0.01, * * \mathrm{p}<0.05, * \mathrm{p}<0.1$. 
Table A23: Two-year Mortality Rate of Hospitalized Patients (2004-2012)

\begin{tabular}{|c|c|c|c|c|c|c|c|c|}
\hline & \multicolumn{8}{|c|}{ Dependent variable: Deaths within two years of discharge per 1,000 hospitalized patients } \\
\hline & $(1)$ & $(2)$ & (3) & (4) & $(5)$ & (6) & (7) & $(8)$ \\
\hline & \multicolumn{8}{|c|}{$\underline{\text { Panel A: Female }}$} \\
\hline Yr Age 21 & $\begin{array}{c}-6.872 * * * \\
(0.231)\end{array}$ & & & & & & & \\
\hline Yr Age 21 x $\mathbb{1}($ Yr Age $21 \geq 1973)$ & $\begin{array}{c}3.438 * * * \\
(0.265)\end{array}$ & $\begin{array}{c}2.451 * * * \\
(0.430)\end{array}$ & $\begin{array}{c}1.884 * * * \\
(0.344)\end{array}$ & $\begin{array}{c}1.808 * * * \\
(0.355)\end{array}$ & $\begin{array}{c}1.776 * * * \\
(0.360)\end{array}$ & $\begin{array}{c}1.724 * * * \\
(0.388)\end{array}$ & $\begin{array}{c}1.716 * * * \\
(0.370)\end{array}$ & $\begin{array}{c}1.535 * * * \\
(0.400)\end{array}$ \\
\hline
\end{tabular}

\section{$\underline{\text { Panel B: Male }}$}

\begin{tabular}{|c|c|c|c|c|c|c|c|c|}
\hline Yr Age 21 & $\begin{array}{c}-8.137 * * * \\
(0.251)\end{array}$ & & & & & & & \\
\hline Yr Age 21 x $\mathbb{1}($ Yr Age $21 \geq 1973)$ & $\begin{array}{c}3.739 * * * \\
(0.345)\end{array}$ & $\begin{array}{c}3.177 * * * \\
(0.413)\end{array}$ & $\begin{array}{c}2.485 * * * \\
(0.397)\end{array}$ & $\begin{array}{c}2.282 * * * \\
(0.388)\end{array}$ & $\begin{array}{c}2.061 * * * \\
(0.445)\end{array}$ & $\begin{array}{c}1.954 * * * \\
(0.475)\end{array}$ & $\begin{array}{c}1.775 * * * \\
(0.483)\end{array}$ & $\begin{array}{c}1.704 * * * \\
(0.489)\end{array}$ \\
\hline Year x County FE & Yes & Yes & Yes & Yes & Yes & Yes & Yes & Yes \\
\hline Age FE & No & Yes & Yes & Yes & Yes & Yes & Yes & Yes \\
\hline Fixed effects: Diagnostic... & No & No & Yes & No & No & No & No & No \\
\hline$\ldots \times$ Public insurance... & No & No & No & Yes & No & No & No & No \\
\hline ... x Hospital... & No & No & No & No & Yes & No & No & No \\
\hline$\ldots \mathrm{x}$ Type of admission... & No & No & No & No & No & Yes & No & No \\
\hline$\ldots \mathrm{x}$ Surgery... & No & No & No & No & No & No & Yes & No \\
\hline ... x Previously admitted & No & No & No & No & No & No & No & Yes \\
\hline Observations (panel A) & 603,878 & 603,878 & 602,862 & 601,722 & 539,443 & 509,174 & 493,174 & 468,553 \\
\hline Observations (panel B) & 519,615 & 519,615 & 518,681 & 517,564 & 455,207 & 426,039 & 410,436 & 390,574 \\
\hline R-squared (panel A) & 0.022 & 0.022 & 0.245 & 0.254 & 0.345 & 0.372 & 0.384 & 0.398 \\
\hline R-squared (panel B) & 0.023 & 0.023 & 0.261 & 0.273 & 0.368 & 0.392 & 0.403 & 0.414 \\
\hline Mean DV (panel A) & 60.04 & 60.04 & 60.01 & 60.01 & 57.17 & 55.45 & 54.38 & 53.19 \\
\hline Mean DV (panel B) & 99.41 & 99.41 & 99.39 & 99.38 & 97.36 & 95.82 & 95.12 & 93.73 \\
\hline
\end{tabular}

Notes: The unit of analysis is a hospitalized patient. Dependent variable is an indicator for whether the patient dies within two years of discharge (multiplied by 1,000). Sample includes patients from cohorts that reached age 21 between 1964 and 1981 (both years inclusive) and is limited to one observation per patient (i.e. first admission). Sample period: 2004-2012. "Yr Age 21" is a continuous variable indicating the year at which the cohort reached age 21, normalized to zero in 1972. "Yr Age 21 x $\mathbb{1}$ (Yr Age $21 \geq 1973$ )" is the interaction of this variable with a dummy for cohorts that reached age 21 on or after 1973. All regressions include year by county of residence fixed effects. Columns 2-8 replace the baseline cohort trend with age fixed effects. Columns 3-8 iteratively add interactions of fixed effects for diagnostic (column 3: 4-digit ICD code), public insurance (column 4), hospital (column 5: 381 establishments), type of admission (column 6: ER, other establishment, etc.), surgery (column 7), previously admitted (column 8: 2002-2003). Standard errors clustered two-way by county and region-year reported in parentheses. $* * * \mathrm{p}<0.01, * * \mathrm{p}<0.05, * \mathrm{p}<0.1$. 
Table A24: Five-year Mortality Rate of Hospitalized Patients (2004-2012)

\begin{tabular}{|c|c|c|c|c|c|c|c|c|}
\hline & \multicolumn{8}{|c|}{ Dependent variable: Deaths within five years of discharge per 1,000 hospitalized patients } \\
\hline & $(1)$ & $(2)$ & (3) & (4) & $(5)$ & $(6)$ & $(7)$ & $(8)$ \\
\hline & \multicolumn{8}{|c|}{$\underline{\text { Panel A: Female }}$} \\
\hline Yr Age 21 & $\begin{array}{c}-10.566 * * * \\
(0.308)\end{array}$ & & & & & & & \\
\hline Yr Age $21 \times \mathbb{1}($ Yr Age $21 \geq 1973)$ & $\begin{array}{c}5.234 * * * \\
(0.340)\end{array}$ & $\begin{array}{c}4.180 * * * \\
(0.501)\end{array}$ & $\begin{array}{c}3.241 * * * \\
(0.407)\end{array}$ & $\begin{array}{c}3.125 * * * \\
(0.420)\end{array}$ & $\begin{array}{c}3.061 * * * \\
(0.472)\end{array}$ & $\begin{array}{c}2.764 * * * \\
(0.481)\end{array}$ & $\begin{array}{c}2.743 * * * \\
(0.464)\end{array}$ & $\begin{array}{c}2.424 * * * \\
(0.458)\end{array}$ \\
\hline
\end{tabular}

\section{Panel B: Male}

\begin{tabular}{|c|c|c|c|c|c|c|c|c|}
\hline Yr Age 21 & $\begin{array}{c}-12.385^{* * * *} \\
(0.327)\end{array}$ & & & & & & & \\
\hline Yr Age 21 x $\mathbb{1}($ Yr Age $21 \geq 1973)$ & $\begin{array}{c}5.720 * * * \\
(0.417)\end{array}$ & $\begin{array}{c}4.986 * * * \\
(0.481)\end{array}$ & $\begin{array}{c}4.090 * * * \\
(0.453)\end{array}$ & $\begin{array}{c}3.707 * * * \\
(0.430)\end{array}$ & $\begin{array}{c}3.203 * * * \\
(0.492)\end{array}$ & $\begin{array}{c}3.052 * * * \\
(0.533)\end{array}$ & $\begin{array}{c}2.867 * * * \\
(0.525)\end{array}$ & $\begin{array}{c}2.640 * * * \\
(0.543)\end{array}$ \\
\hline Year x County FE & Yes & Yes & Yes & Yes & Yes & Yes & Yes & Yes \\
\hline Age FE & No & Yes & Yes & Yes & Yes & Yes & Yes & Yes \\
\hline Fixed effects: Diagnostic... & No & No & Yes & No & No & No & No & No \\
\hline$\ldots \mathrm{x}$ Public insurance... & No & No & No & Yes & No & No & No & No \\
\hline ... x Hospital... & No & No & No & No & Yes & No & No & No \\
\hline$\ldots \mathrm{x}$ Type of admission... & No & No & No & No & No & Yes & No & No \\
\hline$\ldots \times$ Surgery... & No & No & No & No & No & No & Yes & No \\
\hline$\ldots \times$ Previously admitted & No & No & No & No & No & No & No & Yes \\
\hline Observations (panel A) & 603,878 & 603,878 & 602,862 & 601,722 & 539,443 & 509,174 & 493,174 & 468,553 \\
\hline Observations (panel B) & 520,782 & 520,782 & 519,844 & 518,740 & 456,348 & 427,135 & 411,484 & 391,613 \\
\hline R-squared (panel A) & 0.030 & 0.030 & 0.238 & 0.248 & 0.333 & 0.358 & 0.370 & 0.383 \\
\hline R-squared (panel B) & 0.031 & 0.031 & 0.247 & 0.260 & 0.353 & 0.377 & 0.387 & 0.400 \\
\hline Mean DV (panel A) & 92.56 & 92.56 & 92.52 & 92.51 & 89.05 & 86.90 & 85.65 & 83.82 \\
\hline Mean DV (panel B) & 150.1 & 150.1 & 150.1 & 150.1 & 147.9 & 146 & 145.2 & 142.9 \\
\hline
\end{tabular}

Notes: The unit of analysis is a hospitalized patient. Dependent variable is an indicator for whether the patient dies within five years of discharge (multiplied by 1,000). Sample includes patients from cohorts that reached age 21 between 1964 and 1981 (both years inclusive) and is limited to one observation per patient (i.e. first admission). Sample period: 2004-2012. "Yr Age 21" is a continuous variable indicating the year at which the cohort reached age 21, normalized to zero in 1972. "Yr Age $21 \times \mathbb{1}$ (Yr Age $21 \geq 1973$ )" is the interaction of this variable with a dummy for cohorts that reached age 21 on or after 1973. All regressions include year by county of residence fixed effects. Columns 2-8 replace the baseline cohort trend with age fixed effects. Columns 3-8 iteratively add interactions of fixed effects for diagnostic (column 3: 4-digit ICD code), public insurance (column 4), hospital (column 5: 381 establishments), type of admission (column 6: ER, other establishment, etc.), surgery (column 7), previously admitted (column 8: 2002-2003). Standard errors clustered two-way by county and region-year reported in parentheses. $* * * \mathrm{p}<0.01, * * \mathrm{p}<0.05, * \mathrm{p}<0.1$. 
Table A25: Mortality Rate: Unrestricted Sample (2004-2012)

\begin{tabular}{|c|c|c|c|c|}
\hline & \multicolumn{4}{|c|}{ Dependent variable: Deaths per 1,000 people } \\
\hline & \multicolumn{2}{|c|}{ Female } & \multicolumn{2}{|c|}{ Male } \\
\hline & Trend & Age FE & Trend & Age FE \\
\hline & $(1)$ & $(2)$ & (3) & $(4)$ \\
\hline & \multicolumn{4}{|c|}{$\underline{\text { Panel A: Reduced Form }}$} \\
\hline Yr Age 21 & $\begin{array}{c}-0.716 * * * \\
(0.025)\end{array}$ & & $\begin{array}{c}-1.242 * * * \\
(0.039)\end{array}$ & \\
\hline \multirow[t]{2}{*}{ Yr Age 21 x $\mathbb{1}($ Yr Age $21 \geq 1973)$} & $\begin{array}{c}0.429 * * * \\
(0.021)\end{array}$ & $\begin{array}{c}0.076 * * * \\
(0.027)\end{array}$ & $\begin{array}{c}0.783 * * * \\
(0.031)\end{array}$ & $\begin{array}{c}0.283 * * * \\
(0.040)\end{array}$ \\
\hline & \multicolumn{4}{|c|}{$\underline{\text { Panel B: IV }}$} \\
\hline Share with college per 10 people & $\begin{array}{c}-3.305 * * * \\
(0.175)\end{array}$ & $\begin{array}{c}-0.592 * * * \\
(0.215)\end{array}$ & $\begin{array}{c}-5.927 * * * \\
(0.278)\end{array}$ & $\begin{array}{c}-2.094 * * * \\
(0.297)\end{array}$ \\
\hline Year x Region FE & Yes & Yes & Yes & Yes \\
\hline Age FE & No & Yes & No & Yes \\
\hline Observations & 2,430 & 2,430 & 2,430 & 2,430 \\
\hline R-squared (panel A) & 0.829 & 0.864 & 0.871 & 0.900 \\
\hline Mean DV & 4.652 & 4.652 & 8.222 & 8.222 \\
\hline Kleibergen-Paap F-statistic (panel B) & 2734 & 1487 & 2936 & 1476 \\
\hline \multicolumn{5}{|c|}{$\begin{array}{l}\text { Notes: Sample includes all respondents in the } 2002 \text { census that reached age } 21 \text { between } 1964 \text { and } 1981 \\
\text { (both years inclusive), but imposes no restriction on educational attainment. Sample period: 2004-2012. } \\
\text { "Yr Age } 21 \text { " is a continuous variable indicating the year at which the cohort reached age } 21 \text {, normalized } \\
\text { to zero in } 1972 \text {. "Yr Age } 21 \times \mathbb{1}(\text { Yr Age } 21 \geq 1973 \text { )" is the interaction of this variable with a dummy for } \\
\text { cohorts that reached age } 21 \text { on or after } 1973 \text {. In panel B, this variable is used as excluded instrument for the } \\
\text { share with college. Mortality rate and share with college adjusted for previous mortality. Standard errors } \\
\text { clustered by region-year in parentheses. } * * * p<0.01, * * p<0.05, * p<0.1\end{array}$} \\
\hline
\end{tabular}


Figure A1: A comparison of private and public healthcare

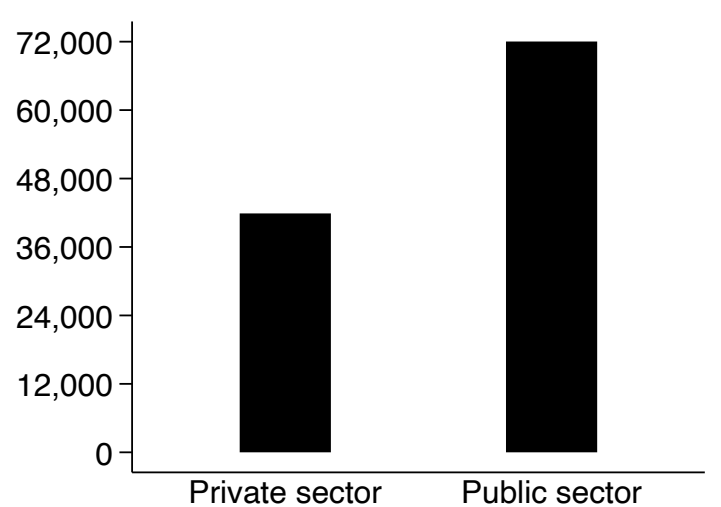

(a) Beneficiaries per hospital

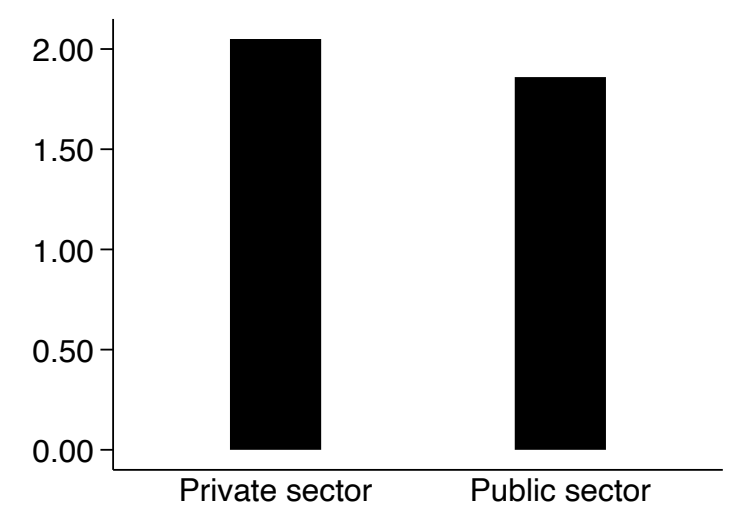

(c) Hospital beds per 1,000 beneficiaries

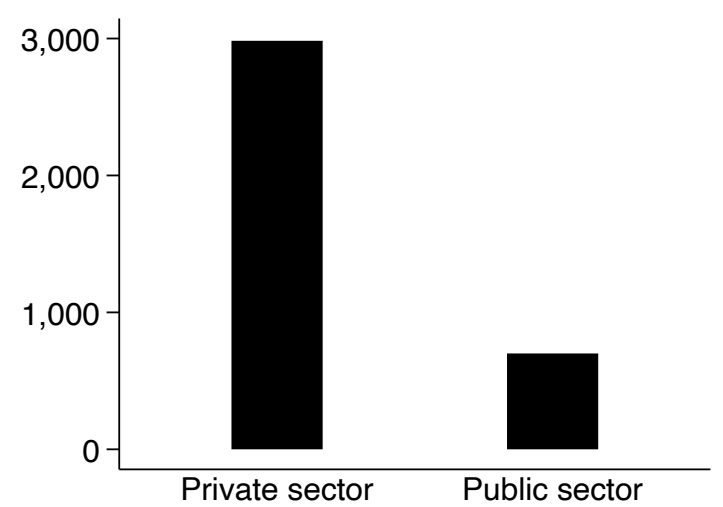

(b) Annual spending per capita (in USD)

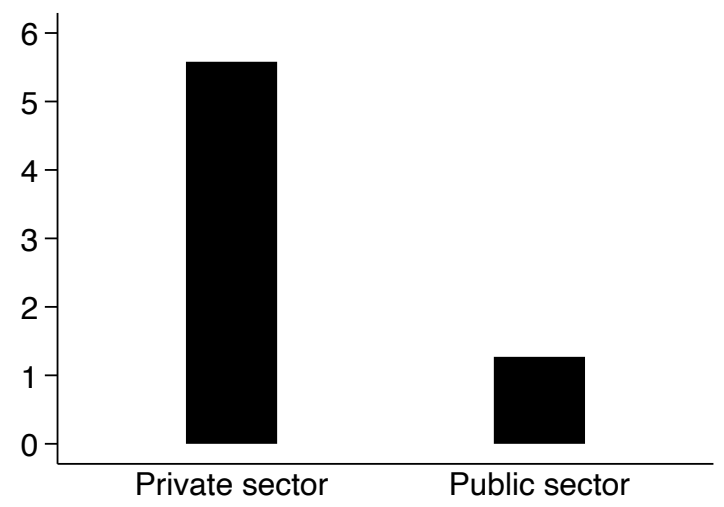

(d) Physicians per 1,000 beneficiaries

Notes: These figures characterize the public and private sectors in the Chilean health system. There are 3.3 million and 13.5 million beneficiaries in the private and public sectors respectively. As can be seen in these figures, the public sector is significantly more crowded than the private sector. These numbers correspond to administrative data presented in Clínicas de Chile (2014). 
Figure A2: Mortality Rate by Age and Year

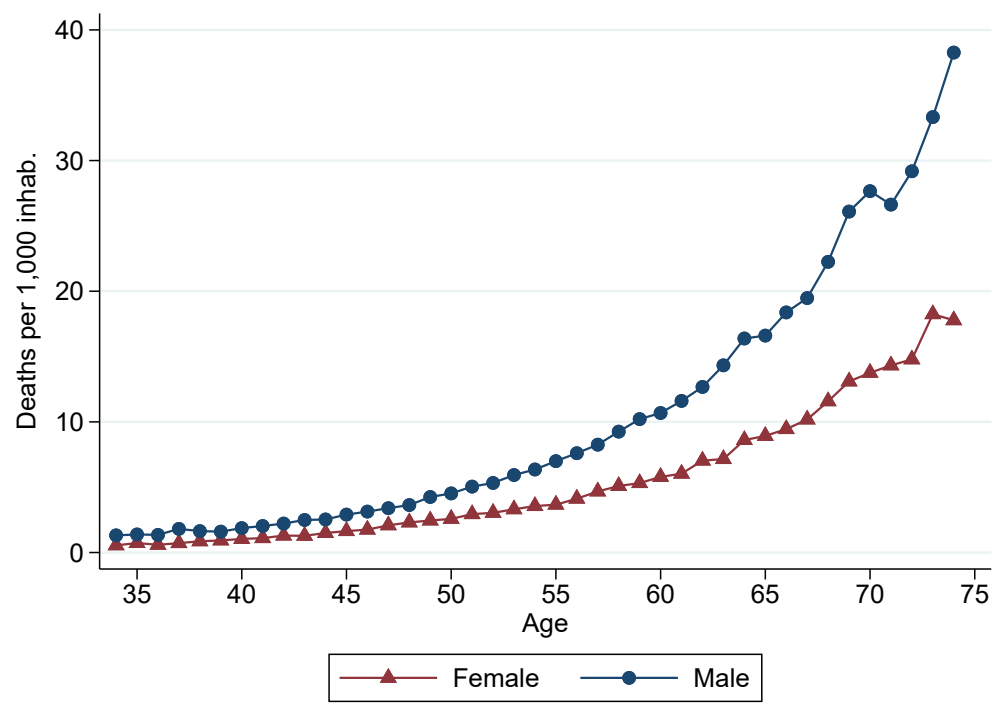

(a) Age

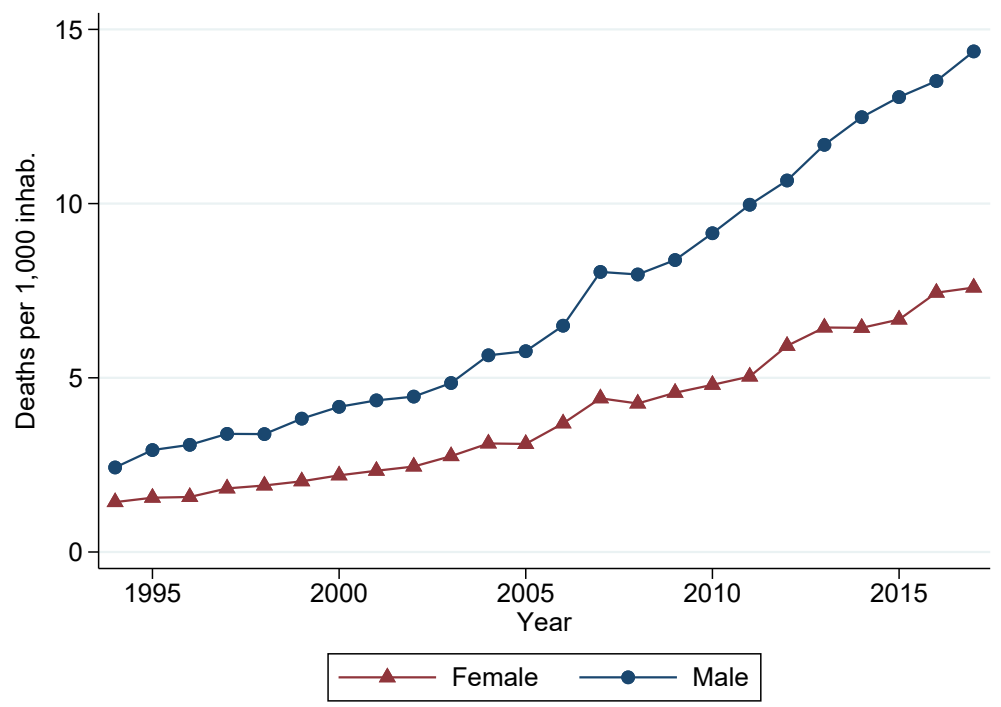

(b) Year

Notes: Plots show female and male mortality rates by age and by year, respectively. Sample period: 1994-2017. Mortality rates calculated based on population counts in the 1992 census, only including individuals from cohorts reaching age 21 between 1964 and 1981 (both inclusive) and reporting $4+$ years of secondary education. These mortality rates have been adjusted for previous mortality per cell (cohort). 
Figure A3: Mortality Rate by Level of Education

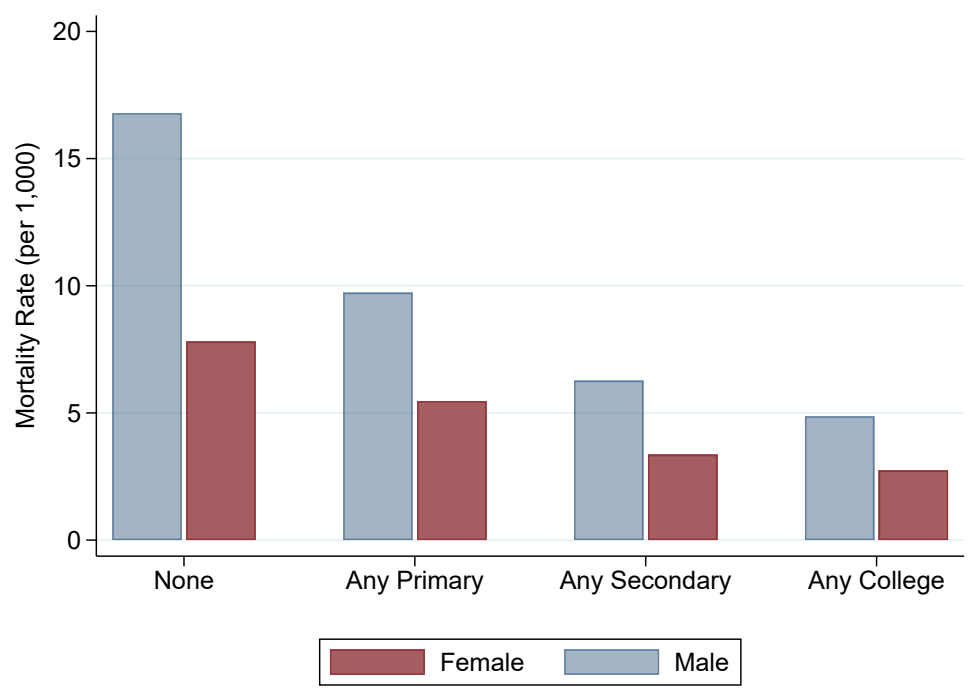

Notes: Plot shows mortality rates by highest level of education for the period 1994-2017. Mortality rates calculated based on population counts in the 1992 census, only including individuals from cohorts reaching age 21 between 1964 and 1981 (both inclusive). These mortality rates have been adjusted for previous mortality per cell (cohort). 
Figure A4: Unemployment and GDP Growth

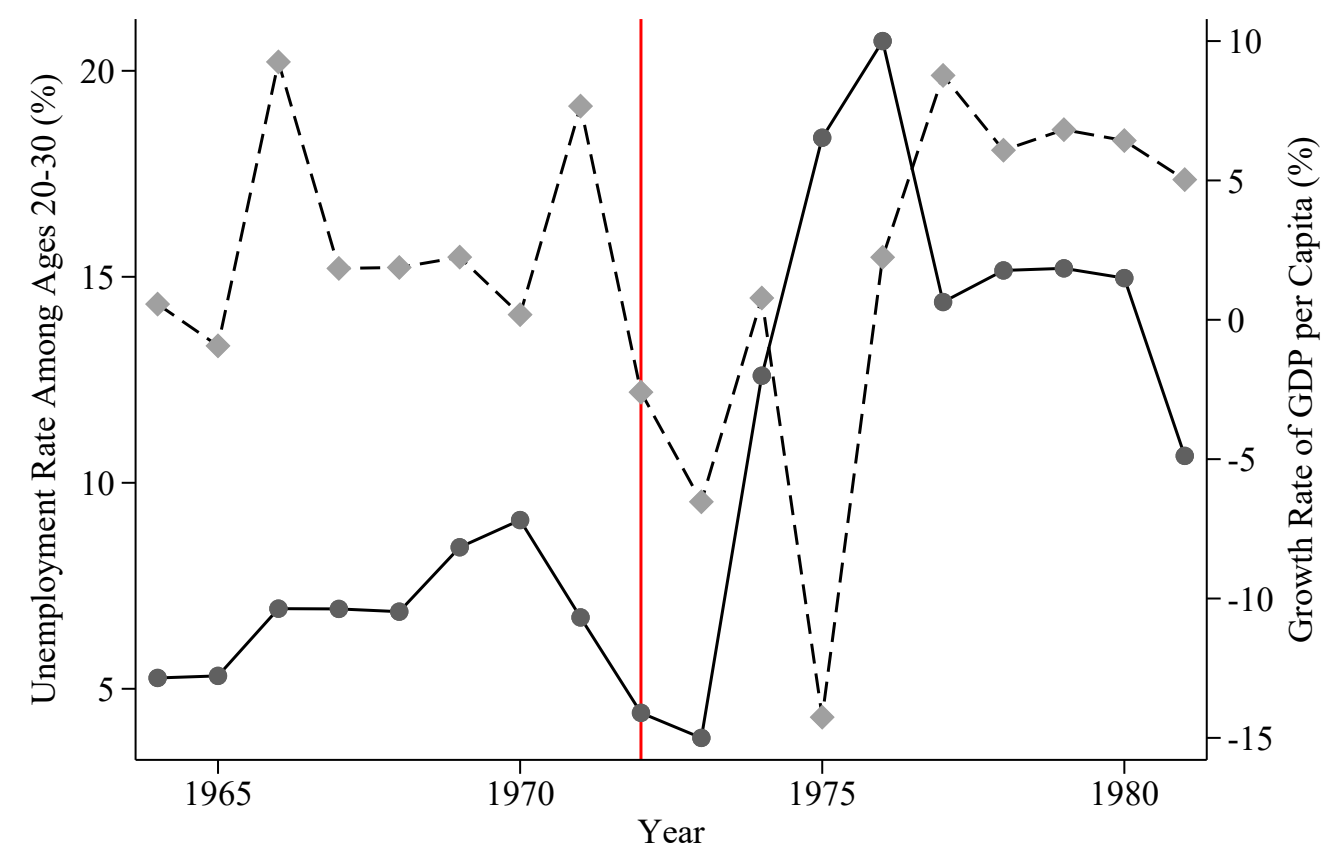

Unemployment $\quad--\bullet--$ GDP p.c. Growth

Notes: This figure plots the unemployment rate among the youth (ages 20-30) and the growth rate of the GDP per-capita around the time of the coup. 
Figure A5: Robustness: Mortality w/ Different Bandwidths

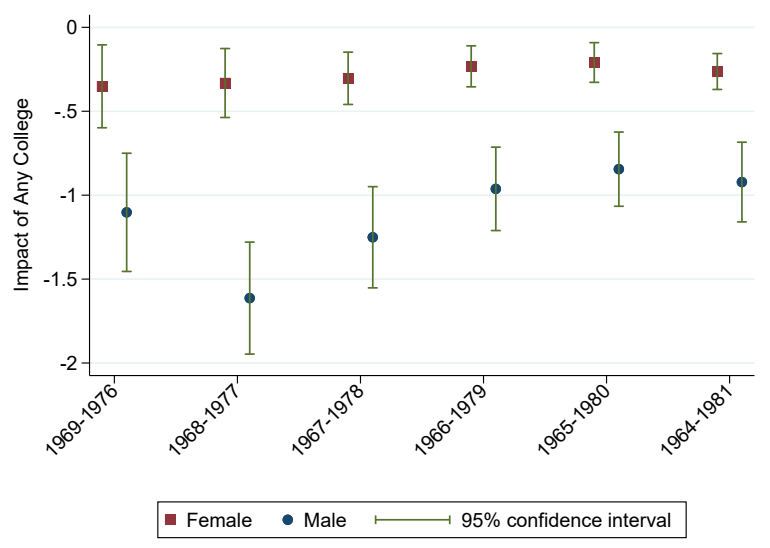

(a) Cohorts

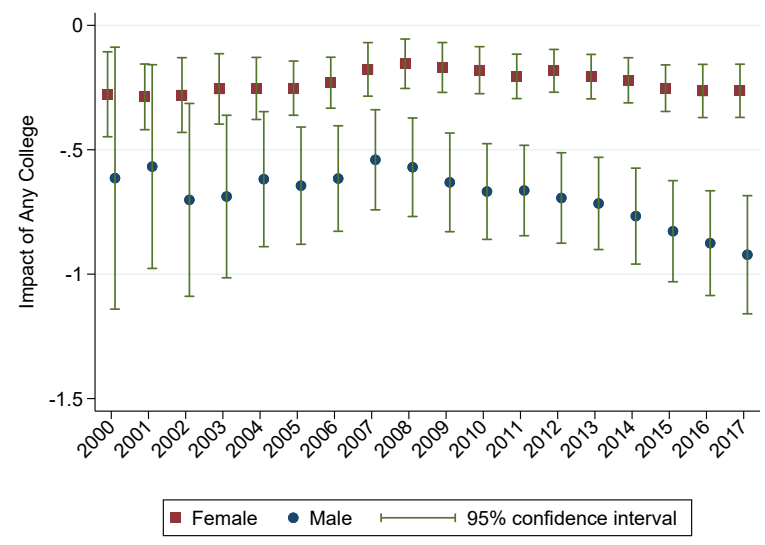

(b) End year

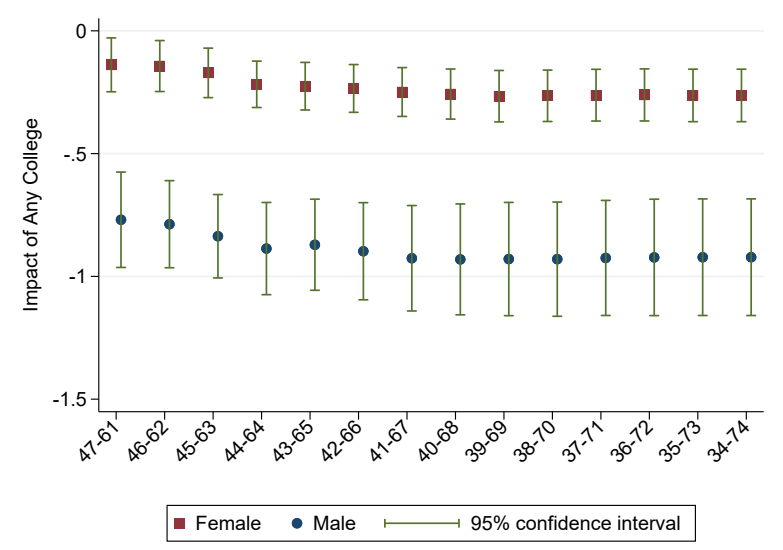

(c) Ages

Notes: Each panel replicates the IV estimation of the impact of college on mortality for varying bandwidths, along different dimensions. The baseline sample includes cohorts reaching age 21 between 1964 and 1981 and the sample period is 1994-2017, without any age restrictions. In panel (a) we consider different bandwidths for the set of cohorts included in the sample. In panel (b), we modify the final year of the sample. In panel (c), we vary the set of ages at which we allow cohorts to enter the sample. In all cases, sample is restricted to people with full secondary education. Dependent variable is the number of deaths per 1,000 individuals, while the endogenous variable is the share with college per 10 individuals. The excluded instrument is the interaction of "Yr Age 21", a continuous variable indicating the year at which the cohort reached 21 years of age (normalized to zero in 1972) with a dummy for cohorts that reached age 21 on or after 1973. All regressions include region by year and age fixed effects (i.e., equation 6). Standard errors clustered by region-year. Bars correspond to $95 \%$ confidence interval. 
Figure A6: Age distribution of Study Cohorts

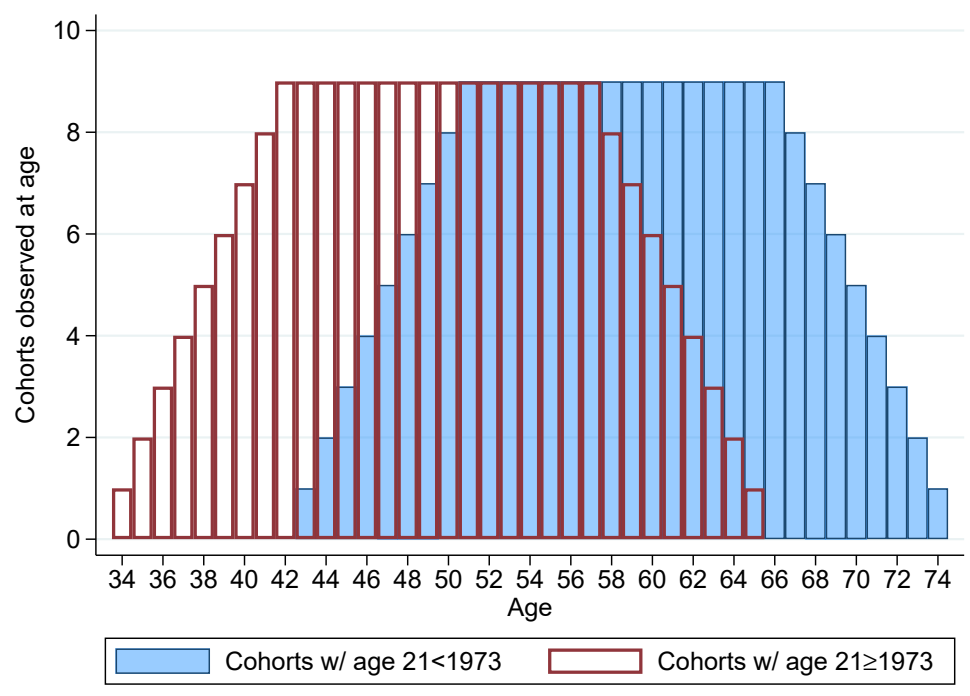

Notes: This figure shows the number of cohorts observed at each age. We disaggregate between cohorts reaching age 21 before 1973 (i.e., age 21 between 1964 and 1972) and those reaching the same age on or after 1973 (i.e., age 21 between 1973 and 1981). Sample period: 1994-2017. 
Figure A7: Robustness: Mortality w/ Different Ages

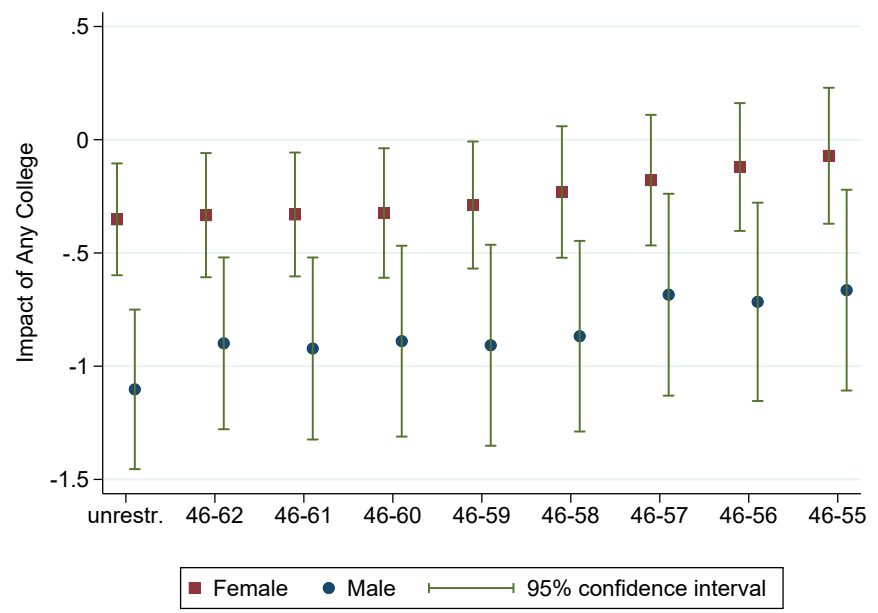

(a) Removing Older Ages

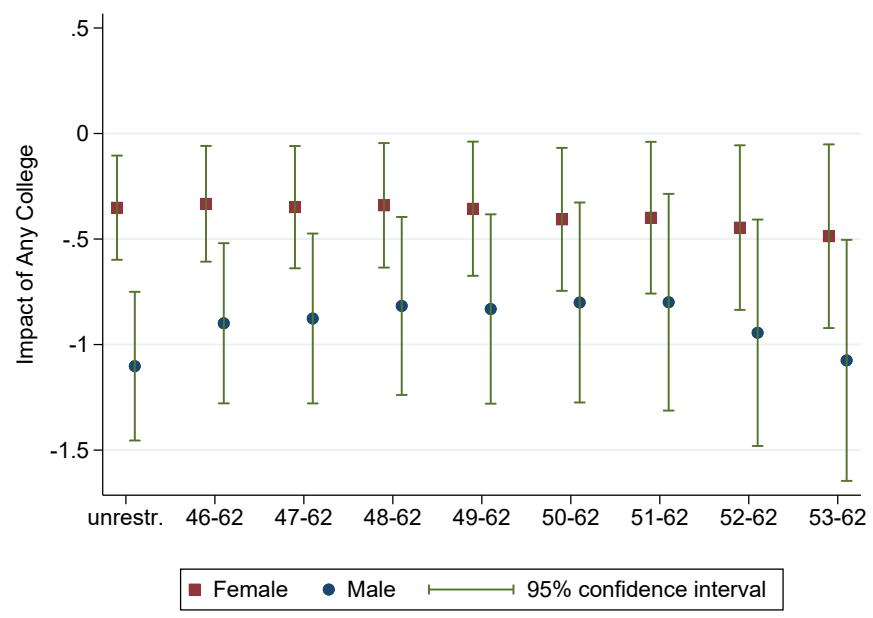

(b) Removing Younger Ages

Notes: Each panel replicates the IV estimation of the impact of college on mortality. The sample includes cohorts reaching age 21 between 1969 and 1976 and the sample period is 1994-2017. The unrestricted sample (leftmost) does not impose any age restrictions. The next set of results restricts the sample to the set of ages observed for all cohorts (ages 46-62). In panel (a), each set of results to the right further restricts the sample by removing the oldest remaining age. In panel (b), each set of results to the right further restricts the sample by removing the youngest remaining age. In all cases, sample is restricted to people with full secondary education. Dependent variable is the number of deaths per 1,000 individuals, while the endogenous variable is the share with college per 10 individuals. The excluded instrument is the interaction of "Yr Age 21", a continuous variable indicating the year at which the cohort reached 21 years of age (normalized to zero in 1972) with a dummy for cohorts that reached age 21 on or after 1973. All regressions include region by year and age fixed effects (i.e., equation 6). Standard errors clustered by region-year. Bars correspond to $95 \%$ confidence interval. 
Figure A8: Visualization of Kink: Hospitalizations (Admitted individuals and disaggregated admissions by type of insurance)

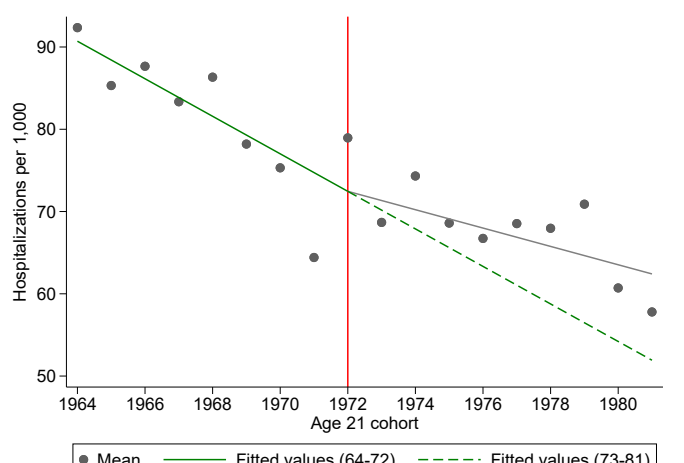

(a) Female: Admitted individuals

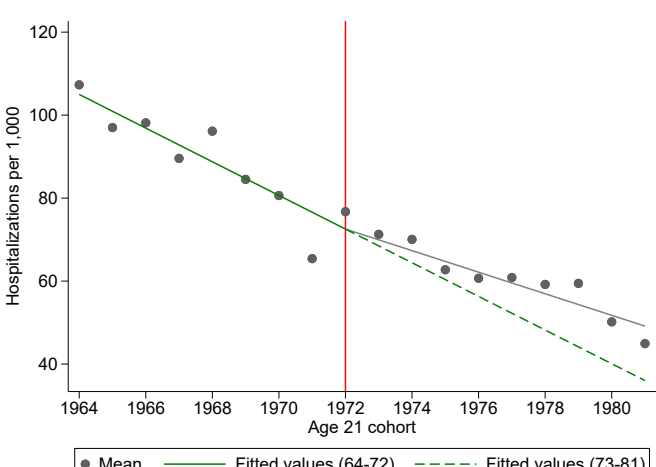

(d) Male: Admitted individuals

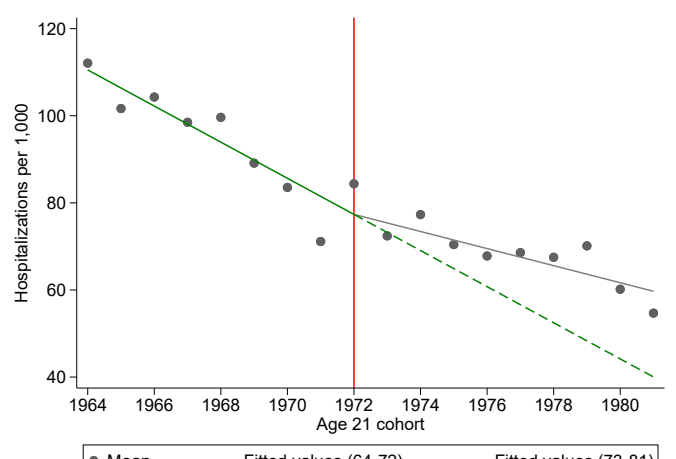

- Mean —_ Fitted values (64-72) - - - . Fitted values (73-81)

(b) Female: Public insurance

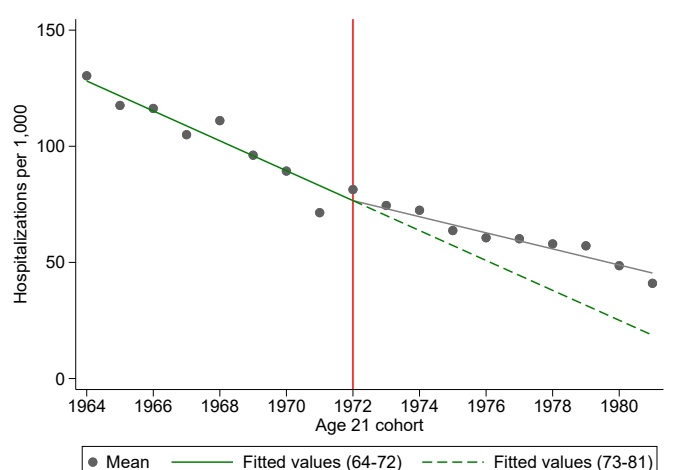

(e) Male: Public insurance

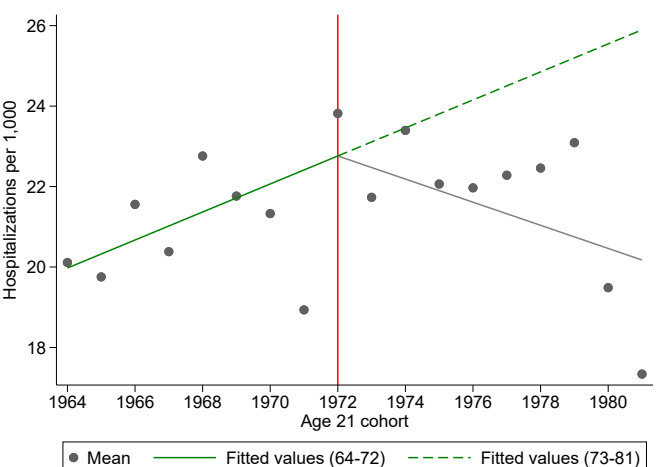

(c) Female: Private insurance

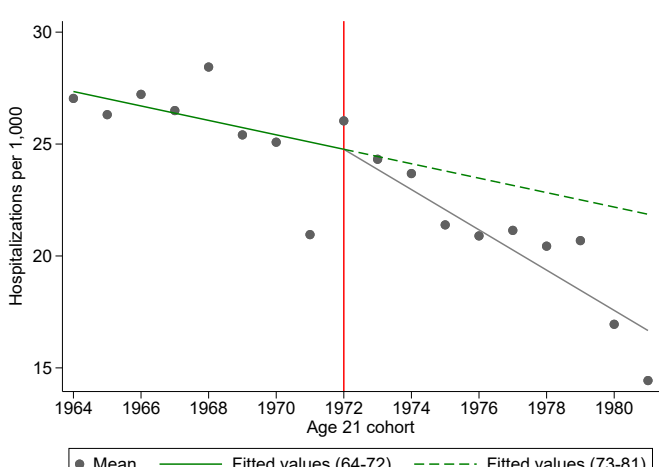

(f) Male: Private insurance

Notes: Panels show average hospitalization rates per 1,000 by cohort (across years). Panels (a) and (d) correspond to the number of admitted individuals (i.e., ignoring readmissions). Panels (b) and (e) show hospital admissions using public insurance (FONASA). Panels (c) and (f) show the hospital admissions using private insurance (ISAPRE, other private, Armed Forces). All hospitalization rates are adjusted for previous mortality before averaging. Average is weighted by cell size (cohort-year). Solid green line corresponds to the line of best fit for cohorts reaching college age before 1973, which we extrapolate for later cohorts (dashed line). Grey line corresponds to line of best fit for cohorts reaching college age in 1973 or afterwards. 
Figure A9: Visualization of Kink: Mortality Rate of Hospitalized Patients (per 1,000)

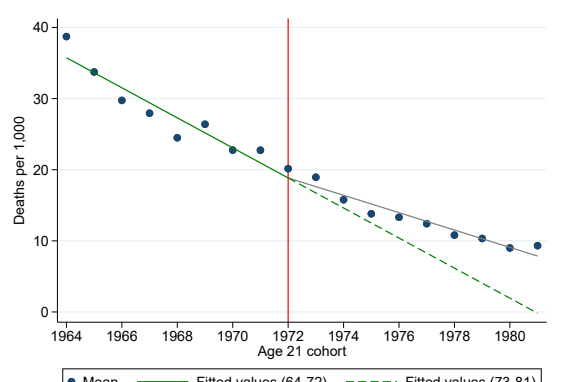

(a) Female: 30 days

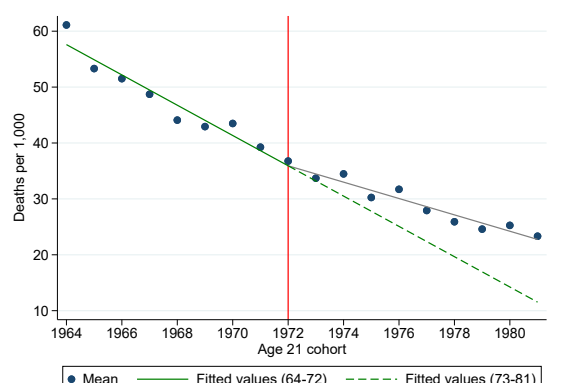

(e) Male: 30 days

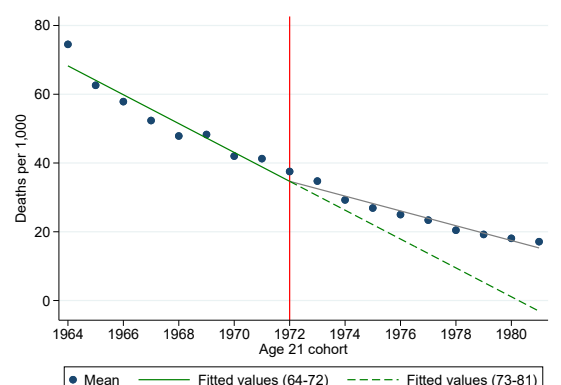

(b) Female: 6 months

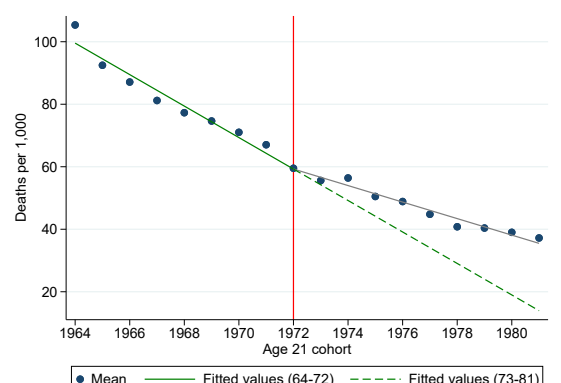

(f) Male: 6 months

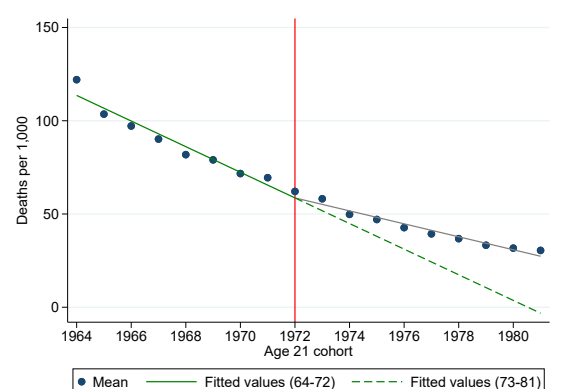

(c) Female: 2 years

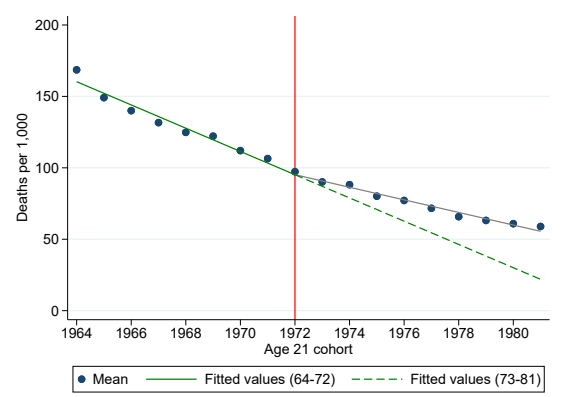

(g) Male: 2 years

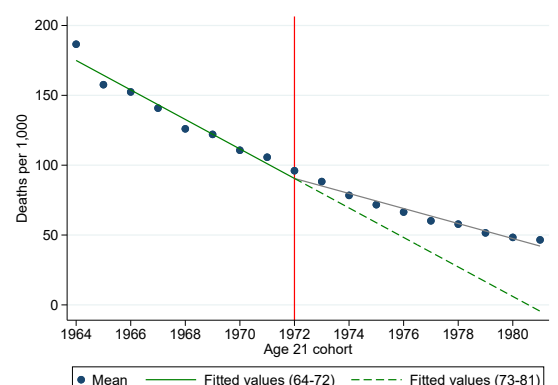

(d) Female: 5 years

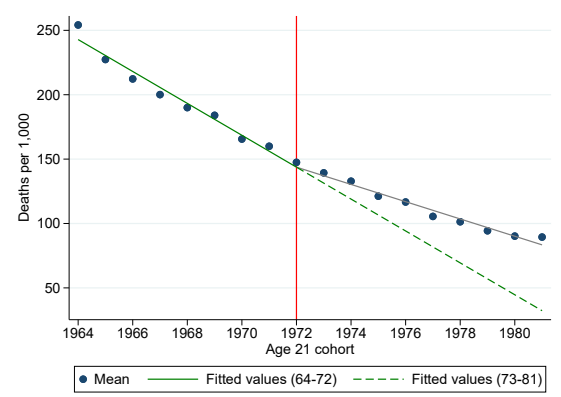

(h) Male: 5 years

Notes: Panels show the average mortality rate of hospitalized patients by cohort (averaged across individuals) over the time horizon in the caption (relative to discharge). Sample includes individuals reaching age 21 between 1964 and 1981 (both inclusive), but places no restriction on educational attainment. Sample period: 2004-2012. Solid green line corresponds to the line of best fit for cohorts reaching college age before 1973, which we extrapolate for later cohorts (dashed line). Grey line corresponds to line of best fit for cohorts reaching college age in 1973 or afterwards. 


\section{Appendix B}

In this section we develop a formal test to establish whether we can reject the null hypothesis of linearity for the evolution of cohort means. To derive this test, we posit the following data generating process for outcome $y_{i c t}$ of individual $i$ of birth cohort $c$ :

$$
y_{i c t}=\delta_{c}+\beta(t-c)+\epsilon_{i c t},
$$

where $c=0$ for those who reach age 21 in 1973, $(t-c)$ is the age effect, and $\epsilon_{i c t}$ is an error term that has mean zero and variance $\sigma^{2}$. If the cohort effect is indeed given by $\delta_{c}=\pi_{0}+\pi_{1} c+\pi_{2} c \times 1[c \geq 0]$, as we posit in the paper, then for a given census year $t$ :

$$
y_{i c t}=\alpha_{0}+\alpha_{1} c+\alpha_{2} c \times 1[c \geq 0]+\epsilon_{i c t}
$$

Then, collapsing to the cohort means we obtain:

$$
\bar{y}_{c t}=\alpha_{0}+\alpha_{1} c+\alpha_{2} c \times 1[c \geq 0]+e_{c t},
$$

where $e_{c t}$ is the sample average of $\epsilon_{i c t}$. By the law of large numbers, $e_{c t}$ will converge to its expected value 0 , and its variance will converge to $\sigma^{2} / N_{c t}$. Since $\sigma^{2}$ is given by: $E\left[\left(\epsilon_{i c t}-E\left[\epsilon_{i c t}\right]\right)^{2}\right]=$ $E\left[\left(y_{i c t}-\hat{y}_{i c t}\right)^{2}\right]$, we can derive the following estimate for the variance of $e_{c t}$ :

$$
\hat{\operatorname{Var}}\left(e_{c t}\right)=\frac{1}{N_{c t}} \sum_{i \in c} \frac{1}{N_{c t}}\left(y_{i c t}-\hat{y}_{i c t}\right)^{2}
$$

Thus, we can create a quadratic score test statistic as an inference function with asymptotic chisquared properties (Lindsay and Qu, 2003) of the form:

$$
\text { Test }=\frac{1}{N_{c t}} \sum_{c} \frac{\left(\bar{y}_{c t}-r\left(\bar{y}_{c t}\right)\right)^{2}}{\hat{\operatorname{Var}}\left(e_{c t}\right)}=\frac{1}{N_{c t}} \sum_{c} \frac{\left(\bar{y}_{c t}-\left(\hat{\alpha}_{0}+\hat{\alpha}_{1} c+\hat{\alpha}_{2} c \times 1[c \geq 0]\right)\right)^{2}}{\hat{\operatorname{Var}}\left(e_{c t}\right)},
$$

Intuitively, this test checks for whether a linear kink model can perfectly explain the evolution of cohort means. Reassuringly, as shown in Figure B1 below, we cannot reject the null hypothesis of a linear kink in the average mortality $(\mathrm{p}$-value $=0.982) .{ }^{35}$

\footnotetext{
${ }^{35}$ In practice, we look at table values from a chi-squared with 14 degrees of freedom, i.e., 18 cohorts, 3 estimated parameters, and the estimated variance.
} 
Figure B1: Visualization of Kink: Higher Education

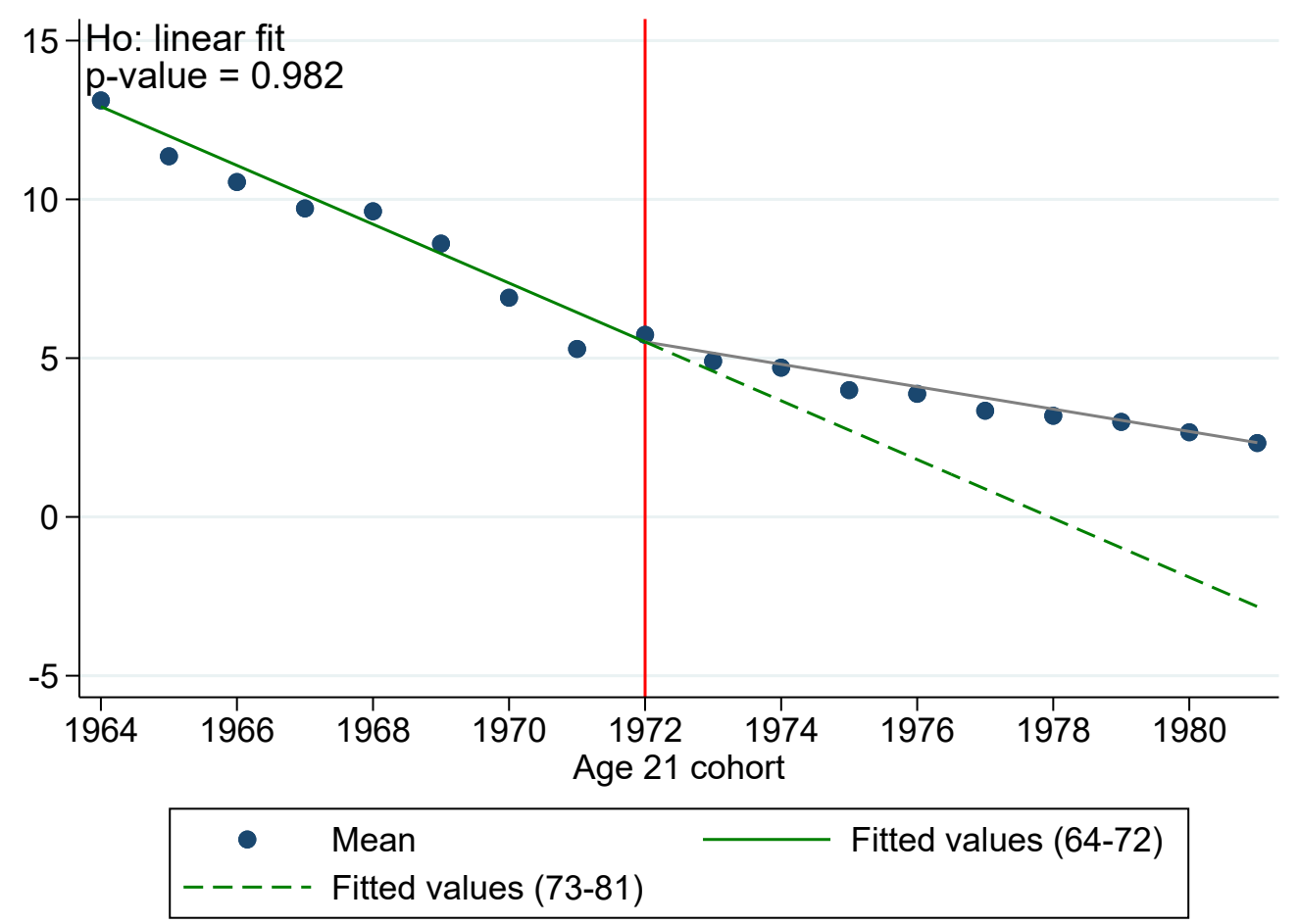

Note: This figure shows the average number of deaths per 1,000 individuals by cohort (for the pooled sample of men and women). Solid green line corresponds to line of best fit for cohorts reaching college age before 1973, which we extrapolate for later cohorts (dashed line). Grey line corresponds to line of best fit for cohorts reaching college age in 1973 or afterwards. 
Figure A10: Visualization of Kink: Smoking

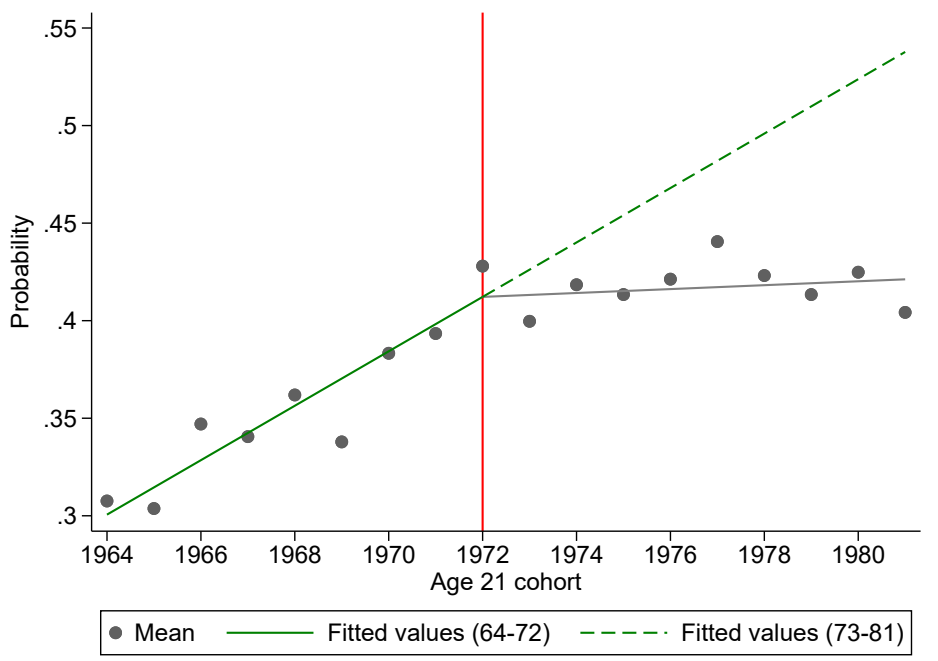

Notes: Panels shows average share per cohort (across years) that reports smoking in the past month, based on individual responses to the CASEN survey. Question on smoking was only included in the CASEN waves from 1990, 1992 and 1998 ( $N=29,636)$. Solid green line corresponds to the line of best fit for cohorts reaching college age before 1973, which we extrapolate for later cohorts (dashed line). Grey line corresponds to line of best fit for cohorts reaching college age in 1973 or afterwards. 